\title{
10th Malaysia-Indonesia-Brunei Medical Sciences Conference 2017
}

\section{"Current Healthcare Challenges in South East Asia"}

\section{6-28 July 2017}

Universiti Kebangsaan Malaysia Medical Centre 
Keynote Address

\section{CURRENT HEALTHCARE CHALLENGES IN SOUTHEAST ASIA}

\section{LOKMAN SAIM}

\section{KPJ Healthcare University College}

Although the South East Asia (SEA) region share many history and cultural elements, the region has many contrasts in socio-politics, economy and geographical environment that affects standards of healthcare. There are many healthcare challenges in the region. One of the major regional healthcare issue that also challenges global healthcare is emergence and re-emergence of communicable diseases. Outbreaks of Severe Acute Respiratory Syndrome (SARS) and avian influenza, challenged the local health authorities and test the ability of regional and international cooperation to control the disease. The region has a high number of HIV/AIDS cases. Malaria control still has many challenges in certain locations while tuberculosis remains a major public health issue because of easier mobility and migration of people in the region. Non communicable diseases are rising at an alarming rate, because of increased prosperity in the region. There is a rapidly growing problem of obesity. The prevalence of diabetes mellitus has doubled in the last 10 years. Serious complications are prevalent because of poor access to health services and lack of awareness. There are still challenges in reproductive health, child and adolescent health. Lack of access to skilled care at birth, family planning and emergency obstetric care are still major risk factors for maternal and neonatal deaths. Except for a few countries that have established national health system, health systems development in SEA countries faces many challenges. The poor and geographically isolated regions continue to have poor access to quality health services. The region also suffers from imbalances in health professionals and skilled workers. Although SEA countries are undergoing significant socioeconomic progress, which may bring wealth to the countries, better wealth may not be translated into better health. To establish the right approach to overcome the challenges for better healthcare in SEA, requires not only political power and financial investment, but also strong collaborative effort by healthcare professionals. Professional regional leadership need to be established and act as professional think-tank group to foster collaborative efforts in overcoming regional healthcare challenges. The MalaysiaIndonesia-Brunei Medical Science Conference can be a platform in bringing together groups of SEA researchers and health leaders. This group can develop sustainable mechanisms for bringing academics, professionals and together with government engagements into effective health policies for the advancement of health for all people in SEA. 
Plenary 1

\title{
THE DEVELOPMENT OF TELE HEALTH SYSTEM AND MOBILE HEALTH APPLICATION: AN OVERVIEW TO ADDRESS CURRENT HEALTH CARE CHALLENGE IN OUR REGION
}

\author{
BUDI WIWEKO \\ Faculty of Medicine, Universitas Indonesia, Dr. Cipto Mangunkusumo General \\ Hospital, Jakarta - Indonesia
}

Current development on information, technology and communication provide us accessibility to improve quality of health services. The challenge of doctor's patient's relationship nowadays is affected by patient's source of information, distance limitation and lack of some experts in rural areas. Today, many patients seem more independent since they are showing curiosity by looking for many information through a lot of resources. Tele health is established to provide better health services by using technology to the patients in remote areas or if they need some referral procedures. It can be based on knowledge transfer, technology transfer, diagnostic and specimen or tissue transfer. Several tele health system that is still under establishment in Indonesia are tele radiology, tele ECG and tele ultrasound included 5 hospitals in West region with Jakarta as the center of communication. Mobile health application is other important modality that can emphasize knowledge of the patients. The terminology of consumer health informatics referred that many information can be retrieved by patients from a lot of electronic resources. Patients are more empowered by using this knowledge let help them making a decision to choose the best option in term of qualified health services. Other important things that is related to tele health and mobile health application is a big data in health which is very useful for continuous quality improvement. 
Plenary 2

\title{
SCREENING FOR DEVELOPMENTAL DYSPLASIA OF THE HIP: A NEED FOR BETTER SURVEILLANCE IN MALAYSIA, INDONESIA AND BRUNEI
}

\author{
SHARAF IBRAHIM \\ Department of Orthopaedics \& Traumatology, Faculty of Medicine, Universiti \\ Kebangsaan Malaysia, Kuala Lumpur, Malaysia
}

Children with developmental dysplasia of the hip (DDH) presenting after the age of one year is not uncommon in Malaysia, Indonesia and Brunei. The treatment of $\mathrm{DDH}$ after the age of one year will almost always require an open reduction. On the other hand, DDH during infancy is usually successfully treated by splinting or a hip spica after close reduction. Late presenting DDH has both health and economic implications - the risk of developing secondary osteoarthritis of the hip is higher and surgery is more expensive than non-surgical treatment.The predisposing factors for the development of DDH includes a positive family history and history of a breech presentation during delivery. Physicians treating infants must be able to assess hip stability with the Ortolani and Barlow tests and to recognize secondary signs of DDH such as limited hip abduction and a limb-length discrepancy. In addition, an ultrasound assessment of the hips is required when the predisposing factors or physical signs of DDH are present.Late presenting DDH in Malaysia, Indonesia and Brunei can be reduced with better clinical and selective ultrasound screening of the hips during infancy. Examination of the hips must be included in the routine physical examination of infants. Since DDH may be undetected at birth, a second and third hip examination is recommended at 6-8 weeks and again at 3-6 months of age. 
Plenary 3

\title{
DIABETES EDUCATION CHALLENGES
}

\author{
RAFIDAH GHARIF ${ }^{1,2}$ \\ 'PAPRSB Institute of Health Sciences, Universiti Brunei Darussalam \\ ${ }^{2}$ Ministry of Health, Brunei Darussalam.
}

The prevalence of diabetes is increasing worldwide. The ASEAN region is not spared from the diabetes pandemic. With the increasing burden of diabetes, ways to improve the management of diabetes is a priority. There are evidence on the effectiveness of diabetes self-management education. Unfortunately, most of the studies are based in the Western industrialised countries. Hence, the question of the effectiveness of diabetes self-management education amongst the population in ASEAN region is important. The different physical, psychological, social and cultural ways justify for local and regional research. The effectiveness of diabetes self-management education for people with diabetes in the ASEAN countries will be explored. Discussions will be based on ways to increase the effectiveness of such programmes in this region despite the challenges faced daily by the health care givers. The overall aim is for a diabetes self-management education programme that is effective, affordable and suitable for the people in the ASEAN countries. 


\title{
REGENERATIVE MEDICINE: ITS SUSTAINABILITY AND WAY FORWARD
}

\author{
RUSZYMAH IDRUS \\ Department of Physiology, Faculty of Medicine, Universiti Kebangsaan Malaysia \\ Medical Centre, Jalan Yaacob Latiff, Bandar Tun Razak, 56000 Cheras, Kuala \\ Lumpur, Malaysia.
}

Regenerative Medicine is among the frontiers of medical biotechnology which holds the promise of replacing or regenerating damaged cells, tissues or organs. At the Tissue Engineering Centre UKM, work in the field was initiated in year 1999, has moved from in vitro to in vivo research and currently in the human clinical trial phase. Progressing to clinical trial is a strategy to ensure sustainability. Researchers must think about sustainability at the early stage of the project. Project has to be assessed and data must be used to determine the future of the project. A state-ofart laboratory was built to ensure R\&D products goes through proper clinical trial. The Phase I/II clinical trial for MyDerm ${ }^{\mathrm{TM}}$ has just been completed and the product has been licensed to a company, CTT Sdn Bhd, for phase III trial. Another product entering Phase I/II trial is a mesenchymal stem cell (MSC) based therapy for the treatment of osteoarthritis. Osteoarthritis is a major degenerative joint disease and to date there is no definitive treatment to stop the degenerative changes and reverse the damage. The research on engineered cornea and peripheral nerve proved viable in the animal study. Work on cardiomyocyte electron transport chain was initiated with the vision of finding cure for myocardial infact and heart failure. Regenerative technologies attempt to change the course of chronic diseases and will regenerate tired and failing organs. Given time, effort, as well as passion, and funding will ensure sustainability of this emerging technology. 


\title{
SCREENING POTENTIAL TARGETS FOR MALE CONTRACEPTION FROM THE EPIDIDYMIS
}

\author{
DWI ARI PUJIANTO"*, EVELYN LOANDA², CUT YASMIN² \\ ${ }^{1}$ Department of Biology, ${ }^{2}$ Master Program for Biomedical Sciences, Faculty of \\ Medicine, Universitas Indonesia, Indonesia.
}

Background: Spermatozoa leaving the testis do not have capacity to fertilize the oocytes. They need to undergo maturation during transit in the epididymal duct. Epididymal sperm maturation process occurs by interaction between sperm and proteins secreted by epithelium lining the epididymal duct. Previous studies showed that genes involved in sperm maturation are expressed specifically in the epididymis either in caput, corpus or cauda region and it is regulated by androgen. Therefore, criteria of tissue distribution of expression and dependency on androgen can be used to screen those genes putatively involved in the process and inhibit them would open possibilities to develop nonhormonal male contraception. The aim of this study is to identify and characterize mouse epididymal specific genes as a model to understand their role in the sperm maturation process. Methods: cDNA microarray and UNIGENE database were used to identify epididymal specific genes. Several genes were selected as potential genes to be characterized further including Spag11a and Serpina1f. Insilico analyses was performed to analyse gene structure and signal peptide. Total RNA from various tissues were used in the tissue distribution analyses and Gonadectomy experiment was performed to analyzed androgen dependency. Gene expressions from both experiments were measured using quantitative real-time RT-PCR (qRT-PCR). Detection of gene expression at protein level using Western immunoblotting was performed for Spag11a. Results: cDNA microarray and UNIGENE database were useful resources for finding genes that are putatively responsible for epididymal sperm maturation. Several genes were discovered to be enriched in the initial segment and caput region such as Spag11a and Serpina1f. Both Spag11a and Serpinalf were expressed specifcally in the epididiymis and showed region specific expression in the caput and initial segment, respectively. Spag11a and Serpinalf expression were down regulated by gonadectomy and reached the lowest level at 3 days after castration. Interestingly, exogenous testosterone brought their expression back almost to the normal levels indicating dependency on androgen. Spag11a and Serpinalf were found to be not regulated by testicular factors. Conclusions: Spag11a and Serpinalf constitute epididymal specific genes that are putatively involved in the sperm maturation process. Expression of both genes are regulated by androgen confirming its important for sperm maturation. Based on our data, mouse Spag11a and Serpina1f could be investigated further to analyse their potential to become targets as a model for epididymal-based nonhormonal male contraception. 


\title{
A GENOTYPE CATALOGUE OF POTENTIAL HUMAN GENETIC DISORDERS IN THE SOUTHEAST ASIAN POPULATIONS
}

\author{
DAVIS H.T. FONG, ZEN H. LU \\ PAPRSB Institute of Health Sciences, Universiti Brunei Darussalam, BE1410 Brunei \\ Darussalam.
}

Introduction and aim: Millions of human genomics variants from different studies have been made publicly available over the last three decades. While many genetic disorders have been identified consequently, much remains undeciphered and yet understanding of these variants is paramount to the realisation of personalised precision medicine. Regrettably, systematic variant data for the majority Austronesian population groups in Southeast Asia have been at best patchy if not upright shortcoming. Our current effort attempts to catalogue all the known genotypes, including their allele frequencies, in this region and link them to reported genetic disorders. Methods: Genotyping data from the genetically closely related Austronesian groups in Singapore, Malaysia, Indonesia and the Philippines were extracted from the Singapore Genome Variation Project and the Pan-Asian SNP Consortium while the Chinese and Indian data from Singapore were used as the "outlying controls". Due to technological differences in the genotyping platforms and differences in the human reference genome used, these data were filtered, cleaned and all genomic positions lifted-over to the latest GRCh38 reference assembly. Genotypes and allele frequencies on genes implicated for known genetic disorders or phenotypes were then catalogued. Results: A total of approximately 2 million genotypes were extracted from 602 individuals in the four Southeast Asian countries. $15 \%$ of the genotypes were found to fall on 2300 disease genes. While genotypes among Austronesians are highly similar, as expected, distinct variations could be still identified. Pending further investigation, some of these variations could serve as potential pharmacogenomics markers for these populations. 
Social Medicine

Symposium 2

\title{
MENTAL HEALTH OF MEDICAL STUDENTS: SAFEGUARDING \& THE CHALLENGES TO PROVIDING CARE
}

\author{
RAYNUHA MAHADEVAN, TUTI IRYANI MOHD DAUD \\ Department of Psychiatry, Faculty of Medicine, Hospital Canselor Tuanku Muhriz, \\ Universiti Kebangsaan Malaysia Medical Centre
}

Medicine is among the most stressful fields of study. Many studies, both locally and internationally, show high rates of medical students presenting with mental health problems such as stress, depression, and anxiety, just to name a few. This paper aims to enlighten about the challenges faced in providing care to medical students affected by mental health issues. It will also highlight the great need to safeguard the mental health of medical students.There has been an increasing number of medical students seeking help with psychiatric services at Universiti Kebangsaan Malaysia Medical Centre (UKMMC) since 2013. As much as it is recognized that providing care to this population is crucial, several challenges with regards to this have been identified. These are issues of confidentiality, conflict of interest, lack of service providers, providing referrals to services outside, and students' preferences. Therefore, the direction taken should be towards actively safeguarding the state of mental health of our medical students. This can be done through a few ways such as early screening, psycho education during orientation week, empowering the students as well as the mentors, and conducting regular mental health programmes. Mental health issues faced by medical students can be addressed early if measures for early detection are put in place. Safeguarding the mental health of our medical students should be considered an investment. 


\section{EVIDENCE-BASE INFORMED HEALTH CARE: HEALTH TECHNOLOGY ASSESSMENT AND CLINICAL PRACTICE GUIDELINE PROGRAM IN CIPTO MANGUNKUSUMO HOSPITAL- FACULTY OF MEDICINE UNIVERSITAS INDONESIA}

\section{EKA DIAN SAFITRI}

Clinical Epidemiology and Evidence Based Medicine (CEEBM) Unit, Cipto Mangunkusumo Hospital-Faculty of Medicine, Universitas Indonesia

Evidence-based informed health care improves the quality, safety, and efficiency of health care services. Health Technology Assessment (HTA) and Clinical Practice Guideline (CPG) are forms of utilization of evidence to support decision making in health policy and clinical practice. Cipto Mangunkusumo Hospital $(\mathrm{CMH})$ and Faculty of Medicine Universitas Indonesia (FMUI) through Clinical Epidemiology and Evidenced Based Medicine (CEEBM) Unit, since 2013 has been developing Hospital Based HTA Program (HB HTA). The HB-HTA activity is not only assessing health technology, but also including capacity building activities in evidence-based practice (EBP), HTA, and systematic review, engagement with stakeholders, need assessment study for HTA, and building the network with national and international HTA agencies. Moreover, along with the implementation of Universal Health Coverage (UHC) in Indonesia and for controlling quality and cost, requisite against hospital clinical practice guideline in $\mathrm{CMH}$ is growing. $\mathrm{CPG}$ is designed to help the healthcare professionals managing patients in an appropriate and effective way based on the current best available evidence. Start from 2015, CEEBM has been involved to assist clinician in developing the evidence based hospital CPG particularly for the diseases in which require multidisciplinary approach management. To date CEEBM as organization keep continue to make efforts to completion best practice of Hospital Based HTA and CPG in CMH-FMUI. CEEBM is also enthusiastic about collaborating in research and education activities to improve the quality, safety and value of care through an EBP approach. 
Social Medicine

Symposium 2

HEALTH SEEKING, MASCULINITY AND PERFORMING CULTURALLY EXPECTED LIFE COURSE TRANSITION: FINDINGS FROM BRUNEI DARUSSALAM

\author{
DEENI RUDITA IDRIS', SIMON FORREST ${ }^{2}$, SALLY BROWN ${ }^{3}$ \\ 'Nursing Lecturer, PAP Rashidah Sa'adatul Bolkiah Institute of Health Sciences, \\ Universiti Brunei Darussalam (deeni.idris@ubd.edu.bn). \\ ${ }^{2}$ School of Medicine, Pharmacy and Health, Durham University, UK. \\ ${ }^{3}$ Sociology Lecturer, Edinburgh Napier University, Edinburgh, Scotland.
}

Introduction/Aim: Despite a growth in interest in the relationship between masculinities and healthseeking behaviour, particularly in the western world, little research exists about intersections of gender and ethnicity with health seeking behaviour in multi-ethniccultures, particularly in Asia. Therefore, a study investigating how being a man in Brunei, a Muslim country holding strong to its cultural identity, influences men's perception and attitudes towards their health and help-seeking behaviour, is timely. Methods: This grounded theory study utilizes semi-structured interview and focus groups with a total of 47 men and women from diverse ethnic backgrounds in Brunei Darussalam. Four themes emerged from the study; this session focusses on one theme, concerning key temporal transitions across the life course and the relationships between masculinities, men's health and well-being. Result/Discussion: Men's marital status and their role in the family influence the relationship between masculinity and health-seeking, with healthseeking bound up with masculine roles: carer for parents, role model for siblings, breadwinner, leader of the family and 'man of the house'. Men regarded being healthy is important as it enables them to perform and be part of the culturally expected life course transitions that will or have happened in their life as a Bruneian man i.e. from being a son, to husband, father then to grandfather. All these transitions in life carry specific roles and responsibilities. However, this does not necessarily reflect their pattern of engagement with the health care services. 
Musculoskeletal Disorder

Symposium 3

RHEUMATOLOGY IN SOUTH EAST ASIA 2017; NEW CHALLENGES

MOHD SHAHRIR MOHAMED SAID

Department of Medicine, Faculty of Medicine, Universiti Kebangsaan Malaysia Medical Centre

The management of rheumatology in South East Asia is not far behind from what is practiced elsewhere in the world. Biologics are used concurrently with other DMARDS in managing rheumatology cases. Newer criterias were now coming up to improve diagnosis and at the same time improving management. There will be a possibility that in the future, biologics will be used earlier and thus inducing remission early. However, in South East Asia when tuberculosis is endemic this can prove to be a daunting task. This discussion will be explored by the speaker. 


\title{
THE IMPACT OF MESENCHYMAL STEM CELL IMPLANTATION ON INJURED SPINAL CORD PERTAINING TO THE MUSCULOSKELETAL FUNCTION
}

\author{
RAHYUSSALIM AHMAD JABIR, ${ }^{1,2}$, ISMAIL HD ${ }^{1,2}$, IFRAN \\ SALEH $^{1}$, TRI KURNIAWATI ${ }^{2}$ \\ ${ }^{1}$ Department of Orthopaedic and Traumatology Faculty of Medicine Universitas \\ Indonesia-CiptoMangunkusumo Hospital \\ ${ }^{2}$ Stem Cell Medical Technology Integrated Service Unit CiptoMangunkusumo \\ Hospital-Faculty of Medicine Universitas Indonesia
}

Introduction: Curently, treatment of spinal cord injury using mesenchymal stem cells were being developed in Stem Cells Medical Technology Integrated Service Unit RSCM-FKUI. Mesenchymal stem cells are expected to replace the defect of the spinal cord, and support the host cell to survive, facilitate the growth of axons and prevent atrophy. Method: Implantation of MSCs were did in ten patients with $\mathrm{SCl}$ using three different route of administration. Physical examination, neurophysiological and RigiScan were done to evaluate the sensoric, motoric and autonomic performance before and after implantation up to six months after the first implantation. Result: All of patient who underwent implantation of MSC gained physical and clinical improvement of sensation (heat, cold, light touch, coarse touch, pain and proprioception), autonomous (imporvement of erectile function and the sensation to urinate). Motor strength and increased muscle mass are improved in patient number two and eight. Patient number two showed controlled volunteer movement (dorso flexion and hip knee flexion), whereas patients number eight shows controlled volunteer movement on both legs (dorso flexion and hip and knee flexion) which initially did not exist at all). Yet, there has been no improvement in SSEP and MEP on all patients. Conclusion: Administration of MSCs in patients with $\mathrm{SCl}$ have an impact on the improvement of neurological function. 


\title{
DISTINCT DOMAINS OF THE $\beta 1$-SUBUNIT CYTOSOLIC N-TERMINUS CONTROL SURFACE EXPRESSION AND FUNCTIONAL PROPERTIES OF LARGE CONDUCTANCE CALCIUM-ACTIVATED POTASSIUM (BK) CHANNELS
}

\author{
LIE CHEN', DANLEI BI ${ }^{2}$, ZEN H. LU', HEATHER \\ MCCLAFFERTY ${ }^{3}$, MICHAEL J SHIPSTON ${ }^{3}$ \\ 'PAPRSB Institute of Health Sciences, Universiti Brunei Darussalam, BE1410 \\ Brunei Darussalam \\ ${ }^{2}$ Neurodegenerative Disease Research Center, University of Science and \\ Technology of China, China \\ ${ }^{3}$ Centre for Integrative Physiology, University of Edinburgh, Edinburgh EH8 9XD, \\ United Kingdom
}

Introduction \& Aim: The large conductance calcium- and voltage- activated potassium (BK) channels participate in the physiological and pathological processes in different cells and tissues. In skeletal muscle, BK channel is involved in (1) the maintenance of the resting potential of muscle membrane and eventually controlling of the muscle contraction; (2) the regulation of the neurotransmission in neuromuscular junction; and (3) the promotion of the myoblast proliferation/ regeneration. The channel has therefore been proposed as potential treatment target for some myopathies such as myotonia and muscular dystrophy. However, the exact regulatory mechanism of the channel remains is not fully understood. Our study aims to understand how BK channels are regulated by its accessory $\beta 1$ subunit in muscle cells. Methods: An integrated mutagenesis and deletion strategy coupled with surface expression and functional macroscopic current analysis was exploited to address whether the surface trafficking effects mediated by the $\beta 1$-subunit $\mathrm{N}$-terminus required distinct or similar $\mathrm{N}$-terminal regions as to those that control functional regulation. Results \& Conclusion: The first six N-terminal residues, including $\mathrm{K} 3, \mathrm{~K} 4$ and $\mathrm{L} 5$, are critical for channel functional regulation of BK channels. This membrane distal region has features of an amphipathic helix that is predicted to control the orientation of the first transmembrane segment of the $\beta 1$-subunit. In contrast, a proximal residue L17 controls trafficking without affecting functional coupling the BK channel. Cell surface trafficking and functional coupling with BK channels are therefore controlled by distinct domains of the $\beta 1$-subunit N-terminus. 
Musculoskeletal Disorder

Symposium 3

\section{UPDATE ON LUPUS ARTHRITIS}

\section{NARISA SULAIMAN SAHARI}

Faculty of Medicine and Health Sciences, Universiti Putra Malaysia

Arthritis is one of the common manifestations in SLE and has a significant impact on patients in term of their burden of disease and quality of life. Despite this it remains understudied in comparison with other inflammatory arthropathies. Patients with arthritis often have symmetrical large and small joints polyarthritis with hand and knee are the most commonly involved and usually unassociated with radiographic evidence of erosive or deforming disease. Treatment generally focuses on anti-inflammatory agents such as NSAIDs and corticosteroids. In patient with persistent active arthritis methotrexate significantly improved arthritis and currently Belimumab, a B lymphocyte stimulator blocker, has shown efficacy in initial trials and is now approved by the FDA in treating lupus arthritis. 


\title{
GLAUCOMA - THE SILENT THIEF OF SIGHT
}

\author{
JEMAIMA CHE HAMZAH \\ Department of Ophthalmology, Faculty of Medicine, Universiti Kebangsaan \\ Malaysia Medical Centre, Jalan Yaacob Latif, Bandar Tun Razak, 56000 Cheras, \\ Kuala Lumpur, Malaysia.
}

Glaucoma is a group of eye disease caused by gradual and progressive damage of the optic nerve $(\mathrm{ON})$ resulting in characteristic excavation of the $\mathrm{ON}$ associated with corresponding visual field (VF) defect. It can cause visual impairment and blindness if left untreated. Globally, it is estimated that 60.5 million people $(2.7 \%$ of the global population over 40) suffered from glaucoma in 2010 and expected to reach around 80 million people in 2020 . Patients usually present late to the health care system as glaucoma is usually asymptomatic and awareness of the disease occurs only when the VF defect impinges on the central vision and affects both eyes. Hence, glaucoma is frequently referred as 'the silent thief of sight'. Even in the developed country, $50 \%$ of the patients are unaware that they have glaucoma and not on treatment. Risk factors of glaucoma include increasing age, black ancestry, myopia, high intraocular pressure and family history of glaucoma. Progression of glaucoma can be reduced by lowering the intraocular pressure through medical, laser or surgical therapy but any vision loss prior to diagnosis cannot be restored. Thus, early identification and treatment of high risk patients may minimize the amount of vision loss to preserve their quality of life. 


\section{NON-COMMUNICABLE DISEASE AND ITS RELATION WITH FRAILTY SYNDROME IN THE ELDERLY}

\section{PURWITA WIJAYA LAKSMI}

Geriatric Division, Department of Internal Medicine, Faculty of Medicine, Universitas Indonesia/ CiptoMangunkusumo Hospital, Jakarta, Indonesia

Frailty syndrome is a biological syndrome due to decreased in physiological reserved capacity and ability to cope with stressors. Frailty syndrome which reflects biological age is a continuum and dynamic spectrum of normal/ robust, pre-frail, and frail state among elderly. Frail elderly has an increased risk to have poor outcome such as falls, hospitalization, poor functional status and quality of life, as well as mortality. There are three domains of frailty syndrome: physical, psychological, and social. The main factors that contribute to the development of frailty syndrome are genetic, aging process, life style, and disease. Sarcopenia has major contribution to the manifestation of physical frailty (exhaustion, weakness, slowness, decreased body weight and physical activity). Moreover, the more co-morbidities and disabilities accumulated in a person, the frailer the person will be. Frail state among the elderly is associated with inflammation, insulin resistance, diabetes mellitus, low vitamin $\mathrm{D}$ serum, low protein intake, consume $>4$ medications daily (poly-pharmacy), and depression. Non-communicable disease has been linked to frailty syndrome. On the other hand, nowadays frail status has been viewed as an essential aspect to be considered in the management of non-communicable diseases such as type 2 DM, hypertension, and dyslipidemia. Hence, it is important to assess frail status among the elderly patients in order to determine appropriate management as well as the prognosis of the patients. 


\title{
NON-COMMUNICABLE DISEASES IN BRUNEI DARUSSALAM: TRENDS AND CHALLENGES
}

\author{
NIK ANI AFIQAH TUAH ${ }^{1,2}$, NORHAYATI KASSIM ${ }^{1,3}$ \\ 'Pengiran Anak Puteri Rashidah Sa'adatul Bolkiah Institute of Health Sciences, \\ Universiti Brunei Darussalam, Jalan Tungku Link, BE1410, Negara Brunei \\ Darussalam. \\ ${ }^{2}$ Department of Primary Care and Public Health, School of Public Health, Faculty \\ of Medicine, Imperial College London, United Kingdom. \\ ${ }^{3}$ Health Promotion Center, Ministry of Health, Commonwealth Drive, Bandar Seri \\ Begawan, BB3900, Brunei Darussalam.
}

Introduction and Aim: Globally, Non-communicable diseases (NCDs) such as cardiovascular diseases, cancers, chronic respiratory diseases and diabetes are the leading causes of deaths among adults. Tobacco use, physical inactivity, unhealthy diet and harmful use of alcohol are common modifiable behavioural risk factors of NCDs, while the metabolic risks factors comprise of hypertension, overweight/ obesity, hyperglycemia and hyperlipidemia. This paper aims to assess trends, risk factors and public health interventions of the common NCDs in Brunei Darussalam. Methods: The review includes reports and primary studies published in English language from 1980 to 2016. The main search methods for identification of articles are using search engines, electronic databases and hand searching. Common themes are identified during data analysis. A narrative review is conducted due to heterogeneity of evidence found in included articles and reports. Results and Discussion: Reports and primary studies are included in the preliminary results showing that cancer, heart diseases, diabetes and cerebrovascular diseases are common NCDs in adults and are rising in Brunei Darussalam. In both adults and children, the common risk factors reported are physical inactivity, unhealthy diet and obesity. Various public health interventions including policies have been implemented to address the main risk factors for NCDs in the last two decades in the nation, however there is limited evidence showing effectiveness of those interventions. Evaluation of public health interventions and policy implementation including evidence and report dissemination are key challenges to assess what worked and what did not, in reducing NCDs and the related risk factors in the population. 


\title{
THE UNIVERSITI SAINS MALAYSIA (USM) PREGNANCY COHORT STUDY FINDINGS ON MATERNAL HEALTH AND INFANT GROWTH
}

\author{
HAMID JAN B. JAN MOHAMED \\ Nutrition and Dietetics Program, School of Health Sciences, Universiti Sains \\ Malaysia, 16150 Kubang Kerian, Kelantan.
}

The first 1000 days of life concept originated from research findings of several birth and pregnancy cohort studies around the world. However, the pioneer of this concept was thelate Professor Barker who suggested the Developmental Origins of Health and Disease hypothesis $(\mathrm{DOHaD})$ based on his findings from old birth records in the United Kingdom. The $\mathrm{DOHaD}$ concept describes how during early life (from conception till early childhood),the unhealthy maternal diet, poor maternal health status and the polluted environment during pregnancy trigger changes in fetal development that leads to long term detrimental effect by modulating risks of non-communicable disease across the life course. Poor dietary intake and exposure of polluted environment during early childhood also contributes to noncommunicable disease development in later life. However, the DOHaD concept was not tested in the local population. Hence, upon discussion with $\mathrm{DOHaD}$ experts, alocal pregnancy cohort was initiated and named as the USM Pregnancy Cohort Study. The background and design of this cohort will be presented. Findings that indicated the association of maternal environment based on the aspects of prenatal dietary intake, Vitamin D status, antioxidants, DNA damage and nicotine exposure with birth outcomes will be discussed. Result from the 3rd year follow up on cognitive function will also be presented. 


\title{
FERTILITY PRESERVATION IN INDONESIA: OPPORTUNITY AND CHALLENGES
}

\author{
ACHMAD KEMAL HARZIF \\ Department of Obstetrics and Gynecology, Faculty of Medicine, Universitas \\ Indonesia
}

As the technological advancements in early diagnosis and treatments of cancer is improving with time, the mortality rate of patients has greatly lowered. However chemotherapy and radiotherapy affects the ovaries with increasing the risk of infertility and premature ovarian insufficiency. Eight percent of malignancies occur in patients younger than 40 years old, who expect their fertility to be maintained. In men, cancer can also cause the infertility, either by the cancer itself or as a side effect of the therapy given. In some cancers such as Hodgkin's disease and testicular cancer, lower sperm count is found. Although it is very difficult to predict the incidence of male infertility as a result of cancer therapy. In Indonesia, assisted reproductive technology is able to help couples with problem in reproduction. Fertility preservation has been developed to take part of great importance in reproductive medicine especially to preserve female reproductive function. Since 2006 several studies has been done in Indonesia such as ovarian vitrification, isolation, follicular cultures, and also ovarian tissue transplantation. In 2010, ovarian vitrification of tissue biopsy was performed to 10 patients undergo benign gynecological surgery resulting good morphological and number of follicles in both pre and post vitrification. Pro and anti-apoptotic gene examination proved that no difference in post-vitrification follicular viability. Currently, isolation techniques and pre-antral cultures of in vitro follicle is still being developed in order to obtain antral follicles and good quality of mature oocytes. Finally, fertility preservation can do a great service to reproductive medicine by development of new techniques. Fertility preservation is still an emerging challenge, cause of several unresolved barriers and many related issues. Compared to other countries, Indonesia is still far behind in fertility preservation. Research on cryopreservation of human tissue is still limited in Indonesia. There is no standard protocol established for freezing ovarian tissue in Indonesia, and maintaining fertility is not a priority in some cancer centers in Indonesia. To overcome these difficulties, innovation development and several strategies are needed. Besides that the care of these patients is challenging, complex, and requires a multidisciplinary approach. 


\title{
CHILDHOOD NUTRITION IN BRUNEI DARUSSALAM: BRIEF OVERVIEW OF THE CURRENT SITUATION AND WHAT CAN THE SCHOOLS DO?
}

\author{
SITI ROHAIZA AHMAD \\ PAPRSB Institute of Health Science, Universiti of Brunei Darussalam.
}

Childhood is a critical period of development that has a large impact on shaping their behaviour in later years. Home as well as the school environment plays a very important role. Within the school environment, children are exposed to many potential influences that affect their social behaviour and well-being, including eating choices and physical activity habit. Children's eating patterns have received increasing attention from health professionals and researchers. Eating patterns and habits of children have a great influence on their health as well as their performance in schools. Based on the reports from the recent $2^{\text {nd }}$ phase of National Survey and Nutritional Status Survey 2014 for Brunei Darussalam (NHANNS) has indicated several eating habits among children aged 5 to 9 years old. Some of the results includes; only $5.3 \%$ of boys and $0.7 \%$ of girls consumed the recommended portions of fruits and vegetables. About $67.2 \%$ of boys and $71.0 \%$ of girls consumed breakfast every day. The intake of daily Sugar Sweetened Beverages (SSB) was at the rate of $39.1 \%$ in boys and $38.4 \%$ in girls. This presentation will include some activities to support healthy physical activity and eating behavior in the primary school settings in Brunei Darussalam as well as other possible recommendations. 


\title{
DO MATERNAL AND EARLY LIFE FACTORS DETERMINE SUBSEQUENT GROWTH AND ADIPOSITY? EXPERIENCE FROM THE GROWING UP IN SINGAPORE TOWARDS HEALTHY OUTCOMES (GUSTO) COHORT STUDY
}

\author{
LEE YUNG SENG \\ Department of Paediatrics, Yong Loo Lin School of Medicine, National University \\ of Singapore, Singapore. \\ Department of Paediatrics, National University Hospital, Singapore.
}

The Growing Up in Singapore towards healthy Outcomes (GUSTO) study was launched in 2009, to examine the influence of in-utero and early life exposures on subsequent risk for obesity and diabetes later in life in the offspring. It has recruited more than 1000 mother-child dyads, and the follow up retention rate is above $85 \%$. Some of the key findings to be discussed include maternal glycemia at mid gestation exert a continuous influence on neonatal adiposity and risk for large for gestation age, even at levels below the W.H.O. clinical cut off level for diagnosis of gestational diabetes mellitus. This influence persisted beyond infancy and extends to childhood adiposity and risk of overweight/obesity at 3 years of age. Prepregnancy BMI and mid-pregnancy gestational weight gain were independently associated with postnatal weight up to two years and skinfold thickness at birth. These associations are ethnic-dependent, and underscore the importance of ethnic specific studies before generalizing the applicability of risk factors reported in other populations. Infant body mass index (BMI) peak has received much interest recently as a potential predictor of future obesity and metabolic risk. We found that the peak occurred later in Malay and Indian infants compared to Chinese, and was lower in magnitude in Indian infants. Higher peak and pre-peak velocity were associated with greater BMI, sum of skinfolds (SSF) and fat-mass index at 48 months of age. Age at peak was positively associated with later BMI and SSF, while peak magnitude was associated with later blood pressure. Older age and higher magnitude at peak were associated with increased risk of overweight at 48 months. We reported one of the largest series of neonatal abdominal adipose tissue data obtained by Magnetic Resonance Imaging (MRI) within 2 weeks of birth in 333 GUSTO neonates. 
Tumour and Oncology

Symposium 6

\title{
CURRENT CHALLENGES IN SURGICAL TREATMENT OF BONE SARCOMA
}

\author{
NOR HAZLA MOHAMED HAFLAH \\ Department of Orthopaedics \& Traumatology, Faculty of Medicine, Hospital \\ Canselor Tuanku Muhriz, Universiti Kebangsaan Malaysia Medical Centre
}

Osteosarcoma is the most common malignant primary bone sarcoma followed by Ewing sarcoma and chondrosarcoma. In the 1970s for curative intent, amputation was the surgical treatment. However, today with advances and improvements in radio-imaging and medical oncological treatment, limb preservation surgery is possible. In limb salvage surgery it is imperative that a wide margin of excision is achieved. Consequently, skeletal reconstruction using endoprosthesis, allograft or composite allograft are required. Endoprosthesis is the preferred method of reconstruction in most centres in Malaysia. It allows immediate weight bearing and has a lower complication rate compared to allografts. However, it is expensive and patients frequently require financial assistance through our local healthcare welfare system. Allograft, although cheaper in comparison to endoprosthesis has a higher postoperative complication rate such as infection and fractures. Furthermore, there is a limited supply of allograft in our country. Occasionally surgeons are required to be innovative when dealing with massive bone defect after tumour resection. 


\section{ADDING VALUE TO CANCER THERAPY}

\section{FUAD ISMAIL}

Consultant Clinical Oncologist, Department of Radiotherapy \& Oncology, Faculty of Medicine, Hospital Canselor Tuanku Muhriz, Universiti Kebangsaan Malaysia

Medical Centre

Evidence based medicine has revolutionised the practice of medicine. Best practises are now based on data generated from clinical trials rather than adage and experience of senior professors. Rigorous randomised clinical trials are required to prove the efficacy of new treatment modalities especially new drugs. The cost of conducting such trial, typically with a high rate of negative results, has translated into higher drug costs to the patients and payers. Akin to Moore's law for computers, the cost of new cancer drugs doubles every 10 years. Many of the drugs are now unaffordable to the larger population and are not sustainable for governments to subsidise. To quantify the value of human life is difficult and fraught with emotional and social issue. However as a guide, the WHO has suggested a value of 1-3 national GDP per Quality Adjusted Life Years (QALY) as a cost-effective price of a drug to be made readily available by governments. With large discrepencies in GDP worldwide and slow rise in GDP relative to drug prices, more innovative methods of payments and evaluation needs to be considered by both innovator companies and payers to make newer cancer therapies available for the public. Value Based Medicine (VBM) aims evaluate new treatment and evaluate fair pricing for treatment to be included in national formularies. 
Tumour and Oncology

Symposium 6

\section{NATURAL KILLER (NK) - CELL NEOPLASMS}

\section{MARIA FRANCISCA HAM}

Department of Anatomical Pathology, Faculty of Medicine, Universitas Indonesia/ CiptoMangunkusumo, National Central General Hospital, Jakarta, Indonesia.

In the $2008 \mathrm{WHO}$ classification of hematolymphoid and myeloid neoplasms, and in the 2016 revised classification, NK-cell neoplasms prototypes consisted of extranodal NK/T-cell lymphoma, nasal type and aggressive NK-cell leukemia. Extranodal NK/T-cell lymphoma, nasal type involves mainly extranodal sites, especially the nasal cavity, while the aggressive NK-cell leukemia may affects broad areas, including bone marrow, peripheral blood, liver, spleen, skin and lymph nodes. The morphological features showed atypical lymphoid cells with fibrinoid necrosis and angiocentricity. The atypical cells showed NK-cell phenotype (CD56 or CD16) in aggressive NK-cell leukemia and NK/T-cell phenotype in extranodal NK/T-cell lymphoma. Both entities showed cytotoxic granules (perforin, granzyme, TIA-1) and Epstein-Barr virus-encoded RNA (EBER) positivity. In the new 2016 revision of WHO hematolymphoid classification, the group of EBV-positive T/ NK cell lymphoproliferative disorders in childhood, which may show NK-cell phenotype include systemic EBV-positive T cell lymphoma, systemic chronic active EBV infection, hydroa-like lymphoproliferative disorders, and severe mosquito bite allergy. The diagnosis of these entities may be challenging due to its rarity and features similarity. 
Tumour and Oncology

Symposium 6

\section{A POTENTIAL ROLE FOR SPLEEN TYROSINE KINASE (SYK) IN BREAST CANCER}

\section{NURIZZYAN BUNGSU', ABDALLA MOHAMED JAMA², MAS RINAWATI HAJI ABDUL HAMID ${ }^{1}$}

${ }^{1}$ PAPRSB Institute of Health Sciences, Universiti Brunei Darussalam, Jalan Tungku Link, Brunei Darussalam

${ }^{2}$ Faculty of Science, Universiti Brunei Darussalam, Jalan Tungku Link, Brunei Darussalam

Introduction: Spleen Tyrosine Kinase (SYK) is a non-receptor tyrosine kinase produced mainly by hematopoietic cells reflecting their important role in B-cell progenitor development. Recently SYK has been identified to play a role in cancer development. SYK has been shown to act as a tumour promoter or suppressor dependent on the stimulating environment. We were interested to study if SYK was involved in apoptosis in breast cancer cells. Methods: Stable transfection of $S Y K$ gene into breast cancer cells was performed using FuGENER. MTT cell proliferation assay was used to show cell death induced by inducing agents. Apoptosis was studied by qPCR and Western blotting to show gene and protein expressions of caspases and inhibitors and promoters of apoptosis, respectively. Results: Our results showed a substantial cell death of breast cancer cells carrying SYK gene when induced with death-inducing agents. Apoptosis was indicated and characterised by the expression of caspases 8 and 9 and the proteins Bax and Bcl-2. Conclusion: SYK gene was stably-expressed in breast cancer cells. Upon drug-induction, SYK appeared to cause apoptosis of breast cancer cells indicating a tumour suppression role. 
Infection and Immunity

Symposium 7

\title{
ANTIMICROBIAL STEWARDSHIP: BREAKING THE ICE
}

\author{
NORDIAH AWANG JALIL \\ Senior Consultant Medical Microbiologist and Head of Infection Control Unit, \\ Faculty of Medicine, Hospital Canselor Tuanku Muhriz, Universiti Kebangsaan \\ Malaysia Medical Centre
}

Antimicrobial stewardship is a rational, systematic approach to the use of antimicrobial agents in order to achieve optimal outcomes. Thus the goals of an antimicrobial stewardship program in a healthcare system are to improve patient outcomes, reduce adverse consequences, minimize the emergence and spread of antimicrobial resistance and deliver cost-effective therapy. This presentation will provide some insight into those factors that are important in crafting effective hospitalbased antimicrobial stewardship programs and discuss the key evidence-based antimicrobial stewardship interventions. Challenges to the success of antimicrobial stewardship programs will be addressed emphasizing on multidisciplinary team effort, behavior culture change in antimicrobial prescribing, leadership commitment and adequate funding. 


\title{
STUDY OF TWO GENES FROM Rpf FAMILY OF MYCOBACTERIUM TUBERCULOSIS AS SEED VACCINE CANDIDATE
}

\author{
ANDRIANSJAH \\ Department of Microbiology, Faculty of Medicine, Universitas Indonesia
}

Tuberculosis (TB) caused by Mycobacterium tuberculosis has long been an attention since the disease suffered by the majority of the world population, and cause death in large numbers. Based on the WHO report in 2013 Indonesia as a country with a high level of its population, ranks fourth highest TB patients after India, China, and South Africa. Various attempts have been made to address the spread and incidence of TB infection, one of them by giving vaccine. Vaccination with BCG vaccine to tackle TB infection has long been done but the protection varies in different countries. The weakness of this vaccine encourages various research on a new vaccine candidate both as a companion to the establish vaccine or vaccines replacement. Now, 11 vaccine candidates in clinical trial phase, e.g., MVA85A, AdAg85A, H1lc31, H1-CAF01, rBCG30, H4-IC31 (AERAS-404), rBCG UreC:Hly (VPM1002), RUTI Mtb72f/M72, Aeras-402 and Mycobacterium vaccae. Most of them are sub unit vaccine or BCG recombinant and implemented as prophylaxis vaccine. In Indonesia, ministry of research technology and higher education, ministry of health and some universities has collaborated to find some candidate vaccine to fill vaccine need based on internally research. TB vaccine consortium has been studied some genes which potentially as vaccine, one of them is $r p f$ family. Rpf protein family is known play a role in dormancy condition of $M$. tuberculosis. Some of proteins have activity to induce cellular immunity in animal tested. IFN $\gamma$ was detected on individual with Tuberculin Skin Test (TST) positive in response to RpfB, RpfC, and RpfE proteins. RpfA and RpfD also reported its immunogenicity in human. We constructed GST-RpfB and GST-RpfD recombinant proteins and DNA plasmid recombinant in pCDNA 3.1 of $M$. tuberculosis Beijing strain isolate from Indonesian TB patient. Those recombinant proteins had been isolated and purified. In vitro cellular immunity examination showed response to GST-RpfB, GST-RpfD, or a mixture of both protein recombinants. Increasing titer of IL12 were significantly different $(p<0.05)$ compared to negative control (RPMI). Recombinant proteins GST-RpfB also stimulate increasing the concentration of cytokines IFN $\gamma$ significantly compared to the control. The different results obtained from the response to IL4 and IL10 wherein the treatment by GST-RpfB, GST-RpfD or mixtures showed nonstimulated the production of those cytokines. Meanwhile, plasmid DNA recombinants also show similar cellular response of animal tested. This research has demonstrated the potential of RpfB and RpfD recombinant protein and plasmid DNA recombinant constructed in this study as a potential seed vaccine candidate. 
Infection and Immunity

Symposium 7

CHALLENGES AND OPPORTUNITIES IN IMMUNOLOGY IN BRUNEI

\author{
ANNE CATHERINE CUNNINGHAM ${ }^{1}$ AND SURITA TAIB ${ }^{2}$ \\ 'PAPRSB Institute of Health Sciences, Universiti Brunei Darussalam. \\ ${ }^{2}$ Department of Laboratory Services, RIPAS Hospital, Brunei.
}

The science of immunology has great potential in the prevention, diagnosis and treatment of disease. Our aim is to increase awareness of basic immunology and immunopathology in Brunei, particularly the burden of disease in the younger people. The two main areas of diagnosis in Brunei are in autoimmunity and allergy. Patients suspected of having systemic rheumatoid diseases (e.g. systemic lupus erythematosus SLE, connective tissues diseases CTD, rheumatoid arthritis RA) will be evaluated for the presence and type of anti-nuclear antibodies (and anti-citrullinated antibodies in the case of RA). Other autoimmune diseases tested for in the population include liver diseases, thyroid diseases and vasculitis. Patients suspected of allergic diseases (eg atopic dermatitis, urticaria, rhinitis) will be evaluated for levels of total and specific IgE as appropriate. Diagnostic tests are mainly immunoassay format (ELISA, indirect immunoflouresence, Enzyme immunofluorescent asssay). Recent findings indicate that there is an increasing burden of allergic and autoimmune diseases, particularly in the younger age group. This is reflected in higher levels of dsDNA, total IgE and positive ANA results in patients aged 18-34 years. The dominant allergens detected in patients are specific to house dust mites Dermatophagoidespteronyssinus, D. farinae, Blomiatropicalis. Laboratory based research has grown in the last 5 years, project areas include T cell modulation in response to various agents, including potential traditional medicines (plant extracts). Flow cytometry is a valuable tool (immunophenotyping, cell trace proliferation assays, apoptosis assays) in combination with tissue culture. 
Infection and Immunity

Symposium 7

\section{ANTI VAX MOVEMENT: DEBUNKING THE MYTH}

\section{AMINAH BEE MOHD KASSIM}

Public Health Physician, Family Health Development Division

Despite being recognized as one of the most successful public health measures, vaccination is perceived as unsafe and unnecessary by certain individuals. The harms of vaccination refusal are real and already seen globally with outbreaks due to vaccine refusal documented in otherwise well-vaccinated populations. Nonacceptance has been attributed to various reasons for example religious beliefs, family practices and media influences. Studies show that reasons for hesitancy are related to safety and the need for immunisation. Clinicians and health personnel have to be more knowledgeable, acquire communication skills and learn the art of negotiating in order to educate the community on issues of immunization. 


\title{
BIG DATA ANALYTICS AND IOT IN HEALTHCARE - THE FUTURE MEDICINE
}

\author{
SAPERI SULONG \\ Department of Health Information, Hospital Canselor Tuanku Muhriz, Universiti \\ Kebangsaan Malaysia Medical Centre.
}

Big Data is used to describe a massive volume of both structured and unstructured data that is so large that it is difficult to process using traditional database and software techniques. In most enterprise scenarios the data is too big or it moves too fast or it exceeds current processing capacity.The primary aim of big data analytic is to provide organisations or companies make better decisions by enabling data scientists and other users to analyse huge volumes of transaction data as well as other data sources that may be left untapped by conventional intelligence programs. These other data sources may include web server logs and internet click stream data, social media activity reports, mobile-phone call detail records and information captured by sensors. There is also plenty of big data in healthcare. Every hospital will have its own set of big data. Big data allows us to know the readmission rates of patients to the hospital with the same diagnosis and this will let us know how good we are in discharging our patients at the appropriate time. Big data allows us to know the average cost of every procedure using the diagnostic research grouping (DRG) and ICD coding. We can even compare the efficiency and performance of each of our surgeon or physician based on treating a similar group of patients (plus revealing those who are the biggest spenders and those who have the biggest number of complications from procedures). Big data will reveal to us which disciplines are our strengths in terms of diseases outcome and survival. Big data will also show us the trend of admissions and help the administrators plan for future budget as well as expansion. Big data can also come up with a risk profile of each of our patient (via predictive modeling) by gathering all their clinical and laboratory data plus their medical histories. Big Data and Internet of Things (IoT) in healthcare are at the forefront of innovation. While robots and computers will probably never completely replace doctors and nurses, machine learning/deep learning and Artificial Intelligence (Al) are transforming the healthcare industry, improving outcomes, and changing the way doctors think about providing care. Machine learning is improving diagnostics, predicting outcomes, and personalized care. The shift to point-of-care delivery, remote monitoring, precision medicine, devices the size of a grain of rice, the new world of brain-computer-interfaced devices are changing the trend of treatment to the patients. Imagine walking in to see your doctor with an ache or pain. After listening to your symptoms, she inputs 
them into her computer, which pulls up the latest research she might need to know about how to diagnose and treat your problem. You have an MRI or an x-ray and a computer helps the radiologist detect any problems that could be too small for a human to see. Finally, a computer looks at your medical records and family history and compares that with the best and most recent research to suggest a treatment protocol to your doctor that is specifically tailored to your needs.Big data will transform healthcare and allow the 4Ps of medicine to be practiced: Precision, Predictive, Preventive and Participatory. Turning data into knowledge that drives better care, outcomes and organizational performance. 


\section{ADDRESSING THE GROWING BURDEN OF NON- COMMUNICABLE DISEASES (NCDS) IN ASIA - A HEALTH SYSTEM PERSPECTIVE}

\section{INDAH S WIDYAHENING}

\section{Department of Community Medicine, Faculty of Medicine, Universitas Indonesia}

Non-communicable diseases (NCDs) are now the leading cause of morbidity and mortality in the Asian region and this burden is projected to increase in the years to come. Successful prevention and management of the diseases requires wellfunctioning health systems. The World Health Organization (WHO) describes a health system as a building block which consisted of six components: service delivery; healthcare workforce; information; medical products, vaccines and technologies; financing; and leadership and governance. The Asian region consisted of many countries with various socio-economic condition which lead to variation in their health system functioning and capacities to manage the NCDs. One study found that quality of health care governance is associated with variation in diabetes prevalence across Asian countries. Various weakness in each of the components of the health systems especially in Asian countries needs to be discussed and several interventions targeted to each of the components which reportedly work in other countries/setting need to be identified and studied. The collaboration of Indonesian, Malaysian and Brunei medical schools needs to continuously attempt to contribute to the effort in controlling the growing burden of non-communicable diseases in the Asian region. A multi-center study on the roles of the health system in NCDs management involving the three countries need to be further discussed as a follow-up of this conference. 
RESULTS FROM THE FIRST NATIONAL DOOR TO DOOR SURVEY
IN ONE SOUTH EAST ASIAN COUNTRY - THE BEST-STUDY (THE
BRUNEI-EPIDEMIOLOGY-OF-STROKE AND MULTIPLE SCLEROSIS)

AGONG LUPAT', UTAMEYDING-LAMADÉ ${ }^{2,3}$, MASLIZA LUISSIN', JOHANNES HENGELBROCK, HEIKO BECHER ${ }^{4}$

${ }^{1}$ Faculty oh Health Sciences, Universiti Brunei Darussalam

${ }^{2}$ Brunei Neuroscience Stroke Rehabilitation Centre (BNSRC), JPMC, Brunei

Darussalam

${ }^{3}$ Department of Neurology, Krankenhaus Nordwest, Germany

${ }^{4}$ University of Hamburg, Germany

Introduction / Aims: Around 6 million people suffer from stroke worldwide. Despite stroke is one of the leading cause of mortality among Asians, no national level epidemiological investigations done to examine risk factors for stroke among general Asian population. This study aims to determine the national-level distribution of stroke risk factors among Bruneian. Methods: Cross-sectional door to door survey was conducted with the use of modified WHO stroke survey questionnaire in Brunei Darussalam from October 2013 to August 2014. Data analysis was conducted using descriptive statistics on population parameters and the prevalence of major diseases were performed. Logistic regression models are used to analyze the association between hypertension and sex, age, body mass index (BMI), education, smoking, family history of hypertension and employment. The non-linear relationship between age and blood pressure is explored using locally weighted scatter plot. Results / Discussions: In total, 5064 participants were interviewed from 2110 randomly selected household. The study participants were $43.6 \%$ (male) and $56.4 \%$ (female). Door to door health assessment revealed that the high prevalence of risk factors for stroke as high blood pressure (25.2\%), elevated cholesterol (25.7\%), smoking (21.7\%), and diabetes mellitus (9.7\%). Although, there is a high prevalence of hypertension in all age groups, but the mean diastolic and systolic blood pressure, is higher in the young age groups. These results shows that risk factors for stroke have a high prevalence particularly among younger age group who have higher hypertension incidence and BMI. Future health promotion activities should focus on younger population. 
Community Medicine

Symposium 8

\title{
PHYSICAL ACTIVITY: PREVENTION \& TREATMENT OF CHRONIC DISEASES
}

\author{
AHMAD TAUFIK JAMIL \\ Population Health and Preventive Medicine, Faculty of Medicine, Universiti \\ Teknologi MARA, Sungai Buloh Campus.
}

Heart disease is the main cause of morbidity and mortality in Malaysia. The important modifiable risk factors for heart disease include hypertension, obesity, diabetes, hyperlipidemia and physical inactivity. Physical activity is able to prevent occurrence of risk factor of heart disease, hence, able to prevent heart disease. Physical activity is able to treat and control the risk factors of heart disease as well. Strategy to increase level of physical activity among Malaysian population is important to reduce morbidity and mortality of heart disease, along with other strategy. At the same time, primary care doctor is also encouraged to prescribe exercise to their patient along with the conventional treatment. The two strategies will help control and reduce the morbidity and mortality of heart disease. 
'WHO DARES TO TEACH, MUST NEVER CEASE TO LEARN'

HARLINA HALIZAH SIRAJ

Department of Medical Education, Faculty of Medicine, Hospital Canselor Tuanku Muhriz, Universiti Kebangsaan Malaysia Medical Centre

The quote came from John Cotton Dana (1856 - 1929), a renowned American librarian when he was asked to suggest a motto for a new college in New York in 1912. Even after a century, it still serves as a great reminder to all educators on the importance of adopting a life-long learning culture, to relearn, unlearn and learn new things. It is beyond doubts that education has taken many quantum leaps with the digital revolution we are witnessing today. Educators the world over have to embrace these changes while remain steadfast to the sacred principles of teaching and learning. Healthcare and medicine in the $21^{\text {st }}$ century will expand tremendously and require skilled healthcare providers (HCPs) who can adapt, adopt and accommodate rapidly to the ongoing changes. Hence, the training of HCPs the world over will have to be upgraded to meet up the demand and challenges. Continuous faculty development is becoming more and more essential and crucial than ever before. Medical and health educators are then required to be able to reflect on their teaching competencies and put on conscious effort to relearn, unlearn and continue learning new teaching advances in their respective fields. This is indeed the best time to go back to school and become learners again, teachers! 


\title{
THE EXPERIENCE TO INVOLVE FMUI INTERNSHIP DOCTORS TO MAINTAIN LEARNING PROCESS IN NEW MEDICAL FACULTY AT WEST PAPUA
}

\author{
KANADI SUMAPRADJA, UMI KUMAYAH, ANDI OMEGA \\ Faculty of Medicine Universitas Indonesia
}

Faculty of Medicine Universitas Indonesia (FMUI) has been long known as a pioneer in medical teaching in Indonesia. FMUI reputation as one of the best medical faculty in Indonesia has brought FMUI to become a benchmark for other medical faculty in Indonesia. Since 2014, the ministry of high education and research ask FKUI to help the new emerging medical faculty in Sorong, West Papua. The decision to erect a new Faculty Medicine since 2014 in Sorong was based on fact there is a significant lack number of doctors for West Papua people. There are many factors contribute to this situation. One of the best solutions that has already considered is to build a Medical Faculty within the region and to train local students who are born and live in West Papua Province. Therefore, it will be expected that doctors who graduates from this Faculty can be deploy straight away to certain areas that need. However, this province still has minimum resources in manpower for teaching and also minimum teaching facility. Based on the agreement that has already signed between Universitas Papua (UNIPA), District Government of Sorong and FMUI, since 2014 FMUI has actively sent their teaching staff regularly to UNIPA. Unfortunately, during the third year of progress, there was a financial problem that delays FMUI staff deployment to Sorong. Therefore, the Dean and staff of UNIPA medical faculty try to look for alternatives in order to maintain teaching process. Fortunately, there are many FMUI alumni that currently working at Sorong region as an internship doctor for one year. This study is trying to observe the result of teaching process on UNIPA medical faculty if teaching process was taking over by FMUI alumni internship doctors. As we know very well, Internship doctors do not have many teaching experiences. However, during this difficult situation, it seems they could become the best option in order to maintain teaching process at UNIPA medical faculty. 


\title{
ADVANCES IN MEDICAL EDUCATION IN BRUNEI DARUSSALAM
}

\author{
FAZEAN IRDAYATI IDRIS, ANNE CUNNINGHAM, RAFIDAH \\ GHARIF
}

PAPRSB Institute of Health Sciences, Universiti Brunei Darussalam

The Master of Medicine (MMed) programme was established in response to the Ministry of Health's needs to introduce accredited and appropriately certified training programmes for medical graduates into the Institute of Health Sciences, Universiti Brunei Darussalam (UBD). The purpose is to allow for structured training within the local setting, in order to develop high quality and comprehensive training from graduate to consultant, which is effective, efficient, responsive, affordable, equitable and accessible. The first cohort of 16 doctors from Critical Care Medicine, Emergency Medicine, General Internal Medicine, Primary Health Care, Surgery and Psychiatry joined the MMed programme in January 2017. The programme enables medical graduates to achieve expert skills in critical appraisal and research evaluation; evaluate evidence based medicine and enhanced skills in knowledge and competencies in their clinical discipline, perform sophisticated analysis and critical peer review of clinical consultations, integrate knowledge of educational theory into Continuing Medical Education and health education, as well as enhance leadership and management skills as appropriate to their discipline. The next step towards advancing in postgraduate medical education is to introduce Advanced Specialty Training opportunities in the country, an extension of the current MMed programme, enabling formal training to take place locally and in collaborating partners overseas. This will allow UBD to align the national goal in producing highly qualified consultants to serve the population of Brunei. The new programme will introduce doctoral qualifications in response to the needs of the career progression of professionals working in different fields. 


\title{
VIRGIN COCONUT OIL AND WOUND HEALING IN DIABETIC RATS: HISTOLOGICAL AND PROTEIN ANALYSIS
}

\author{
AMRO MOHAMED SOLIMAN, TEOH SEONG LIN, \\ NORZANA ABD GHAFAR, SRIJIT DAS \\ Department of Anatomy, Faculty of Medicine, Universiti Kebangsaan Malaysia \\ Medical Centre, Jalan Yaacob Latif, Bandar Tun Razak, 56000 Cheras, Kuala \\ Lumpur, Malaysia.
}

Introduction: Virgin coconut oil (VCO) is a natural oil characterized by antimicrobial, antiviral, anti-inflammatory and anti-oxidant effects. Methodology: A total of 72 Sprague Dawley rats were divided into 4 groups i.e. (i) non-diabetic and non-treated [control], (ii) diabetic treated with VCO [VCO], (iii) diabetic treated with Silver sulfadiazine cream [SS] and (iv) diabetic non-treated [SHAM]. Wounds were inflicted on all groups using punch biopsy needles, and the animals were treated topically for 14 days. Total protein content (TPC) of wound tissue was estimated on day 1,7 , and 14 . Wound contraction rate (WCR) was assessed on day 5, 10 and 14, and histological analysis was performed on day 7 and 14. Results: In the VCO group, TPC on day 1, 7, and $14(14.6 \pm 1.5,20.04 \pm 0.5$, and $24.3 \pm 1.4$ $\mathrm{mg} / \mathrm{g}$ tissue respectively) was significantly $(\mathrm{P}<0.05)$ higher compared to both SHAM and SS groups. WCR on day 5, 10, 14 was significantly $(P<0.05)$ higher in VCO group. Histological analysis on day 7 and 14 showed more collagen deposition, neovascularization and intact epidermis in the VCO group compared to SHAM and SS groups. Conclusion: VCO promoted healing of diabetic wounds and it showed better results compared to silver sulfadiazine used topically. This shows that VCO may have beneficial potential properties in treating diabetic wounds. 
Biomedical Sciences

Oral

\section{NDP (NORRIE DISEASE PSEUDOGLIOMA) GENE POLYMORPHISM \\ IN INDONESIAN INFANTS WITH RETINOPATHY OF PREMATURITY. AN EPIDEMIOLOGY STUDY}

\section{JO EDY SISWANTO', SUDARTO RONOATMOJO', RITA \\ S.SITORUS ${ }^{3}$, AG.SOEMANTRI ${ }^{4}$, ISWARI SETIJANINGSIH ${ }^{5}$, PIETER JJ SAUER 6}

${ }^{1}$ Neonatology Working Group Harapan Kita Women and Children Hospital, Jakarta.

${ }^{2}$ Dep. Epidemiology of Public Health Faculty, Jakarta.

${ }^{3}$ Dep. Ophtalmology Ciptomangunkusumo Hospital, Jakarta.

${ }^{4}$ Dep. Pediatrics of Dr. Kariadi Hospital, Semarang.

${ }^{5}$ Eijkman Institute, Jakarta.

${ }^{6}$ Department of Pediatrics, Beatrix Children Hospital, University Medical Center

Groningen, the Netherlands

Introduction: Retinopathy of Prematurity (ROP) is a major cause of blindness in newborn infants, also in developing countries. Why ROP progresses is some infants while it regresses in others is presently unknown. Studies suggest that genetic factors might be involved. Mutations in the Norrie Disease Pseudoglioma gene (ND) are suspected to be related to advanced ROP development. Whether these genetic factors may play a role in Indonesia, a country with a relatively high incidence of severe ROP, is unknown. Aim: We investigated the presence of mutations in the Norrie Disease Pseudoglioma gene (ND) on the $X$ chromosome in infants with both non-advanced and advanced ROP in Indonesia. Methods: We analyzed polymorphisms in six genes in exon 3, C597A, L108P, R121W, A05T, V60E and C110G in 162 preterm newborn infants. ROP was diagnosed in 83 infants, Stage 1-2 was present in 61 patients, 22 patients showed stage 3-5 and 79 infants served as control. Results: In none of the infants, both patients with ROP and controls we found a polymorphism in any of the genes. Conclusion: We conclude that mutations in the ND gene play either no or only a minor role in the occurrence or progression of severe ROP in preterm infants in Indonesia. 


\title{
DEVELOPING AND VALIDATING PHOPHODIESTERASE-5 INHIBITOR (PDE5i) ASSAY USING SPECTROMETRY
}

\author{
NUR AZIEMAH MOHAMMAD AZIZI, UMMI FATIN \\ FAKHRIAH ABU BAKAR, ASRIN TENGAH \\ 'PAP Rashidah Sa'adatul Bolkiah Institute of Health Sciences, Universiti Brunei \\ Darussalam, Jalan Tungku Link, BE1410, Brunei Darussalam
}

Introduction: Phosphodiesterase-5 inhibitor (PDE5i), a drug of choice for treating erectile dysfunction, is widely subjected to adulteration. Currently, high performance liquid chromatography (HPLC) is the common method for analysing pharmaceutical compounds with high specificity and accuracy, but it has limitations. The samples must be completely soluble to ensure the analytical process can proceed accurately and also to prevent unnecessary damage to the HPLC column. Hence, the study aims to develop an alternative assay which is more effective. Methods: Malachite green assay is adopted in developing this alternative technique as a colour change is observed from blue to green when exposed to inorganic phosphate (Pi), measured at $630 \mathrm{nM}$. Initially, a standard graph of a known [Pi] (0 to $30 \mathrm{uM})$ was established. Next, a dual biochemical reactions system was performed, converting GMP from cGMP by PDE5 and followed by Pi generation from the first reaction's product by CIAP. To assess the feasibility of this dual reactions system; consecutive end-point and coupled-end point assays were conducted. Finally, a standard curve of pure Sildenafil was generated before quantifying PDE5i in an adulterated drug sample. Results: The standard graph of known [phosphate] $(0-30 \mathrm{uM})$ shows a linear relationship $\left(R^{2}=0.99\right)$. The consecutive end-point assay has produced lower absorbance $(0.161 \mathrm{AU})$ than the couple-end assay $(0.699 \mathrm{AU})$, indicating the presence of released $\mathrm{Pi}$ in the latter assay. The above optimized method was then able to generate a sigmoidal standard curve of pure Sildenafil sample $(0.1 \mathrm{nM}$ to $10 \mathrm{mM})$. Finally, this standard curve managed to quantify two separate samples from the same adulterated drug with $21.6 \%$ and $53.6 \%$ of PDE5i, respectively. Conclusion: This developed assay has the potential to become an alternative analytical method for PDE5i. 


\title{
PIPER SARMENTOSUM REDUCES BLOOD PRESSURE AND ANGIOTENSIN II IN DEXAMETHASONE-INDUCED HYPERTENSIVE RATS
}

\author{
MUHAMMAD FIRDAUS AZMI', AZIZAH UGUSMAN', \\ AMILIA AMINUDDIN', JAMIA AZDINA JAMAL ${ }^{1,2}$
}

\author{
'Jabatan Fisiologi, Fakulti Perubatan, Pusat Perubatan Universiti Kebangsaan \\ Malaysia, Tingkat 18, Bangunan Pra-Klinikal, Jalan Yaakob Latif, Bandar Tun \\ Razak, 56000 Cheras Kuala Lumpur, Malaysia \\ ${ }^{2}$ Fakulti Farmasi, Universiti Kebangsaan Malaysia, Jalan Raja Muda Abdul Aziz, \\ 50300 Kuala Lumpur, Malaysia
}

Introduction: Hypertension is a multi-factorial disease and it is one of the common complications of dexamethasone use. There are multiple mechanisms involved in dexamethasone-induced hypertension; which include activation of renin angiotensin system and increased vasopressor response to angiotensin II (Ang II). Piper sarmentosum (P.s) is an herb with antihypertensive effect. However, it is unclear whether P.s has beneficial effect on dexamethasone-induced hypertension. Objective: Therefore, this study was designed to investigate the antihypertensive effect of P.s on dexamethasone-induced hypertension in Sprague Dawley rats. Methods: Aqueous extract of P.s $(500 \mathrm{mg} / \mathrm{kg} /$ day $)$ was administered to the rats via oral gavage while dexamethasone $(20 \mu \mathrm{g} / \mathrm{kg} /$ day $)$ was administered via subcutaneous injection for 28 days continuously. Blood pressure was measured using non-invasive tail cuff method (CODA ${ }^{\mathrm{TM}}$ ) at baseline, day 14 and day 28 of the study. After completing 28 days of treatment, the rats were sacrificed and the serum was obtained for measurement of Ang II using enzyme-linked immunosorbent assay (ELISA) technique. Results: Induction with dexamethasone caused an increase in both systolic blood pressure (SBP) $(103.11 \pm 4.07 \mathrm{mmHg}$ to $132.72 \pm 3.07 \mathrm{mmHg}$, $\mathrm{p}<0.001, \mathrm{n}=6)$ and diastolic blood pressure (DBP) $(76.83 \pm 4.09 \mathrm{mmHg}$ to $105.28 \pm$ $2.58 \mathrm{mmHg}, \mathrm{p}<0.05, \mathrm{n}=6$ ). In dexamethasone-induced hypertensive rats, treatment with P.s was able to reduce the SBP $(109.28 \pm 2.95 \mathrm{mmHg}, \mathrm{p}<0.001, \mathrm{n}=6)$ and DBP $(86.56 \pm 5.31 \mathrm{mmHg}, \mathrm{p}<0.05, \mathrm{n}=6)$. Ang II was decreased when P.s was given to the dexamethasone-induced hypertensive rats, compared to dexamethasoneinduced hypertensive rats group $(229.25 \pm 9.36 \mathrm{pg} / \mathrm{mL}$ vs. $281.35 \pm 17.14 \mathrm{pg} / \mathrm{mL}$, $\mathrm{p}<0.05, \mathrm{n}=6$ ). Conclusions: P.s reduces blood pressure in dexamethasone-induced hypertensive rats and this may be partly mediated by decreased Ang II level. 
Biomedical Sciences

\title{
FLUORESCENCE IN SITU HYBRIDIZATION (FISH) ANALYSIS OF HUMAN EPIDERMAL GROWTH FACTOR RECEPTOR 2 (HER-2) STATUS FOR BREAST CANCER CASES IN BRUNEI DARUSSALAM
}

\author{
JESSICA PEI CHII KOK'1, MAS RINA WATI HAJI ABDUL \\ HAMID', RAVI SEKHAR PATNAIK ${ }^{2}$ \\ ${ }^{1}$ Universiti Brunei Darussalam \\ ${ }^{2}$ The Brunei Cancer Centre (TBCC)
}

Introduction: Breast cancer is one of the leading cancers among Bruneian women. There are many known subtypes of breast cancer and one particular subtype is the HER-2 positive breast cancer. This group of cancer is known to be more aggressive and having a poor prognosis. This study aims to assess the proportion of HER-2 positive cases and the association of HER-2 positivity with factors under study. Methods: A total of 146 breast cancer cases that were sent for FISH analysis from 1 January 2012 to 31 December 2016 were derived from TBCC, Brunei. Data analysis were done taking in the age at diagnosis, ethnicity, stage at diagnosis and HER-2 results by IHC and FISH. All analysis were done using IBM SPSS Statistics version 23.0 for Windows. Results: Majority of the study population were diagnosed before the age of 50 and the median age was 52.8 years. $73.3 \%$ of the study population were Malays. $58.2 \%(n=85)$ cases were reported as IHC $3+$, followed by $23.3 \%$ $(n=34) \mathrm{IHC} 2+$ cases and $18.5 \%(\mathrm{n}=27)$ negative cases. The proportion of true HER2 positive cases in total by FISH test was $34.9 \%(n=51)$. Majority of Stage IV HER-2 positive cases had metastasis to the liver or bones. Age at diagnosis is significant in determining HER-2 status of tumours by FISH $(P=0.045)$. Tumour size $(P<0.001)$ and lymph node $(P=0.006)$ are significant in metastases of tumours. 
Biomedical Sciences

\title{
EFFECTS OF PIPER SARMENTOSUM ON ASYMMETRIC DIMETYLARGININE IN HUMAN UMBILICAL VEIN ENDOTHELIAL CELLS
}

\author{
UMA MAHGESSWARY SUNDAR, AZIZAH UGUSMAN, \\ CHUA KIEN HUI, NOR ANITA MEGAT MOHD NORDIN \\ Department of Physiology, UKMMC, Jalan Yaakob Latif, Bandar Tun Razak, \\ Cheras 56000, Kuala Lumpur, Malaysia.
}

Introduction: Asymmetric dimethylarginine (ADMA) is an endogenous competitive inhibitor of endothelial nitric oxide synthase (eNOS). Elevated level of ADMA leads to reduction in nitric oxide (NO) production which is linked to endothelial dysfunction. Piper sarmentosum (PS) is an herb that has previously been shown to stimulate endothelial $\mathrm{NO}$ production by increasing both expression and activity of eNOS. Thus, this study will determine whether the positive effects of PS on NO production is related to its effect on ADMA concentration in cultured HUVEC exposed to TNF- $\alpha$. Methodology: HUVEC were divided into four groups: control, treatment with $250 \mu \mathrm{g} / \mathrm{ml}$ of aqueous extract of PS (AEPS), induction with $30 \mathrm{ng} / \mathrm{ml}$ of TNF- $\alpha$ and concomitant treatment with AEPS and TNF- $\alpha$ for 24 hours. HUVEC were subsequently collected and lysed to measure ADMA concentration using ELISA. NO level in the culture medium was measured using Griess assay. Results: Induction of HUVEC with TNF- $\alpha$ increased ADMA concentration (785.72 $\pm 3.3 \mathrm{ng} /$ $\mathrm{ml}, \mathrm{p}<0.05)$ and treatment with AEPS suppressed the increment of ADMA brought by TNF- $\alpha(273.22 \pm 10.3 \mathrm{ng} / \mathrm{ml}, \mathrm{p}<0.05)$. AEPS also enhanced NO production in TNF- $\alpha$-induced HUVEC $(0.5 \pm 0.37 \mu \mathrm{M}$ vs $9.7 \pm 1.53 \mu \mathrm{M}, \mathrm{p}<0.05)$. Conclusion: AEPS increases NO level by reducing ADMA concentration in HUVEC exposed to TNF- $\alpha$. 


\title{
THE POTENTIAL OF CENTELLA ASIATICA (L.) ON NEURAL DIFFERENTIATION OF HUMAN MESENCHYMAL STEM CELLS IN VITRO
}

\author{
NORAZZILA OMAR', YOGESWARAN LOKANATHAN ', \\ RUSZYMAH BINTI HAJI IDRUS ${ }^{2}$
}

'Tissue Engineering Center, Universiti Kebangsaan Malaysia Medical Center, 56000 Cheras, Kuala Lumpur, Malaysia.

${ }^{2}$ Department of Physiology, Faculty of Medicine, Universiti Kebangsaan Malaysia, 56000 Cheras, Kuala Lumpur, Malaysia.

Introduction: Increasing evidences have shown the potential of various herbs in differentiating human Wharton's jelly-derived mesenchymal stem cells (hWJMSCs) to neural lineages. Yet, there is almost no report on such effects for Centella asiactica (L.), which was used as nervine during prehistorical times. This study was performed to investigate the potential of raw extract of Centella asiatica (L.), (RECA) on neural differentiation of hWJMSCs in vitro. Methodology: The cytotoxicity effect of RECA was evaluated via PrestoBlue viability assay. Then, RECA at different concentrations $(25,100,400,1200,2000 \mu \mathrm{g} / \mathrm{ml})$ was supplemented to hWJMSCs (P3) alone or in combination of neurotrophic factors for 10 days. The morphology of induced hWJMSCs was documented and neural markers expression (p75 NGFR, S100 $\beta$, GFAP and MOG) was analyzed through immunocytochemistry and quantitative PCR. RECA effects on cell cycle of induced hWJMSCs was evaluated using flow cytometry. Results: It was found that RECA exerted effects on neural differentiation of hWJMSCs in a dose-dependent manner with $\mathrm{IC}_{50}, 1800 \mu \mathrm{g} / \mathrm{ml}$. The stimulatory effects of RECA on neural differentiation of hWJMSCs was pronounced at 400 and $1200 \mu \mathrm{g} / \mathrm{ml}$, though such concentrations inhibited the proliferation of the cell. No DNA aneuploidy was detected across the induced groups. Nonetheless, all the cells mainly populated in $\mathrm{G}_{0} / \mathrm{G}_{1}$ phase due to cell growth arrest attributed by cell's confluency and/or inhibitory effect of RECA. Conclusion: Although RECA above certain dose has inhibitory effects on hWJMSCs, a safer dose of RECA, alone or in combinations of neurotrophic factors, was able to differentiate the cells to neural lineages. 
Biomedical Sciences

\section{PIPER SARMENTOSUM REDUCES BLOOD PRESSURE IN DEXAMETHASONE-INDUCED HYPERTENSIVE RATS}

\section{NOOR FAZILAH MD FADZE, AZIZAH UGUSMAN, AMILIA AMINUDDIN, ZAITON ZAKARIA}

Department of Physiology, Universiti Kebangsaan Malaysia Medical Centre (UKMMC), Jalan Yaacob Latif, Bandar Tun Razak, 56000 Cheras, Kuala Lumpur.

Introduction: Decreased nitric oxide (NO) bioavability is a cardinal feature of endothelial dysfunction which is linked to hypertension. Dexamethasone (Dex) is a glucocorticoid with various clinical applications and hypertension is a common complication its chronic use. The aim of this study was to determine the effects of aqueous extract of Piper sarmentosum (AEPS) on blood pressure (BP) and NO level in hypertensive rats induced with Dex. Methods: Thirty male Sprague Dawley rats were randomly divided into five groups of six rats each as follows: group I served as control; group II was treated with AEPS (500 mg/kg/day) given orally; group III received Dex $(20 \mu \mathrm{g} / \mathrm{kg} / \mathrm{day}$, s.c), group IV and $V$ were treated with Dex+AEPS (500 $\mathrm{mg} / \mathrm{kg} /$ day) and Dex+Captopril (40 mg/kg/day), respectively. All treatments were given for 28 days. Systolic (SBP) and diastolic blood pressure (DBP) were measured using the tail cuff method. After 28 days, all rats were sacrificed and $\mathrm{NO}$ level in the serum was measured using Griess assay. Results: Administration of Dex caused an increase in both SBP $(146 \pm 2.7 \mathrm{mmHg}, \mathrm{p}<0.001)$ and DBP $(104 \pm 3.1 \mathrm{mmHg}$, $\mathrm{p}<0.001)$. Treatment with AEPS lowered SBP $(107 \pm 2.9 \mathrm{mmHg}, \mathrm{p}<0.001)$ and DBP $(79 \pm 1.7 \mathrm{mmHg}, \mathrm{p}<0.01)$ in Dex-induced hypertensive rats. Dex also caused reduction in NO level $(31.0 \pm 5.18 \mu \mathrm{M}, \mathrm{p}<0.05)$ but AEPS was able to restore NO in Dex-induced hypertensive rats $(56.8 \pm 6.22 \mu \mathrm{M}, \mathrm{p}<0.05)$. Piper sarmentosum reduces blood pressure in dexamethasone-induced hypertensive rats and this may be partly mediated by restoration of NO. 


\title{
THE EXPANSION AND CHONDROGENIC DIFFERENTIATION POTENTIAL OF MESENCHYMAL STEM CELLS ON GELATIN MICROSPHERE: DYNAMIC VS STATIC CULTURE CONDITIONS
}

\author{
SHAMSUL SULAIMAN', MOHD FAUZI MH BUSRA', NG \\ MIN HWEI' , RIZAL ABDUL RANI ${ }^{2}$, NOR HAMDAN \\ MOHAMAD YAHAYA ${ }^{2}$, YASUHIKO TABATA ${ }^{3}$, RUSZYMAH \\ IDRUS ${ }^{4}$, SHIPLU ROY CHOWDHURY ${ }^{1}$
}

\begin{abstract}
'Tissue Engineering Centre, ${ }^{2}$ Department of Orthopedic \& Traumatology, ${ }^{4}$ Department of Physiology, Faculty of Medicine, Universiti Kebangsaan Malaysia, Clinical Block, Jalan Yaacob Latiff, 56000 Cheras, Kuala Lumpur, Malaysia. ${ }^{3}$ Department of Biomaterials, Institute for Frontier Medical Sciences, Kyoto University, 53 Kawara-cho Shogoin, Sakyo-ku Kyoto 606-8507, Japan
\end{abstract}

Introduction: Mesenchymal stem cells (MSCs) known to have criteria as selfrenewal ability in monolayer culture and can be differentiated into mesodermal lineages, including osteogenic, adipogenic, and chondrogenic. However, numerous studies have reported a loss of the mitotic ability and capacity of MSCs to differentiate in monolayer culture. Thus, the aim of the study was to evaluate the expansion and chondrogenic differentiation potential of MSCs cultured on gelatin microsphere (GM) under static and dynamic conditions. Methodology: MSCs was isolated from the bone marrow sample of consented patients. Cells were seeded with GM, and cultured with chondrogenic induction medium (CIM) under static and dynamic conditions. Cell attachment, proliferation, and chondrogenic differentiation were evaluated via confocal microscopy, presto blue assay and RTPCR (expression of collagen type I and II and aggrecan), respectively. Moreover, sulfated glycosaminoglycan (sGAG) production was also measured to confirm the chondrogenic differentiation. Results: MSCs attached and spreaded on the microspheres. Cells formed large cell-microsphere clusters with strong cell-cell and cell-matrix interactions. We demonstrated higher attachment and proliferation of MSCs on GM under dynamic condition as compared to that under static condition. Moreover, expression of collagen type II, aggrecan genes and production of sGAG were higher when cultured under dynamic condition as compared to static condition. Conclusion: MSCs on GM under dynamic culture condition facilitates cell proliferation and chondrogenic differentiation. 


\title{
MEDICAL NEGLIGENCE AND LIABILITIES OF A DOCTOR: AN OVERVIEW
}

\author{
MD. HABIB ALAM, ANOWAR ZAHID \\ Faculty of Law National University of Malaysia (UKM)
}

Ancient medical practice may be dated from classical Greek and later Roman Periods where different evidences of medical treatment and diagnoses were found (i.e. as early as 4000BC). In ancient time, it was perceived that disease or illness was happened due to sin or spiritual issues. Medical practices were developed through 4 river-valley civilizations, i.e. Egypt, Indus, Mesopotamia and China. A medical malpractice suit was filed at around 1700 BC under Hammurabi Codified law. Under Greek Medical practices, physicians' code was "first do not harm", i.e. it was related to current medical negligence. Medical negligence is one kind of professional negligence. Doctors are bound to discharge their professional duties with good faith and be aware of and avoid irregular conduct. There is a saying "Doctors are meant to make you better not worse". But things may go wrong because of not taking proper care to patient during treatment. The court may ask whether concerned doctor acted" in accordance with a practice of competent and respected medical opinion". This is an objective test and question of fact and needs to take consideration of circumstantial evidences. Doctors may be liable for both civil liability and criminal liability. The main source of medical negligence law is the common law. There are concerns of public policy and defensive medicine in relation to Medical Negligence. Defensive medicine may include over cautious, perform unnecessary test or refuse to undertake risky surgery by doctors. Currently, two types of medical practices may exist around the world, i.e. civilized medical practice and uncivilized medical practice. Malaysia has different medical laws, i.e. Medical (Amendment) Act 2012, Medical Act 1971, Private Healthcare Facilities and Service Act 1998, Traditional and Complementary Medicine Act 2013, Medical Device Authority Act 2012 etc. This research will emphasize how doctor's negligence and liabilities may be minimized by adopting "Advanced Modern Approach" and friendly relationship with clients (i.e. consumers) by rendering proper treatment (i.e. good contractual treatment procedure) with sincerity. 
Social Medicine

\title{
EVALUATION OF RISK FOR DEPRESSION, STRESS AND ANXIETY IN UNIVERSITY STUDENTS FROM UNIVERSITI BRUNEI DARUSSALAM (UBD) USING THE DEPRESSION, ANXIETY AND STRESS SCALE 21 (DASS21)
}

\author{
JIA YING TAN'', FAZEAN IRDAYATI IDRIS' ${ }^{1}$ DAVID KOH'', \\ JUSTIN WONG ${ }^{2}$ \\ ${ }^{1}$ PAPRSB Institute of Health Sciences, Universiti Brunei Darussalam \\ ${ }^{2}$ Ministry of Health, Brunei Darussalam
}

Introduction/ Aim: Mental illness in university students is a global and growing problem. The objective of this study was to examine the prevalence of depression, anxiety and stress in Universiti Brunei Darussalam students as well as to identify predictors of mental distress. Methodology: The Depression Anxiety and Stress Scale 21 (DASS-21) questionnaire was distributed to students across five faculties, and 312 students completed the questionnaire. According to DASS21 reference ranges, depression was categorised as having a score of $>10$, anxiety $>8$ and stress $>15$. Results/ Discussion: This study found depression levels of mild and moderate severity in $17 \%$ of respondents. $33.8 \%$ had mild to severe anxiety while $4.5 \%$ had mild stress levels. Statistically significant findings show higher mean anxiety and stress scores in Malay students and students facing financial difficulty. Students from Institute of Health Sciences and medical students had lower depression and anxiety scores. Students who rarely exercised had higher mean scores for stress and those who rated their sleep as 'poor and very poor' had significantly higher anxiety and stress scores. The study findings show groups with certain socioeconomic and lifestyle factors had higher scores for mental health indicators. Although these scores are categorized as normal level, this raises awareness that university students can be potentially at risk of mental health issues. In addition, the finding of depression, stress and anxiety found from this study raises concern for their mental well-being and the need to develop adequate support services and referral pathways. 


\title{
KNOWLEDGE AND ATTITUDE AMONG COLLEGE STUDENTS IN A SOUTH INDIAN CITY ABOUT THE PREVALENCE, INFLUENCING FACTORS AND REDRESSAL MECHANISMS FOR INTIMATE PARTNER VIOLENCE
}

\author{
KRITHIKA LAKSHMI \\ Velammal Medical College and Research Institute Madurai
}

Introduction: Young people's attitude towards Intimate Partner Violence (IPV) may influence their future practices. We aimed to assess the knowledge and attitude of college students in a South Indian city in relation to IPV, associated factors and redressal mechanisms. Methods: A convenient sample of students participated in this cross sectional study. They responded to a self-administered questionnaire comprising statements from a third person's perspective to reduce social desirability bias. Clearance was obtained from the Institute Ethical Committee. Results: Among 247 students, $47 \%$ were male and $24.9 \%$ hailed from rural areas. A $17.7 \%$ of students believed that IPV occurred only among females. Commonly perceived factors associated with IPV were alcoholic spouse (78.9\%), low income (53.8\%), personality (52.2\%) and dowry (51\%). About 38\% believed that some physical violence was allowable in a marital relationship while $57.6 \%$ thought IPV could be an expression of love. Males agreed more with negative gender stereotypes such as husband can-'threaten wife' (55\% vs. $34 \%$, p $<0.001)$, 'spy on wife' ( $41 \%$ vs. $27 \%$, $\mathrm{p}<0.001)$ and 'financially deprive' ( $13 \%$ vs. $3.8 \%, p=0.001)$. About $28 \%$ foresaw themselves as becoming perpetrators. Conclusion: Knowledge about IPV and the associated risk factors among the study population was satisfactory but attitudes towards societal gender roles and acceptability of IPV leaves much to be desired. 


\title{
PUBLIC KNOWLEDGE OF AND ATTITUDES TOWARD GENETICS AND GENETIC TESTING
}

\author{
HAZREANA HAJI MD. JAYA', HJ MUHD SYAFIQ \\ ABDULLAH ${ }^{2}$, MAS RINA WATI HJ ABDUL HAMID ${ }^{1}$ \\ 'PAPRSB Institute of Health Sciences, Universiti Brunei Darussalam \\ ${ }^{2}$ Department of Oncology, Raja Isteri Pengiran Anak Saleha Hospital, Brunei
}

Introduction: The world has been experiencing encouraging research in genetics but current public perception of this area remains unknown for Brunei Darussalam. This study aims to assess the direction of knowledge and attitudes of the public in Brunei. Methods: Questionnaires on knowledge and attitudes were offered in frequented venues in Brunei, and online. Results: Sample population $(N=474)$ comprised of $75.7 \%$ female, $64.3 \% 18-29$ years old, $39.7 \%$ with a Degree education, $2.5 \%$ with a personal history of genetic disease(s), and $5.5 \%$ with a family history. Younger participants scored higher for disease-related questions, showed more concern on the impact of testing on employment, but were more fearful of testing. Higher educational qualifications were associated with a higher knowledge score, a more optimistic view on DNA research, and less reluctance to take a genetic test for an untreatable disease. Participants with a personal history of genetic disease(s) were more knowledgeable and displayed higher curiosity. Participants with a family history of genetic disease(s) were also more knowledgeable and would want testing even for an untreatable disease. Significantly less was known by about the social consequences of testing compared to the medical possibilities. Discussion: Investigating the knowledge and attitudes of the population is vital preceding efforts towards national adaptation of genetic testing, keeping in mind the various obstacles and issues surrounding the subject. 


\title{
HEALTH PROMOTION INITIATIVE THROUGH MOBILE LEARNING: EXPERT PERSPECTIVE
}

\author{
FAIZ DAUD \\ Department of Community Health, UKM Medical Centre
}

Introduction: Videos have been found to be effective in promoting health issues as it is simple and accessible across age groups, cultures and literacy levels. This qualitative study evaluates the reflections of content experts concerning the use of health education videoclips as a possible tool for promoting health literacy among Malaysian multicultural populations. Methodology: A total of ten videoclips, each lasting 5-minutes, were evaluated by experts concerning contemporary public health issues such as HIV stigma, obesity, teenage pregnancy, depression and vaping. Reports were gathered through focus group discussion and written reflections. Data were analyzed using thematic analysis. Result: All videoclips revolve around health education topics which were deemed "justified to the current public health issues". Reviewers responded positively to the videoclips in terms issues appraised, execution and message conveyed. Consensus was achieved that the makers of the videoclips have explored each topic adequately in order to synthesize and express their thoughts, knowledge and perception in an accurate manner. The execution via numerous methodologies such as video animations and live screenplay (acting) shows the critical thinking in exploring ideas in executing an excellent videoclips. Some scattered comments about video technical aspect such as character rendering, pacing, tone, and preference for animation versus live-actors, highlights the particular communication needs in a health promotion video. The videoclips were tailored towards contemporary design and culturally acceptable. Generally, the videoclips were aesthetically pleasing and engaging with an impact towards viewers. Conclusion: This study has explored the content and acceptability of health education video to enhance health communication and literacy among Malaysian populations. 
Social Medicine

\title{
GEOMETRIC MORPHOMETRIC ANALYSIS FOR CLASSIFICATION OF MALAYSIAN CRANIA USING CT SCAN
}

\author{
ABDEL NASSER IBRAHIM ${ }^{1,2}$, ASPALILAH ALIAS ${ }^{1,3}$, \\ MOHAMED SWARHIB ${ }^{1}$, SITI NOORAIN ABU BAKAR', \\ FARIDAH MOHD NOR ${ }^{1}$
}

${ }^{1}$ Forensic Unit, Department of Pathology, Faculty of Medicine, Universiti Kebangsaan Malaysia Medical Centre, Jalan Yaacob Latif, Bandar Tun Razak, 56000 Cheras, Kuala Lumpur, Malaysia.

${ }^{2}$ Forensic Medicine and Clinical Toxicology, Faculty of Medicine, Al Azhar University, Cairo, Egypt.

${ }^{3}$ Faculty of Dentistry, Universiti Sains Islam Malaysia, Tingkat 15, Menara B, Persiaran MPAJ, Jalan Pandan Utama, Pandan Indah, 55100 Kuala Lumpur, Malaysia

Introduction/Aim: Determination of sex and race are the main steps in the identification of unknown human skeletalised remains. The present study examined variations between sexes and ancestries in the Malaysians. It aims to use the geometric morphometrics as it is the most widely used current method, and compared it with the traditional morphometrics. Methods: A total of 101 crania comprised 31 Malay, 39 Chinese and 31 Indians were studied by Postmortem Computed Tomography. Of this sample, 61 were male and 40 were female. About 13 landmarks were located in three dimensional coordinates using the Stratovan Checkpoint, and were exported in morphologika format to be analysed by MorphoJ software. Generalized Procrustes Analysis was used to register the landmark dataset to minimize the sum of squared distances between homologous landmarks. Principal Components Analysis was performed to explore shape variations between male and female and between different ancestries. Results: The first 3 Principle Component Analysis accounted for $30 \%, 11 \%$ and $8 \%$ of the total shape variance, respectively. Variation among groups was estimated by canonical variate analysis and results $91 \%$ variation among ancestries. The Principle Component Analysis showed significant variation between male and female. Conclusion: In brief, geometric morphometrics can be used as an alternative to traditional methods for demonstrating and quantifying morphologic differences in human crania between male and female, and among different ancestries. 


\title{
A PREVALENCE STUDY AND CLINICAL SIGNIFICANCE OF ANTI- NUCLEAR ANTIBODY PROFILE IN PATIENTS DIAGNOSED WITH AUTOIMMUNE RHEUMATIC DISEASES IN BRUNEI DARUSSALAM
}

\author{
YUSNIDA ZAHIRAH MOHD YUSSOF1, MARGARET \\ WANG CHOON LEE ${ }^{2}$, SURITA MOHAMAD TAIB ${ }^{2}$, ANNE \\ CATHERINE CUNNINGHAM
}

${ }^{1}$ PAPRSB Institute of Health Sciences, Universiti Brunei Darussalam. ${ }^{2}$ RIPAS Hospital, Brunei.

Background: The incidence of systemic autoimmune rheumatoid diseases (SARD) are increasing globally. SARD includes systemic lupus erythematosus (SLE), connective tissue diseases (CTD) and rheumatoid arthritis (RA) and diagnosis is made serologically by detection of anti-nuclear antibodies (ANA). Aim: To investigate the ANA profile of SARD patients in Brunei Darussalam. Methods: A retrospective cohort study of adults diagnosed with SARDs from 2013 to 2016 was performed. Demographic data, diagnosis, and ANA profiles were collected from electronic patient records. Results: 260 SARD patients, diagnosed with SLE (43\%), CTD $(16 \%)$ and RA (42\%) were investigated. The majority of the patients diagnosed with each SARD were female (91\%; SLE 95\%; CTDs 92\%; RA 88\%). The median age of diagnosis for SLE was 37y, CTD 53y and RA 55y. A relationship between gender and ANA-positivity was demonstrated. The presence of ANA and titre of antidsDNA was significantly higher in the younger age group (18-34y). Homogenous nuclear ANA staining was most common but there less cytoplasmic pattern in this population. There was an association between the presence of anti-dsDNA antibodies, Scl-70, anti-Sm and the homogenous pattern of nuclear staining. A significant association was observed between the nucleolar pattern in SLE patients, in addition to the other established ANA patterns i.e. homogenous and speckled pattern. There was a significant association between ANA titre specific to antidsDNA and a positive ENA anti-Ro and anti-RNP in SLE patients. Significance: The increase in ANA in younger patients in Brunei Darussalam suggests a worrying trend on the increasing burden of disease. 


\title{
THE EFFECTS OF ANNATTO TOCOTRIENOL ON BONE MINERAL DENSITY AND BONE BIOMECHANICAL STRENGTH IN AN ANIMAL MODEL OF OSTEOPOROSIS INDUCED BY BUSERELIN (GNRH AGONIST)
}

\section{NUR VAIZURA MOHAMAD, IMA NIRWANA SOELAIMAN, CHIN KOK YONG}

\author{
Department of Pharmacology, Faculty of Medicine, Universiti Kebangsaan \\ Malaysia Medical Centre, Jalan Yaacob Latif, Bandar Tun Razak, 56000 Cheras, \\ Kuala Lumpur, Malaysia.
}

Introduction: Long term administration of buserelin, a gonadotropin-releasing hormone $(\mathrm{GnRH})$ agonist, is associated with serious adverse effects on bone health. Bone loss reduces the skeletal strength and increases the risk for fracture. Annatto tocotrienol has been shown to improve bone structural indices in osteoporotic rats. This study aimed to evaluate the effects of annatto tocotrienol on biomechanical strength of the bone loss induced by buserelin. Methodology: Thirty six male Sprague-Dawley rats aged three months old were randomly assigned into six groups. The baseline control $(\mathrm{BC})$ group $(n=6)$ was sacrificed at the onset of the study. The normal control group $(\mathrm{NC})(\mathrm{n}=6)$ received corn oil (the vehicle of tocotrienol) orally daily and normal saline (the vehicle of buserelin) subcutaneously daily. The buserelin control $(\mathrm{BuC})(\mathrm{n}=6)$ received corn oil (the vehicle of tocotrienol) orally daily and subcutaneous buserelin injection $75 \mu \mathrm{g} / \mathrm{kg} /$ day daily. The calcium control $(\mathrm{CaC})(\mathrm{n}=6)$ was served with $1 \%$ calcium in drinking water and daily subcutaneous buserelin injection $75 \mu \mathrm{g} / \mathrm{kg} /$ day. The remaining rats were treated with two different treatments, i.e., (1) daily oral annatto tocotrienol at $60 \mathrm{mg} /$ $\mathrm{kg}$ plus daily subcutaneous buserelin injection $75 \mu \mathrm{g} / \mathrm{kg} /$ day $(\mathrm{n}=6)$; (2) daily oral annatto tocotrienol at $100 \mathrm{mg} / \mathrm{kg}$ plus daily subcutaneous buserelin injection 75 $\mu \mathrm{g} / \mathrm{kg} / \mathrm{day}(\mathrm{n}=6)$. The rats were scanned for bone mineral density (BMD) and bone mineral content (BMC) using dual-energy $\mathrm{x}$-ray absorptiometry (DXA) at baseline. Following 12 weeks of treatment, BMD and BMC were measured again with DXA. The rats were euthanized, and their femoral were collected for biomechanical strength analysis. Results: Annatto tocotrienol treatments at $60 \mathrm{mg} / \mathrm{kg}$ and 100 $\mathrm{mg} / \mathrm{kg}$ improved femoral load, strain and elastic force, as well as bone calcium content significantly compared to osteoporotic rats $(p<0.05)$. Annatto tocotrienol also increased whole body BMD and BMC significant compared to untreated rats after adjusting for body weight $(p<0.05)$. Conclusion: Annatto tocotrienol is a potential antiosteoporotic agent for men receiving $\mathrm{GnRH}$ therapy by preserving their BMD, BMC and bone strength. 


\title{
RADIOGRAPHIC OUTCOMES VERSUS PATIENT REPORTED QUALITY OF LIFE FOLLOWING SURGICAL TREATMENT OF ADOLESCENT IDIOPATHIC SCOLIOSIS
}

\author{
ILYAAS ALI-NOOR, MOHD HISAM MUHAMAD ARIFFIN, \\ AZMI BAHARUDIN, SHAHARUDDIN ABD RHANI, \\ Department of Orthopaedics and Traumatology, Faculty of Medicine, Universiti \\ Kebangsaan Malaysia Medical Centre, Jalan Yaacob Latif, Bandar Tun Razak, \\ 56000 Cheras, Kuala Lumpur, Malaysia.
}

Objective: This study compared radiological measures of deformity correction using Harm's Radiographic Deformity Score (RDS) with patient's postoperative health related quality of life (HRQL) measurement using the Scoliosis Research Society 22r (SRS-22r) questionnaire, among female subjects with Adolescent Idiopathic Scoliosis (AIS). Methods: This retrospective study looked at AIS subjects who had pedicle screw scoliosis surgery between 2009-2012. For each subject, data was collected from pre and post operative radiographs, scored and tabulated according to the RDS system. Patient satisfaction was assessed by answering a selfadministered SRS-22r questionnaires. Results: Analysis of RDS showed the mean preoperative and postoperative RDS were significantly different $(p<0.01)$ and the mean radiographic score improvement was $25.4 \pm 10.3$, indicating that radiographically, the surgeries were successful. Results of the SRS-22r questionnaire showed that the subjects were satisfied with the surgery, both overall and in the different domains based on function, pain, self-image, mental health and mangement. Overall mean SRS score was $4.35 \pm 0.39$ (of which the lowest possible score is 1 and highest is 5). Differences in Lenke curve did not show any significant differences for both RDS and SRS -22r scores. There was no correlation between the improvement in radiological scores and SRS-22r scores. Conclusion: This study shows that whilst surgical correction of AIS was successful radiologically, this did not correlate with greater patient satisfaction. 


\section{THREE-DIMENSIONAL GEOMETRIC MORPHOMETRIC ANALYSIS OF MANDIBLE: AN IMPORTANT STEP FOR IDENTIFICATION}

\section{ASPALILAH ALIAS ${ }^{1,2,}$ ABDEL NASSER IBRAHIM ${ }^{1,3}$, MOHAMED SWARHIB ${ }^{1}$, SITI NOORAIN ABU BAKAR ${ }^{1}$, FARIDAH MOHD NOR $^{1}$}

${ }^{1}$ Forensic Unit, Department of Pathology, Faculty of Medicine, Universiti Kebangsaan Malaysia Medical Centre, Jalan Yaacob Latif, Bandar Tun Razak, 56000 Cheras, Kuala Lumpur, Malaysia.

${ }^{2}$ Faculty of Dentistry, Universiti Sains Islam Malaysia, Tingkat 15, Menara B, Persiaran MPAJ, Jalan Pandan Utama, Pandan Indah, 55100 Kuala Lumpur, Malaysia

${ }^{3}$ Forensic Medicine and Clinical Toxicology, Faculty of Medicine, Al Azhar University, Cairo, Egypt

Several methods have been used for identification of skeletal remains in forensic anthropology. The new methods have constantly developed, and helped in the refinements of traditional method. The present study concerned the application of geometric morphometrics to assess the potential of mandibular morphology as a marker for determination of ancestry in adult human skeletal remains. The sample comprised 113 known age and sex adult individuals of Malay, Chinese and Indian from Postmortem Computed Tomography in the Malaysian population. The data was collected in the DICOM form from CT scan, and 24 bilateral 3-D landmarks were designed using Stratovan checkpoint software, and were exported in the Morphologica format. The data was analysed for Generalized Proscrustes Analysis and Principal Component Analysis using MorphoJ software. Results showed signifcant morphologic difference between the samples, and cross-validation showed $70 \%$ accuracy in identification of unknown individuals. It is hoped that this method could be used to provide identification of race in Malaysian adults. 


\title{
SAFETY AND EFFICACY OF ACELLULAR TISSUE-ENGINEERED 3D SKIN PATCH OF DERMAL FIBROBLAST CONDITIONED MEDIUM (DFCM)
}

\author{
MANIRA MAAROF ${ }^{1}$, AMINUDDIN SAIM ${ }^{2}$, RUSZYMAH \\ IDRUS $^{1,3}$, SHIPLU ROY CHOWDHURY'
}

\begin{abstract}
${ }^{1}$ Tissue Engineering Centre, ${ }^{2}$ Department of Physiology, Faculty of Medicine, Universiti Kebangsaan Malaysia Medical Centre, Jalan Yaacob Latif, Bandar Tun Razak, 56000 Cheras, Kuala Lumpur, Malaysia. ${ }^{3}$ Ear Nose \& Throat Consultant Clinic, Ampang Puteri Specialist Hospital, 1 Jalan Mamanda 9, Ampang 68000, Selangor, Malaysia.
\end{abstract}

Introduction: Commonly available cell-based skin substitutes required longer production time that limits its applications in severe skin injury. Acellular skin substitutes that promote wound healing can be the solution for this issue. Dermal fibroblast is known to secrete numerous healing mediators that can be collected from the waste medium, define as dermal fibroblast conditioned medium (DFCM). This study aims to fabricate an acellular 3D skin patch containing DFCM, and evaluates its safety and efficacy for skin regeneration. Methodology: Confluent fibroblasts were incubated with serum-free keratinocyte-specific medium (KM) and fibroblast-specific medium (FM) to collect DFCM-KM and DFCM-FM, respectively. The DFCM were analyzed for in vitro and in vivo immune response. An acellular skin patch was fabricated using collagen hydrogel with DFCM-KM $(400 \mathrm{~g} / \mathrm{mL})$ and DFCM-FM $(800 \mathrm{~g} / \mathrm{mL})$ and was implanted to evaluate the healing efficiency in a mice model. Results: DFCM does not promote PBMC proliferation on in vitro culture, and no sensitization was observed on the guinea-pig skin after induced with collagen and DFCM. Implantation of skin patch with or without DFCM in an animal model demonstrated significantly faster healing compared to no-treatment group after 7 days of implantation. However, no difference was observed between the DFCM-KM and DFCM-FM groups. Conclusion: In conclusion, acellular skin patch containing collagen with DFCM does not induce the immune response and safe to be used allogenically. Its also helps in wound healing and can be applied for immediate treatment of skin injury. Further investigation is required in the large animal model to demonstrate its potential clinical application. 


\section{NICKEL AS A RISK FACTOR FOR MYOCARDIAL INFARCTION AMONG PATIENTS IN UNIVERSITY KEBANGSAAN MALAYSIA MEDICAL CENTRE: A CASE-CONTROL STUDY}

\section{MOHD HASNI JAAFAR, NUR AZALINA SUZIANTI FEISAL, OTEH MASKON}

Faculty of Medicine, Universiti Kebangsaan Malaysia Medical Centre, Jalan

Yaacob Latif, Bandar Tun Razak, 56000 Cheras, Kuala Lumpur, Malaysia.

Introduction: Cardiovascular disease (CVD) is the leading cause of mortality in all over the world. Environmental toxicants, including heavy metals have been suggested to play a role in progression of CVD. The study assessed the association between blood nickel $(\mathrm{Ni})$ and risk of myocardial infarction (MI). Methodology: This case-control study is conducted in Universiti Kebangsaan Malaysia Medical Centre (UKMMC) from April 2014 to April 2015. Through a purposive sampling, a total of 109 self-administered questionnaires are being distributed among respondents together with consent to donate additional $10 \mathrm{ml}$ of their venous blood. At the end of the study, the response rate is $83 \%$. The element in biological sample was analysed by Inductively Coupled Plasma-Mass Spectrometry (ICP-MS). Results: Total respondent enrolled was 71 in the case group (MI) and 38 in the control group (non-Ml). All cases have an abnormal blood nickel of more than $0.2 \mu \mathrm{g} / \mathrm{L}$ compared to the control group (36.8\%), which is significant $\left(\chi^{2}=30.01 ; p=0.022\right)$. The study also found that elderly, female, Chinese, low educational and economic status, smoking, consumed alcohol, and normal body mass index have insignificant higher blood nickel compared to the other group. Conclusion: Blood nickel may be a potential risk factor for $\mathrm{Ml}$ among people in Malaysia. This study suggested for a comprehensive study in this research, particularly among myocardial infarction and other CVD patients. Blood heavy metals analysis needs to be implemented among the general population in ensuring their heart health. 


\title{
ANTI-HYPERTENSIVE EFFECT OF "SAMBUNG NYAWA" (GYNURA PROCUMBENS) LEAVES EXTRACTS ON ISOLATED RAT AORTA IN VITRO
}

\author{
SYAHIRAH HJ SHAHLEHI, NUR AZIEMAH MOHAMMAD \\ AZIZI, ASRIN TENGAH \\ PAP Rashidah Sa'adatul Bolkiah Institute of Health Sciences, Universiti Brunei \\ Darussalam, Jalan Tungku Link, BE1410, Brunei Darussalam
}

Introduction: Gynura procumbens (GP) or "Sambung Nyawa" in Malay is an evergreen herb which is found in Africa, and in South East Asian countries, including Brunei. The plant is used traditionally to treat various diseases such as rashes, kidney disease, fever, diabetes and hypertension. Therefore, we examined whether or not GP's anti-hypertensive effect via vasodilatory action is associated with and/or able to potentiate the cholinergic-mediated pathway. Methods: GP leaves were prepared by filtration and evaporation processes to obtain aqueous and methanol extracts of $\mathrm{GP}$, respectively. Isolated aortic rings mounted in a $10 \mathrm{ml}$ organ bath, were allowed to equilibrate for 20 minutes before adding the extracts. Four concentrations $(0.25$, $0.5,1.0$ and $2.0 \mathrm{mg} / \mathrm{ml}$ ) were tested, in the presence or absence of acetylcholine (ACh). Results/Discussion: Vasorelaxant effect by $100 \mu \mathrm{M}$ ACh was examined on intact isolated endothelium rat aortic rings precontracted with $50 \mathrm{nM}$ noradrenaline. Both extracts caused relaxation to the precontracted endothelial intact aorta in a concentration dependent manner. To determine whether this relaxation is mediated through cholinergic pathway, we exposed the precontracted aorta with ACh followed by the cumulative additions of an increasing concentration of the extracts. Both extracts did not significantly amplify ACh-endothelium dependent vasodilation. However, the pattern of amplification to the ACh-mediated relaxation was observed especially at $0.5 \mathrm{mg} / \mathrm{ml}$. In endothelium denuded rat aorta, both extracts significantly enhanced relaxation. Furthermore, methanol extracts of GP was found to be more effective vasodilator than the aqueous extracts of GP. Conclusion: This study has demonstrated that GP's antihypertensive property is due to the vasodilatory effect in which the mechanism could be associated with the cholinergic pathway. 


\section{CEREBRAL SMALL VESSEL DISEASE IN INDONESIA: LACUNAR INFARCTION STUDY FROM INDONESIAN STROKE REGISTRY 2012-2014}

\section{SALIM HARRIS, MOHAMMAD KURNIAWAN, AL RASYID, TAUFIK MESIANO, RAKHMAD HIDAYAT}

Neurovascular dan Neurosonology Division, Department of Neurology, Faculty of Medicine, Universitas Indonesia - Cipto Mangunkusumo Hospital (FKUI-RSCM), Jakarta

Background and Purpose: Lacunar infarction is caused by the occlusion of arterioles or capillaries which is limited to a small area of the brain. It is a form of cerebral small vessel disease and the most common cause of stroke in Asia. It is seen as dark gray areas with diameter less than $20 \mathrm{~mm}$ in CT or MRI. The purpose of this study is to explore the prevalence of lacunar infarction in Indonesia. Methods: This study was a multicenter prospective cross-sectional study using standardized Stroke Case Report Form from 2012 to 2014. All stroke patients presenting to any of 18 hospitals in Indonesia were included. Results: There were 5411 stroke patients and $56.25 \%$ were male. Of these, $3627(67.03 \%)$ had ischemic stroke. Further analysis showed 1635 (45.07\%) had evidence of lacunar infarction. Associated risk factors found were hypertension $(77 \%)$, followed by smoking $(27.5 \%)$, diabetes $(18.26 \%)$, and dyslipidemia (12.1\%). The highest age population who suffered from stroke was above 60 years of age group, which encompassed 1621 (44.69\%) ischemic stroke patients and $649(36.37 \%)$ hemorrhagic stroke patients. Conclusions: Ischemic stroke was the leading cause of stroke. Forty five percent of the total ischemic stroke were lacunar infarction, corresponding to epidemiological studies which stated that lacunar stroke is the highest cause of stroke in Asia. The prevalence of stroke in the male was higher than in the female population, and was found highest in patients over 60 years of age. The main risk factor was hypertension. 


\title{
CROSS SECTIONAL STUDY OF CAROTID INTIMA MEDIA THICKNESS (CIMT) IN GOUTY ARTHRITIS PATIENTS WITH LOW FRAMINGHAM RISK SCORE
}

\author{
MOHD SHAHRIR MOHAMED SAID', HAZWANI AZIZ², \\ SYAHRUL SAZLIYANA SHAHARIR', OTEH MASKON', \\ SHARIFAH MAJEDAH ${ }^{1}$
}

'Department of Medicine, Faculty of Medicine, Universiti Kebangsaan Malaysia Medical Centre, Jalan Yaacob Latif, Bandar Tun Razak, 56000 Cheras, Kuala Lumpur, Malaysia. ${ }^{2}$ Ministry of Health

Introduction: This study was done to determine the association between subclinical atherosclerosis and gouty arthritis. Objectives: The main objective of this study is to compare the carotid intima media thickness (CIMT) in gouty arthritis patients with low Framingham risk score, with normal controls. Other objectives include: to study the association between CIMT and sociodemographic data, Framingham Risk components, serum uric acid and presence of tophi. Materials and Methods: This was a comparative cross sectional study, involving 30 gouty arthritis patients with 30 age- and gender-matched healthy controls. Only subjects with low Framingham risk scores of less than $10 \%$ were included in this study. The carotid intima media thickness was measured using the B-mode ultrasonography. Results: The CIMT for gout and control groups showed no significant difference. Gouty arthritis patients had significantly higher diastolic blood pressure, body mass index, total cholesterol, serum high density lipoprotein $(\mathrm{HDL})$ and serum uric acid as compared to the healthy controls (all $p<0.05$ ). On univariate analysis, age and Framingham scores had significant correlation with CIMT among gouty arthritis patients. No association was found between CIMT and presence of tophi and the level of serum uric acid. On multivariate analysis, after corrected for age, diabetes mellitus was the only independent factor associated with CIMT in gouty arthritis patients ( $p$ value 0.04). Conclusion: Gouty arthritis was not associated with subclinical atherosclerosis in patients with low Framingham risks. Diabetes mellitus was the only independent factor which had significant association with CIMT in gouty arthritis patients. 


\title{
CLINICAL CHARACTERISTICS AND CARDIAC MAGNETIC RESONANCE FINDINGS IN PATIENTS WITH HYPERTROPHIC CARDIOMYOPATHY IN BRUNEI DARUSSALAM
}

\author{
KAH CHEONG TONG ${ }^{1}$, CUNNINGHAM ANNE${ }^{1}$, LUQMAN \\ NAZAR $^{2}$ \\ 'PAPRSB Institute of Health Science, Universiti Brunei Darussalam \\ ${ }^{2}$ Department of Cardiology, RIPAS Hospital.
}

Introduction: Hypertrophic Cardiomyopathy $(\mathrm{HCM})$ is a genetic heart disease that poses a risk for sudden cardiac death. It has not been studied systematically in South East Asian countries. The purpose of this study is to investigate the characteristics and patterns of fibrosis in HCM as well as determining the risk of sudden cardiac death in relation to age, sex and myocardial fibrosis in Brunei Darussalam. Methods: All patients diagnosed with HCM from 2011 to 2017 were studied in Brunei Darussalam. Data was acquired from clinical notes of these patients and studied for the demographic profile of the disease, clinical manifestations and risks for sudden cardiac death. Results: A total of 39 patients with HCM were identified with mean age at diagnosis of $47.46 \pm 12.27$ years. $51.3 \%$ of HCM patients were found to be asymptomatic. A total of 30 patients underwent Cardiac Magnetic Resonance. 53.8\% showed myocardial fibrosis. This was more prevalent and significant in Apical HCM compared to Asymmetrical Septal HCM, 10 (83.3\%) and $9(60 \%)$ respectively, $(p=0.032)$. Apical and Asymmetrical Septal HCM are the most common types of HCM in the population, 15 (38.5\%) and $16(41 \%)$ respectively. Asymmetrical Septal HCM presented with more murmurs than Apical HCM patients, $9(56.3 \%)$ and $1(6.7 \%)$, respectively $(p=0.001)$. Asymmetrical Septal HCM has a higher average risk score compared to Apical HCM, 2.05 (1.78) and $1.44(0.85)$ respectively $(p=0.025)$. There was no statistical difference in terms of clinical and imaging characteristics between male and female HCM patients. 
Non-communicable Diseases

\title{
CARBOXYHAEMOGLOBIN LEVEL AMONG BUS EXPRESS DRIVERS IN MALAYSIA
}

\author{
SITI HASNAH NASARUDIN' ${ }^{1}$, MOHD HASNI JA'AFAR', \\ ROSNAH SUTAN', WAHIDA AMEER BATCHA ${ }^{2}$, NOOR \\ KAMALIAH ALIAS ${ }^{2}$, ILHAMAH OTHMAN ${ }^{2}$, AZIEMAH \\ AZHAR $^{2}$, MOHAMAD SUFFIAN AHMAD ${ }^{2}$
}

\author{
'Department of Community Health, Faculty of Medicine, Universiti Kebangsaan \\ Malaysia Medical Centre, Jalan Yaacob Latif, Bandar Tun Razak, 56000 Cheras, \\ Kuala Lumpur, Malaysia. \\ ${ }^{2}$ Malaysian Institute of Road Safety Research
}

Carbon Monoxide (CO) is tasteless, odourless, colourless and non-corrosive gas in the atmosphere that was released from incomplete combustion. Administration of environmental $\mathrm{CO}$ into human body is through inhalation. The $\mathrm{CO}$ will then be absorbed through the lung into the blood stream and caused hypoxic state to most sensitive body tissues. Individual carboxyhaemoglobin $(\mathrm{COHb})$ level among express bus drivers seldom been evaluated in Malaysia. The objective of this study is to measure the individual $\mathrm{COHb}$ level among express bus drivers and its risk factors. This is a cross sectional study that was conducted in between November 2016 till March 2017 among express bus drivers playing in Peninsular Malaysia. The $\mathrm{COHb}$ levels were measured using a direct reading instrument. From the study, the minimum $\mathrm{COHb}$ levels are $0.0 \%$ and maximum is $4.3 \%$. Where the mean of $\mathrm{COHb}$ is $1.1 \pm 0.72 \%$, median is $0.9 \%$ and mode is $0.8 \%$. For non-smoker respondent, the $\mathrm{COHb}$ level were range in between $0.0 \%$ to $1.3 \%$ while for smoker respondent, the $\mathrm{COHb}$ level were around $1.4 \%$ to $2.6 \%$. There are one non-smoker respondent with $\mathrm{COHb}$ of $4.3 \%$ and the risk factor was noted due to open burning around housing area. In conclusion, $\mathrm{COHb}$ level in the body were higher among smoker respondent compared with non-smoker respondent and the finding of this study was not contradicted with previous results. There were $9.2 \%$ of the respondent were exposed to $10 \mathrm{ppm}$ of environmental $\mathrm{CO}$ and further study are needed to exclude risk of occupational exposure to $\mathrm{CO}$. 
Non-communicable Diseases

Oral

\title{
HYPERPROLACTINAEMIA ASSOCIATION WITH LUPUS NEPHRITIS DISEASE ACTIVITY
}

\author{
WAN ASYRAF WAN ZAIDI, MOHD SHAHRIR MOHAMED \\ SAID, KONG WEI YEN, ASRUL ABD WAHAB HANITA \\ OTHMAN, NORASYIKIN ABD WAHAB, AZMI MOHD \\ TAMIL
}

Department of Medicine, Faculty of Medicine, Universiti Kebangsaan Malaysia Medical Centre, Jalan Yaacob Latif, Bandar Tun Razak, 56000 Cheras, Kuala Lumpur, Malaysia.

Introduction: Prolactin has been found to be associated with immune regulation in SLE. The aim of this study is to determine the correlation between high prolactin level in comparison with IL -6 with lupus nephritis disease activity in UKMMC. Methodology: In this cross-sectional study, the analysis was conducted in SLE patients who attended Nephrology clinic in UKMMC from August 2015 till February 2016. Results: Out of 43 patients with lupus nephritis, $27.9 \%$ of the patients had raised serum prolactin. The median of serum prolactin level at 0 minutes was 19.91 $\mathrm{ng} / \mathrm{ml}$ (IQR: 15.95-22.65) for active lupus nephritis that was significantly higher as compared to the median of serum prolactin level $14.34 \mathrm{ng} / \mathrm{ml}$ (IQR: 11.09-18.70) for patients in remission $(p=0.014)$. The serum prolactin level was positively correlated to SLEDAI (rhos: $0.449, \mathrm{p}=0.00$ ) and UPCI level in lupus nephritis patients (rhos: $0.241, p=0.032$ ). Assessment of serum IL- 6 levels found that the active lupus nephritis patients were having a higher median level of $65.91 \mathrm{pg} / \mathrm{ml}$ (21.96-146.14) compared to in remission level of $15.84 \mathrm{pg} / \mathrm{ml}$ (IQR: 8.38-92.84), ( $p=0.039)$. ROC curve analysis of serum prolactin 0 minute and serum prolactin 30 minutes and IL-6 level for prediction of SLE diseases activity provide the cutoff value of serum prolactin 0 minutes was $14.63 \mathrm{ng} / \mathrm{ml}$ with sensitivity $91.7 \%$ and specificity $58.1 \%$ and AUC of $0.74(p=0.015)$. Conclusion: Baseline fasting serum prolactin level was found to be a sensitive biomarker for evaluation of lupus nephritis disease activity. 


\title{
KNOWLEDGE, ATTITUDE AND PRACTICE TOWARDS OBESITY AMONG BRUNEIAN CHILDREN THAT INFLUENCE THE DEVELOPMENT OF CHILDHOOD OBESITY: A CROSS-SECTIONAL STUDY
}

\author{
ZAIDAH RIZIDAH MURANG ${ }^{1}$, NIK ANI AFIQAH TUAH ${ }^{1,2}$, \\ LIN NAING ${ }^{1}$
}

'Pengiran Anak Puteri Rashidah Sa'adatul Bolkiah Institute of Health Sciences, Universiti Brunei Darussalam, Jalan Tungku Link, BE1410, Brunei Darussalam. ${ }^{2}$ Department of Primary Care and Public Health, School of Public Health, Faculty of Medicine, Imperial College London, United Kingdom.

Introduction: Childhood obesity has become a global public health crisis. Numerous studies had been done among parents on their knowledge, attitude and practices towards obesity but limited evidence is known in children. It is imperative to understand factors associated with the development of obesity among children as obesity tend to persist to adulthood. Therefore, this study aimed to assess the knowledge, attitude and practice of Bruneian children towards obesity to identify contributing factors in the development of childhood obesity. Methods: We conducted a cross-sectional study from July to September 2016 using random sampling that involved 353 parents from 3 primary schools in in Brunei. The data collection tool used was modified validated questionnaires with sections on demographic characteristic, knowledge about obesity, eating habits and physical activity. Results: The majority of children had good knowledge on obesity and intake of healthy food but $70 \%$ of them lacked the knowledge on the required daily servings of fruits and vegetables. $68.8 \%$ of the children purchased food from their school canteen. $93.8 \%$ of the children were informed about the health benefits of physical activity and spent 1 to 2 hours of screen time per day. $46.9 \%$ did not meet the recommended amount of physical activity although they reported that they had performed enough. Conclusion: Our findings suggested that a comprehensive education on daily food requirement and physical activity is needed to better educate children. Public health professionals may find our findings useful in order to plan and develop tailored intervention for children. 


\title{
DID COMPLICATION DURING PREGNANCY, DELIVERY PROCESS AND NEONATAL PERIOD INCREASE THE RISK FOR HAVING AUTISM SPECTRUM DISORDER (ASD)?
}

\author{
TJHIN WIGUNA ${ }^{1}$, MUHAMMAD AGUNG BHASKORO \\ HARDIYAN SYAHPUTRO ${ }^{2}$, RAHMAH YULAM SARI ${ }^{2}$ \\ OKLA SEKAR MARTANI ${ }^{2}$, PUTRI PERMATA SARI ${ }^{2}$, TASHA \\ FARHANA DAHLAN ${ }^{2}$
}

${ }^{1}$ Child and Adolescent Psychiatry Division, Department of Psychiatry, dr. Cipto Mangunkusumo General Hospital, Faculty of Medicine Universitas Indonesia, Jakarta, Indonesia.

${ }^{2}$ Faculty of Medicine, Universitas Indonesia, Jakarta, Indonesia.

Introduction: The etiology of Autism spectrum disorder (ASD) is unknown nowadays; several factors are said to increase the risk for having ASD. Therefore, this study aimed to identify and support the prior studies that mentioned; complication during pregnancy, delivery and neonatal period increased the odds ratio for ASD. Method: This was a case - control study that involved 52 parents of children with ASD and 152 parents with gender- and age-matched healthy children. The complication during pregnancy, delivery and neonatal period were discovered through detailed interviewed with parents, especially mother. Data was tabulated and analysed by using the SPSS for Mac version 21. Results: Factors that increased risk for ASD included; infection during pregnancy $(\mathrm{OR}=4.25,95 \% \mathrm{Cl} 3.32-5.44$; $\mathrm{p}<0.05)$; prenatal depression ( $\mathrm{OR}=4.508,95 \% \mathrm{Cl} 2.01-10.08 ; \mathrm{p}<0.05)$; prolonged delivery process (more than 12 hours) $(\mathrm{OR}=3.22,95 \% \mathrm{Cl} 1.32-7.83$; $\mathrm{p}<0.05)$; labor complication $(\mathrm{OR}=2.42,95 \% \mathrm{Cl} 1.01-5.831 ; \mathrm{p}<0.05)$; postpartum hemorrhage $(\mathrm{OR}>3)$; asphyxia and the used of ventilator during neonatal period definetely (OR $=3.31 ; 95 \% \mathrm{Cl} 1.10-9.94 ; \mathrm{p}<0.05)$; smoking during pregnancy also played an improtant role in ASD (OR $=6.42,95 \% \mathrm{Cl} 1.14-36.12 ; p<0.05)$. Conclusion: The findings supported the prior studies that difficulties during pregnancy, delivery and neonatal period was very critical due to the infant brain development. Any factor and complication that related with it might increased the risk for having ASD. 


\title{
PERCEIVED PATERNAL ENGAGEMENT DURING PREGNANCY IN AN URBAN PRIMARY CARE CLINIC IN MALAYSIA
}

\author{
SITI AISYAH ABD MAJID ${ }^{1}$, EZURA MADIANA MD \\ MONOTO $^{2}$, SENG FAH TONG ${ }^{2}$
}

${ }^{1}$ Klinik Kesihatan Seksyen 7, Shah Alam - MOH

${ }^{2}$ Faculty of Medicine, Universiti Kebangsaan Malaysia Medical Centre, Jalan

Yaacob Latif, Bandar Tun Razak, 56000 Cheras, Kuala Lumpur, Malaysia.

Introduction: Paternal engagement during pregnancy has been proven to be beneficial in improving maternal and child health outcome. There is an effort in improving paternal engagement in ante-natal care in Malaysia, but the response has been variable. This study aimed to objectively evaluate maternal perception of paternal engagement in an urban Malaysian primary care clinic setting. Methods: This was a cross sectional study involving 273 participants of third trimester mothers that attended antenatal clinic between August to October 2016. A set of selfadministered questionnaire was used in this study to look at the perception of paternal engagement in the area of antenatal visits (booking and follow-ups), participation in antenatal class, supports (emotional and financial) and finding pregnancy-related information together. Results / Discussion: Almost half of participants reported that their husbands were present during antenatal booking and follow-up visits, gave emotional and financial support, and obtained pregnancy-related information together. However, husband's participation in antenatal class was only $15.0 \%$. Husbands of primigravidae and younger mothers had more engagement in term of their presence during antenatal visits and obtaining information together with their wives. Husbands of younger mothers and from lower income family also tend to be present during antenatal booking. Conclusion: Paternal engagement in our setting was still lack in antenatal class participation compared to other aspects. Further research is needed to explore the contributing factors and the types of intervention that are effective in improving their engagement in maternal healthcare system. 


\title{
RISK FACTORS FOR OBSTETRICS ANAL SPHINCTERS INJURY: A CASE-CONTROLLED STUDY
}

\author{
${ }^{1}$ NG BENG KWANG, ${ }^{2}$ TOH CHIN HENG, ${ }^{2}$ THENMALAR \\ SELVAM, ${ }^{2}$ MUHAMAD AMIN CHE AZMI, ${ }^{2}$ SARAH NABILA \\ HAMDAN, ${ }^{2}$ NORFAEZATUL FAZLINA NASRI@ASHARI, \\ 'IXORA KAMISAN ATAN, 'LIM PEI SHAN \\ ${ }^{1}$ Department of Obstetrics and Gynaecology, UKM Medical Centre, Jalan Yaacob \\ Latif, 56000, Kuala Lumpur, Malaysia. \\ ${ }^{2}$ Faculty of Medicine, UKM Medical Centre, Jalan Yaacob Latif, 56000, Kuala \\ Lumpur, Malaysia.
}

Introduction: Obstetric anal sphincters injuries (OASIS) are not uncommon after vaginal delivery. Multiple obstetric risk factors had been associated with OASIS. However, results so far were contradicting. The aim of this study was to determine the possible risk factors for OASIS. Methodology: This was a case-controlled study. All cases of OASIS diagnosed in the labour ward Department of Obstetrics and Gynaecology, Universiti Kebangsaan Malaysia Medical Centre over a period of 5 years between $1^{\text {st }}$ January 2012 and $31^{\text {st }}$ December 2016 were recruited. Controls were taken from the next three women who delivered vaginally after the case of OASIS. A total of 71 cases of OASIS and 272 controls were recruited. Results: The incidence of OASIS was 0.18-0.46 yearly between the years 2012 to 2016. History of diabetes mellitus and one previous caesarean section, duration of oxytocin augmentation, use of intra-partum analgesia, duration of second stage, instrumental deliveries, delivery accoucher, and baby's birth weight were significantly associated with risk of OASIS. Conclusion: Identification of women at risk for OASIS may help in preventive strategies as well as counseling. Most of the risk factors were modifiable such as duration of oxytocin use and second stage, instrumental deliveries and delivery accoucher. 


\author{
THE STUDY OF FACTORS THAT INFLUENCE THE \\ LOCAL OR METASTATIC RECURRENCE OF SOFT TISSUE \\ SARCOMA IN UNIVERSITI KEBANGSAAN MALAYSIA \\ MEDICAL CENTRE (UKMMC)
}

\author{
WENXUAN L, ILHAM FADHLIN N, VINODHINII S, ASMA I, \\ MUZAFFAR M, YAZID MK, HAZLA MH
}

Faculty of Medicine, Universiti Kebangsaan Malaysia Medical Centre, Jalan

Yaacob Latif, Bandar Tun Razak, 56000 Cheras, Kuala Lumpur, Malaysia.

Introduction: Soft tissue sarcomas (STS) are a diverse group of neoplasm that arises in the connective tissue throughout the body. Prognostic factors for survival in patients with STS are poorly defined. The main aim of this research was to study the impact of prognostic factors such as age, gender, tumour size, tumour site, tumour presentation, tumour grade, final resection margin, histopathology and treatment on the outcome of patients with STS that underwent surgery from year 2009 to 2015 in UKMMC. Methodology: A retrospective study was conducted for 12 months under Orthopaedic department and the information were collected from UKMMC database on patients with STS who underwent surgical resection. Results: Fifteen out of the total of thirty patients with STS were found to have poor outcome in which twelve patients had distant metastasis, two patients had local recurrence and one patient died. Analysis with Pearson Chi-Square test showed significant association between tumour grade $(p=0.000)$ and final resection margin $(p=0.028)$ with outcome of patients with STS. Other prognostic factors such as presentation $(p=0.099)$, age $(p=0.143)$, treatment sequence $(p=0.388)$, histopathology $(p=0.399)$, size $(p=0.429)$, gender $(p=0.464)$ and site $(p=0.484)$ showed no significant association between factors above with outcome of patients with STS. Conclusion: Fifteen out of the total of thirty patients with STS were found to have poor outcome in which twelve patients had distant metastasis, two patients had local recurrence and one patient died. Analysis with Pearson Chi-Square test showed significant association between tumour grade $(p=0.000)$ and final resection margin $(p=0.028)$ with outcome of patients with STS. Other prognostic factors such as presentation $(p=0.099)$, age $(p=0.143)$, treatment sequence $(p=0.388)$, histopathology $(p=0.399)$, size $(p=0.429)$, gender $(p=0.464)$ and site $(p=0.484)$ showed no significant association between factors above with outcome of patients with STS. 


\title{
EGFR MUTATIONS IN NON SMALL CELL LUNG CANCER CASES IN BRUNEI DARUSSALAM; CHARACTERISTICS, DEMOGRAPHIC ASSOCIATIONS AND TREATMENT OUTCOMES.
}

\author{
CHIE HUI LEONG', SUWARNI DIAH', SHIR KIONG LU² \\ 'Universiti Brunei Darussalam, \\ ${ }^{2}$ The Brunei Cancer Centre
}

Background: Since 2009 to 2015, cancer remained the leading cause of mortality in Brunei Darussalam. Amongst other cancers, the highest mortality rate nationally in 2015 was attributed to lung cancer (including trachea and bronchus) (16.7\%). Mutations in the Epidermal Growth Factor Receptor (EGFR) gene have been identified in a distinct subgroup of Non Small Cell Lung Cancer (NSCLC) patients with Adenocarcinoma subtype, which confers sensitivity to EGFR Tyrosine Kinase Inhibitors (TKI). This study was conducted to characterize NSCLC patients harbouring EGFR mutations in Brunei Darussalam. Methods: Retrospective data collection on NSCLC patients diagnosed between January 2010 to March 2017 was undertaken in The Brunei Cancer Centre. Relevant patients' demographic data, clinical characteristics and treatment outcomes were extracted from the hospital's medical notes. Results: EGFR mutations were detected in 31 (43.7\%) NSCLC patients of the Adenocarcinoma subtype. The mean age was $63.3 \pm 12$ years, with a significant proportion being female non-smokers (56.7\%). 33.3\% of smokers were also found to harbour EGFR mutations. Point mutation in Exon 21 (L858R) (43.3\%) was the most prevalent, followed by Exon 19 deletion (40.0\%). The median progression-free survival (PFS) for EGFR mutated patients treated with first line TKI was 7 months. The PFS between patients harbouring L858R mutation and Exon 19 deletion upon receiving first TKI was not statistically significant $(P=0.142)$. Survival analysis showed a trend in improvement of overall survival (OS) in EGFR mutated patients compared to wild type, although not statistically significant $(P=0.232)$. 


\title{
INVESTIGATING THE ANTI-CANCER PROPERTIES OF CLINACANTHUS NUTANS EXTRACTS
}

\author{
NURUL ATIQAH SULAIMAN, RAJAN RAJABALAYA, SHEBA \\ DAVID, IHSAN NAZURAH ZULKIPLI
}

\section{PAP Rashidah Sa'adatul Bolkiah Institute of Health Sciences, Universiti Brunei Darussalam, Jalan Tungku Link, BE1410, Brunei Darussalam}

Introduction: Clinacanthus nutans $(\mathrm{CN})$ is a tropical plant that is native to Southeast Asia and has received much attention recently, particularly on social media for its anti-cancer properties. Various studies have identified the anti-proliferative activity of $\mathrm{CN}$ against cancer cell lines. However, the mechanism of $\mathrm{CN}$ efficacy in cancer cell killing was also not clear as very few studies have been conducted. Therefore, the aim of this study was to confirm the anti-proliferative activity of $\mathrm{CN}$ extracts and to investigate possible mechanisms of cell death. Methods: $\mathrm{CN}$ leaves were processed with several different methods to generate different $\mathrm{CN}$ crude extracts. The cytotoxicity of $\mathrm{CN}$ extracts towards MCF-7 breast cancer cells were evaluated via MTT assay. The study employed immunoblotting and immunofluorescence microscopy to look at the effect of $\mathrm{CN}$ extracts on microtubule dynamics, as well as flow cytometry in order to investigate effects of $\mathrm{CN}$ extracts on the cell cycle and cell death profile of MCF-7 cells. Results/Discussion: The study demonstrated that $\mathrm{CN}$ extracts were cytotoxic at high concentrations. The results suggest that $\mathrm{CN}$ may perturb MCF-7 microtubule dynamics and also induce apoptosis, but does not affect the cell cycle profile. Conclusion: Overall, the study shows that CN has the potential to be used in cancer treatment and further studies are required understand more of its anti-cancer mechanism, as well as to isolate the possible anti-cancer compound. 


\title{
MISINTERPRETATIONS IN VERBAL FEEDBACK: THE SOURCES AND ITS SOLUTIONS
}

\author{
MOHD NASRI AWANG BESAR, MOHAMAD NURMAN \\ YAMAN, SITI MARIAM BUJANG, NURUL HUSNA AHMAD \\ RAHMAN, MOHAMMAD ARIF KAMARUDIN
}

\section{Department of Medical Education, Faculty of Medicine, The National University of Malaysia}

Effective feedback depends on whether students are able to correctly response to the intended feedback given to them. Unfortunately, students' misinterpretations of feedback occur due to the different level of understanding and this gives various effects on students' learning. While the mismatch between lecturers' intentions and students' interpretations may be inevitable, this phenomenon should not be ignored. This study was designed to determine the sources and solutions of misinterpretations during the verbal feedback. As part of qualitative methodology, this case study was designed to determine the sources and the solutions of misinterpretations in feedback during the verbal feedback session. 47 participants were selected using convenient purposive sampling. 33 feedback sessions involving 33 final year medical students at the department of family medicine and their 14 family physician lecturers were indirectly observed. The semi-structured interview was designed to focus on students' interpretations and to study the possibilities of misinterpretations and its solutions during the verbal feedback. The semi-structured interviews were transcribed and analysed using thematic analysis. Analysis of the qualitative data had identified four main themes namely non-dialogic feedback, misperception towards feedback, miscommunication and lack of clarity regarding lecturers' information. Each theme consisted of several sources of misinterpretation in feedback. Several strategies were suggested by the interviewees namely interactive feedback, feedback training to both lecturers and students, and improve trust. Some strategies had already been adopted by the lecturers such as praise, justification of ratings and invite inquiries to reduce the incidence of miscommunication in verbal feedback. In conclusion, both lecturers and students had agreed that misinterpretations occurred during feedback. Despite the various sources of misinterpretations, it is still manageable by adopting several strategies as part of the solution to enhance the level of students' understanding towards feedback. 


\title{
A PRELIMINARY STUDY OF BLENDED LEARNING, MIXING ONLINE CLASS WITH CONVENTIONAL METHOD: UNPAD STYLE IN UPDATING METHODS IN PROBLEM BASED LEARNING
}

\author{
M. HASAN BASHARI, PUTRI HALLEYANA, FATHUL HUDA, \\ ASTRID FEINISA KHAIRANI, ANDRI REZANO, ALMIRA \\ ZADA, ACHADIYANI, DANY HILMANTO, YONI FUADAH \\ SYUKRIANI
}

Medical Education Research \& Development Unit, Faculty of Medicine, Universitas Padjadjaran

Background: Universitas Padjadjaran's teaching methods have been shifting from traditional to better methods including problem based-learning, e-learning and blended learning. These methods facilitate students to perform andragogic and active learning in order to make students more independent. In order to develop a curriculum that maximized the utilization of information technology and also in line with our campus vision to be a green campus, we seek a novel improvement in our teaching methods via a blended learning method. This study aims to evaluate student's perception on blended learning in a problem based-learning (PBL) environment. Methods: A PBL case was delivered to the 3rd year medical students. We random 8 out of 24 tutorial groups to receive this blended method, the rest if the groups still receive conventional one. In our blended learning trial we asked the tutor to come to the class, supervise and distribute the case problems, however in blended method, google classroom is used in distributing the case problems, making the discussion notes and also reporting learning issues. The rest of delivery method is similar with conventional one. Student's perceptions as well as learning outcomes were evaluated at the end of the course. Results: It is very intriguing, our data showed that student's post-test average score of blended learning group is statistically significant better than the conventional tutorial method $(p<0.05)$. However, in technical aspect some students faced challenges in using the online platform including internet connections, adapting to the new application therefore they suggested conducting some training for students, presumably due to their unfamiliarity with the platform. Majority of students appreciate this paperless method and consider this method more efficient. Conclusion: Blended learning method is a promising method as an improvement of PBL teaching method for medical school. Surely optimization and tweak are needed since we still in preliminary study. 


\title{
LECTURERS' INTENTIONS AND STUDENTS' INTERPRETATIONS OF THE PERFORMANCE FEEDBACK: WHAT ARE THE SIMILARITIES AND THE DIFFERENCES?
}

\author{
MOHD NASRI AWANG BESAR, MOHAMAD NURMAN \\ YAMAN, SITI MARIAM BUJANG, NURUL HUSNA AHMAD \\ RAHMAN, MOHAMAD ARIF KAMARUDDIN
}

Department of Medical Education, Faculty of Medicine, Universiti Kebangsaan Malaysia Medical Centre, Jalan Yaacob Latif, Bandar Tun Razak, 56000 Cheras, Kuala Lumpur, Malaysia.

Giving feedback is incomplete without determining the receivers' understanding. Furthermore, the final product of feedback is to ensure the students respond according to the intended feedback. The objective of this study is to identify the similarities and the discrepancies between lecturers' intentions and students' interpretations during feedback session in Mini-Clinical Examination assessment (mini-CEX). A semi-structured interview method was adopted for this study. There were 33 final year medical students, which attached to the Department of Family Medicine and 14 Family Medicine Specialist were selected using convenient sampling. Firstly, 33 feedback sessions were indirectly observed and analysed to identify the feedback strategies based on the 12 domains stated in the literature. The feedback strategies were self-assessment, student's plan for improvement, selfrating, praise, lecturer's plan for improvement, inform rating, justification of rating and invite inquiries. Secondly, the semi-structured interviews were conducted and questions were focusing to the lecturer's intentions and the student's interpretations toward the feedback strategies. An inductive approach was used in the thematic analysis of the interview transcripts. The result showed several feedback strategies consisted more than one intention or interpretation. Generally, both intentions and interpretations of feedback were related to promoting self-regulated learning, perceiving fairness, increase motivation, power sharing, positive reinforcement, and opportunity. Despite some similarities, some of the feedback strategies had been interpreted differently by the students such as self-assessment and inform rating. As a conclusion, even though the lecturers' intentions and students' interpretations are similar in each of the feedback strategies, some discrepancies still exist. Further study needs to focus on the sources and solutions of misinterpretations during feedback. 


\title{
REMEDIATION PROGRAM FOR MULTIPLE FAILURES ON NATIONAL MEDICAL DOCTOR EXAM BOARD: A CASE STUDY
}

\author{
NUR MELANI SARI, SUSI SUSANAH, ACHADIYANI, ASTRID \\ FEINISA KHAIRANI, DANY HILMANTO, YONI SYUKRIANI \\ FUADAH
}

Faculty of Medicine Universitas Padjadjaran Bandung-Indonesia

Background: etaker of medical education high stakes exam becomes a burden for the strugglers and medical institution due to the growing number each year. The remediation program is really needed for the strugglers because repeated failures may result in the student being considered to leave medical school. The aim of the study was to investigate the complexity problem from the student's perspective. Methods: A total of 21 students were identified as retaker of written test on high stakes medical doctor exam board n Faculty of Medicine Universitas Padjadjaran. Students were invited to join deep individual semi structured that conducted by non-formal remediation lecture. The previous academic performances were evaluated from length of study, GPA of undergraduate and clerkship program, and score of written test. Results: There were only 20 students enrolled. During the exam, two students were failed on the $4^{\text {th }}$ attempt, two on the $3^{\text {rd }}$ attempt, 1 student in her $2^{\text {nd }}$ attempt, and the rest were on the $1^{\text {st }}$ attempt. All students did not have learning disabilities and attention problem before. Non-academic origin were more pronounced in multiple failure ( $>3^{\text {rd }}$ attempt). Two students were found has psychiatric distress and anxiety. Most of the student experience lack of reading speed and accuracy, wrong interpretation of standard curriculum, and 1 student had financial problem. Conclusion: The causes of failure in high stakes exam are diverse and often related with non-academic's origin. Tailored supporting programs have to be developed as complementary of the regular curriculum included rehabilitation psychology, psychiatrist, and dedicated lectures. 
Infection and Immunity

\title{
CARBAPENEM USAGE IN MEDICAL WARDS: AN ANTIBIOTIC STEWARDSHIP FEEDBACK PROJECT
}

\author{
NG CHOON SEONG, PETRICK PERIYASAMY, LAU CHEE \\ LAN, \\ Faculty of Medicine, Universiti Kebangsaan Malaysia Medical Centre, Jalan \\ Yaacob Latif, Bandar Tun Razak, 56000 Cheras, Kuala Lumpur, Malaysia.
}

Introduction: Carbapenem stewardship is designed to restrict its use particularly among medical wards with high prevalence of carbapenem's prescription to combat such emerging resistance. Methodology: Our single-center prospective cohort study involved 144 subjects across medical wards in a tertiary university hospital setting. The impact of such stewardship was analysed according to the compliance and the rejection groups. Results: Out of the total 144 patients that were prescribed carbapenem, only $65 \%(n=94)$ of cases were deemed to be indicated. However, only about $57 \%$ of acceptance rate was reported. Actions recommended about usage restriction of this broad spectrum antibiotic include deescalating carbapenem (36.8\% of total cases); stopping the carbapenem $(22.2 \%)$; to use for a short duration of 5-7 days (19.4\%); up to 2-weeks' usage if culture positive (20.1\%); dose adjustment (0.7\%) and surgical intervention for removal of septic foci $(0.7 \%)$. Carbapenem-resistant isolates had been identified in three cases throughout the study period ( $2 \%$ of total cases). Our carbapenem stewardship project attained positive impact on the duration of hospitalization. Those that compliance with our program had shorter hospital stay $(p<0.01)$. This was the first university hospitalbased carbapenem stewardship program. Conclusions: Carbapenem stewardship program in the medical wards not only saves money, but most importantly it is safe and does not harm the patients with added benefits of reducing the length of hospital stay. 
Infection and Immunity

Oral

\title{
PRODUCTION OF INTERLEUKIN-6 AND CXCL1/KCAND THEIR ROLES IN IN-VITRO BLOOD-BRAIN BARRIER HYPER- PERMEABILITY IN RESPONSE TO DENGUE INFECTION
}

\author{
FAKHRIEDZWAN IDRIS', SITI HANNA MUHARRAM', \\ ZAINUN ZAINI ${ }^{2}$, SUWARNI DIAH ${ }^{1}$ \\ 'PAP Rashidah Sa'adatul Bolkiah Institute of Health Sciences, Universiti Brunei \\ Darussalam, Jalan Tungku Link, Brunei Darussalam. \\ ${ }^{2}$ Virology Laboratory, Clinical Laboratory Services, Laboratory Services, Ministry of \\ Health, Brunei Darussalam.
}

Introduction: Severe dengue infection can progressed to dengue haemorrhagic fever (DHF) or dengue shock syndrome (DSS) which has been associated with increased circulating immunological mediators such as interleukin-6 (IL-6) and interleukin-8 (IL-8) that affect endothelium integrity. To date, there are few studies investigating the specific effects of IL- 6 and IL-8 on blood-brain barrier (BBB). Therefore, the objectives of this study were to detect IL- 6 and CXCL1/KC, a mouse homologue of human IL-8,produced by DENV-infected brain endothelial cells (bEnd.3) and astrocytes (C8-D30) and to investigate the effects of these molecules on in-vitro BBB model and Tight Junction (TJ) proteins, specifically occludinand claudin-5. Methodology: bEnd.3 and C8-D30 monolayers were infected with DENV1-4 at 1.5 MOI in a time-dependent manner. IL-6 and CXCL1/KC productions were detected using enzyme-linked immunosorbent assay (ELISA). Subsequently, an in-vitro BBB model was treated with both moleculesfor 6 and 24 hours. BBB integrity was assessed using transport study and TJ proteins were detected using immunofluorescence assay. Results: IL-6 was elevated as high as 200-fold, whereas 10-fold increase were observed for CXCL1 during infection. IL-6- and CXCL-1-treated BBB model showed a significant leakage of sucrose $(p<0.0001)$ and albumin $(p<0.0001)$ as early as 6 hours post-treatment. The results also showed a significant degradation of both TJ proteins $(p<0.0001)$ indicating that IL- 6 and CXCL1 directly alter TJ proteins expression, leading to BBB leakage. Conclusion: IL-6 and CXCL-1 played a role in facilitating the breaching of BBB, which may enhance the disease progression. 
Infection and Immunity

\title{
FIRST DETECTION AND CHARACTERIZATION OF CLOSTRIDIUM DIFFICILE AMONG HOSPITALIZED CHILDREN IN SABAH, MALAYSIA
}

\author{
NUR NASHYIROH', ZULINA MAZLAN ${ }^{1,2}$, SHAMSUL \\ BAHARI SHAMSUDDIN', MOHAMMAD ZAHIRUL

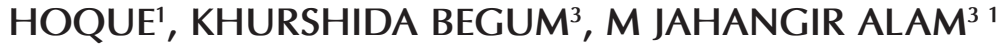

${ }^{1}$ Faculty of Medicine \& Health Sciences, University Malaysia Sabah, Jalan UMS, 88400 Kota Kinabalu, Sabah, Malaysia.

2Pathology Department, Women \& Childrens Hospital, Sabah, Kota Kinabalu, Sabah, Malaysia.

${ }^{3}$ Department of Pharmacy Practice and Translational Research, University of Houston College of Pharmacy, 1441 Moursund St, Houston, Texas 77030, USA.

Introduction: Clostridium difficile is a gram positive, anaerobic, spore-forming bacterium. Toxigenic strains of $\mathrm{C}$. difficile can cause diarrhoea and complications in human and other animals. C. difficile infections (CDI) are rarely studied in Malaysia and many other Asian countries. CDI are increasing among hospitalized patients and also in the community all over the world. The objectives of the study were to detect $C$. difficile in hospitalized children and characterise the pathogen from a large hospital in Sabah, Malaysia. Methods: This cross-sectional study was done in on 98 stool samples suspected for CDI. The study period was from June 2016 to March 2017. All the patients were from the Womens and Childrens Hospital, Kota Kinabalu, Sabah. A commercial test kit, C. DIFF QUIK CHEK COMPLETE (Alere, Techlab, USA), were used which simultaneously detects both glutamate dehydrogenase $(\mathrm{GDH})$ antigen and toxins A \& B of C. difficile in fecal samples. Results: Twenty six of the 98 stool samples was positive either C. difficile antigen and/or toxin. The overall incidence of $\mathrm{C}$. difficile infection/colonization in tested children was $26.5 \%(26 / 98)$. The rate of antigen positivity was $80.8 \%(21 / 26)$ and toxin positivity was $19.2 \%$ (5/26). The recurrence rate was $11.5 \%(3 / 26)$. The median age of the studied children was 9.2 years (male $53.8 \%$ and female $46.2 \%$ ). Most of the test positive children were colonized with non-toxigenic C. difficile. Discussions: We have detected low incidence of toxigenic $\mathrm{C}$. difficile among hospitalized children. Colonized or infected children can be the potential source of CDI for others. It will be of considerable interest to examine large number of samples from all ages of patients. This is the first report of CDI prevalence hospitalized children from Sabah, Malaysia. 
Infection and Immunity

Oral

\title{
INTERACTION OF VON WILLEBRAND FACTOR WITH STREPTOCOCCUS PNEUMONIAE USING A BRAIN ENDOTHELIUM MODEL
}

\author{
NURUL ADHWA RAHMAN, SUWARNI DIAH, SITI HANNA \\ MUHARRAM \\ Pengiran Anak Puteri Rashidah Sa'adatul Bolkiah Institute of Health Sciences, \\ Universiti Brunei Darussalam, Brunei Darussalam
}

Introduction: von Willebrand factor (vWF) is a large multimeric glycoprotein which is released normally by the brain endothelial cells and is therefore present as a circulatingproteinin the blood. The initial and mature structure of vWF is uncleaved, however pneumococcal infection can cause the cleavage of the protein, thus forming several multimers at different sizes.This current study tested the hypothesis that Streptococcus pneumoniae infection of brain endothelial cells in culture induces the release of VWF at certain sizes time-dependantly. Methods: Immortalized mouse brain endothelial cells (bEnd.3) were infected at specific hours with Streptococcus pneumoniae ATCC 49619 control strain and one Brunei clinical strain (serotype 19F). Immunofluorescence microscopy was performed and quantified accordingly. Cells were also extracted and the proteins were separated into different sizes by western blot. The expression of vWF was then analysed and compared for potential relationship between the strains and between the specific time of infection. Results/Discussion: The expression of vWF was elevated during infection. Even though multiple and non-specific events can also cause the cleavage of $\mathrm{VWF}$, this study showed that the cleavage pattern of VWF is potentially dependant on the time of infection. 


\title{
INCIDENCE AND CHARACTERISTICS OF INFLAMMATORY BOWEL DISEASE (IBD) IN BRUNEI DARUSSALAM
}

\author{
HUI LING ONG', FAZEAN IRDAYATI IDRIS' ${ }^{1}$, VUI HENG \\ $\mathrm{CHONG}^{2}$ \\ 'PAPRSB Institute of Health Sciences, Universiti Brunei Darussalam, \\ ${ }^{2}$ Department of Gastroenterology, RIPAS Hospital
}

Introduction: The prevalence of Inflammatory Bowel Disease (IBD) is increasing worldwide with a notable emergence in Asian countries. This is the first study from Brunei Darussalam to determine the country's overall incidence of IBD and its association with socio-demographic data and to investigate characteristics of patients diagnosed with IBD, Crohn's disease (CD) and ulcerative colitis (UC). Methodology: 71 patients diagnosed with IBD was identified through records from the Pathology Department, RIPAS Hospital. Clinical case notes were systematically reviewed for demographic data, presenting complaints and investigation results. Missing data, due to incomplete patient information, for each variable was excluded in the analysis. Results/ Discussion: 48 (67.6\%) patients were diagnosed with UC and $23(32.4 \%)$ with CD. There was an increasing trend of UC incidence while CD was decreasing. The mean age of diagnosis for $U C$ and $C D$ was $40.5 \pm 17.5$ and 32.1 \pm 13.6 years respectively, slightly older than in Western countries. Analysis of $45 \mathrm{UC}$ and $20 \mathrm{CD}$ patients with documented clinical presentations revealed UC patients were more likely to present with BPR/bloody diarrhoea $(p<0.001)$ and diarrhoea $(p=0.003)$. Similar to most studies, our results showed that the rectum was more likely to be affected in UC $(p<0.001)$, although rectal sparing was observed more frequently than expected, and the terminal ileum $(p=0.004)$ and caecum $(p=0.002)$ were more likely to be affected in $\mathrm{CD}$. Contrasting results may be attributed to small sample size, but this study remains an accurate model of IBD in the country as all histologically proven IBD diagnoses was used in the study. 


\title{
HEALTH RELATED QUALITY OF LIFE (HRQOL) OF MEDICAL FACULTY'S ACADEMIC EMPLOYEES: PILOT ONLINE SURVEY
}

\author{
LENY SUZANA SUDDIN, ZAHIR IZUAN AZHAR, NIK \\ SHAMSIDAH NIK IBRAHIM \\ Faculty of Medicine, Universiti Teknologi MARA, Malaysia
}

Introduction: Health-related quality of life (HRQOL) a subjective assessment across the physical, psychological, social and somatic domains of functioning and well-being is widely used by policymakers in making population health and equity decisions. Majority of QOL study had focused on specific diseases. The main objective of this study is to investigate the reliability of specific HRQOL instrument and measure the health status among working population. Methods: Cross sectional survey was conducted using website online application among the employees in medical faculty using Medical Outcome Study Short Form 36 questionnaire. Data collection was done via email survey link to the organization's official network. Result: Total of 30 respondents completed the online survey. Median duration to complete an individual survey was about 4.5 minutes. The internal consistency for this questionnaire was good with Cronbach alpha coefficient of 0.938 . The overall summary scores for physical health and mental health component were 76 (range 52-100) and 59 (range 42-76), respectively. Role limitations due to physical and mental health both showed perfect scores of 100. Nonetheless, lowest score was seen in general health component at scale of 65 (range 45-83). Conclusion: Study findings suggested health status among the employees differed between physical and emotional components. MOS SF-36 questionnaire was found to be a reliable tool to collect data using online platform for measurement of HRQOL among the employees in academic organization. Future studies with larger population will provide high quality information on the HRQOL and assist in identifying its determinants. 


\title{
MAKE OR BREAK OF HEALTHCARE MANAGERS: IDENTIFYING OBSTACLES OF HEALTHCARE MANAGEMENT
}

\author{
CHIEW WYE LEE, ANIZA ISMAIL \\ Department Community Health, Faculty of Medicine, Universiti Kebangsaan \\ Malaysia Medical Centre, Jalan Yaacob Latif, Bandar Tun Razak, 56000 Cheras, \\ Kuala Lumpur, Malaysia.
}

Introduction: The demand for healthcare services often exceeds available resources yet healthcare managers were expected to deliver healthcare services. Healthcare management obstacles could either make or break the healthcare manager and bring about a few kinds of performance outcome; successful, mediocre outcome or failure. Hence, the study believes that by identifying healthcare management obstacles and investigation the relationship between these obstacles and the perceptions of coping ability of these obstacles were worth for managerial development. Methodology: Doctors in management were approached to answer self-administered driver of managerial questionnaires on rules, initiatives, emotions, immediate action and integrity. Data were analysed using descriptive analysis and linear regression. Results: Immediate action was the hardest obstacles to cope. Emotions were perceived as the easiest obstacles to cope. Duration in management was a significant factor to driver of rules $(b=0.02, p<0.05)$ and driver of initiatives $(b=0.02, p<0.05)$ and perceived easier obstacles to cope. Working in the health office has significant relationship to emotions and perceived harder obstacles to cope $(b=-0.18, p<0.05)$. Conclusion: Healthcare manager perceived the obstacles encountered in descending order of difficulty of obstacles were immediate actions, rules, initiatives, integrity and lastly emotions. The findings from this study provided insights as to what were needed to strengthen in healthcare managers and help them cope with the obstacles in healthcare management. 


\title{
DIALYSIS PROVISION AND IMPLICATIONS OF HEALTH ECONOMICS ON PERITONEAL DIALYSIS UTILISATION: A MALAYSIAN PERSPECTIVE
}

\author{
NAREN KUMAR SURENDRA, ABDUL HALIM ABDUL \\ GAFOR, MOHD RIZAL ABDUL MANAF
}

Faculty of Medicine, Universiti Kebangsaan Malaysia Medical Centre, Jalan Yaacob Latif, Bandar Tun Razak, 56000 Cheras, Kuala Lumpur, Malaysia.

Introduction: End-stage renal disease (ESRD) is managed by either lifesaving haemodialysis (HD) and peritoneal dialysis (PD) or a kidney transplant. In Malaysia, the prevalence of dialysis-treated ESRD patients has shown an exponential growth over the last few years. They consume a substantial portion of healthcare costs. Remarkably, PD is underutilised although it is more cost-effective than HD. Methodology: A review of dialysis provision, issues related to dialysis provision and implications of health economics on PD utilisation was conducted from a Malaysian perspective. The 22nd Malaysian Dialysis and Transplant Registry report and other published articles through limited literature search on key resources including Pubmed, Medline and a focused internet search were used in this review. Results: As of 2014, there were 31, 497 patients on HD and 3270 patients on PD. Kidney transplants are limited. Malaysia adopts public-private financing model for dialysis. Inequality in access to dialysis is visible within geographical regions where majority of HD centres are scattered around developed areas. Meanwhile, the expenditure on dialysis has been escalating in recent years but economic evaluations of dialysis modalities are scarce. Evidence shows that health policies and reimbursement strategies influence dialysis provision. Increased uptake of PD can produce significant economic benefits and improve patients' access to dialysis. As a result, some countries implemented a PD First or Favored Policy to expand PD use. Conclusion: A current economic evaluation of dialysis modalities is essential to assist decision makers to establish a more equitable and economically sustainable dialysis provision. 


\section{NURSING STRESSORS AND POST TRAUMATIC STRESS DISORDER (PTSD) AMONG KUALA KRAI HOSPITAL NURSES EIGHT MONTHS POST "BAH KUNING" FLOOD}

\section{KHAIRIL IDHAM ISMAIL', 2ROSNAH ISMAIL ${ }^{2}$, RAFIDAH BAHARI $^{3}$}

${ }^{1}$ Department of Anesthesia and Critical Care, Hospital Serdang, Malaysia. ${ }^{2}$ Department of Community Health, Faculty of Medicine, Universiti Kebangsaan Malaysia Medical Centre, Jalan Yaacob Latif, Bandar Tun Razak, 56000 Cheras, Kuala Lumpur, Malaysia.

${ }^{3}$ Department of Psychiatry, Cyberjaya University College of Medical Sciences, Malaysia.

"Bah Kuning" flood was reported as the worst flood in the history of Kelantan state. But nurses in the affected state have continuously worked during the event despite themselves being affected. The aim of this study was to identify the association between nursing stressors and religious coping mechanism on PTSD among affected nurses. A cross sectional study was conducted among Hospital Kuala Krai nurses eight months after the "Bah Kuning" flood. A package of selfadministered questionnaire i.e. Malay PTSD Checklist-Civilian Version (MPCL-C), Nursing Stress Scale (NSS), the Malay Version of Duke University Religious Index (DUREL-M) and flood experience were completed. The results were analyzed using t-test and Multiple Logistic Regression. Prevalence of PTSD among sampled nurses is $19.3 \%$ but only $21.6 \%$ of them have met DSM-IV criteria. There is significant mean different in workload $(t=1.75, p=0.041)$, lack of support $(t=1.72, p=0.044)$, death and dying concerns $(t=2.08, p=0.039)$, feel inadequate preparations $(t=3.37$, $p<0.001)$ and organizational religious activity $(t=2.50, p=0.013)$ among PTSD nurses compared to non-PTSD nurses. The significant predictors for PTSD are workload $(\mathrm{OR}=1.12,95 \% \mathrm{Cl}: 1.01,1.24)$, inadequate preparation $(\mathrm{OR}=1.55,95 \% \mathrm{Cl}: 1.15,2.09)$, organizational religious activity (OR=1.85; 95\%Cl: 1.29, 2.65) and estimated loss of more than $\mathrm{RM} 1000(\mathrm{OR}=1.68,95 \% \mathrm{Cl}: 1.12,2.51)$. Nursing stressors are identified. Preparedness and response for disaster should focus on these aspects in order for mental health risk mitigation, particularly PTSD among them. 


\title{
PREVALENCE OF DIABETES MELLITUS AND ITS ASSOCIATION WITH JOB FACTORS AMONG CONSTRUCTION WORKERS IN SAUDI ARABIA
}

\author{
ALI AL-AHDAL, HALIM ISMAIL \\ Department of Community Health, Faculty of Medicine, Universiti Kebangsaan \\ Malaysia Medical Centre, Jalan Yaacob Latif, Bandar Tun Razak, 56000 Cheras, \\ Kuala Lumpur, Malaysia.
}

Introduction: Diabetes Mellitus (DM) is a common chronic disease worldwide. World Health Organization (WHO) estimated that the prevalence of DM worldwide is $24 \%$ (382 million people with DM) and the number could rise to 55\% (592 million people with DM) within 22 years. In 2013, the prevalence of DM in Saudi Arabia was estimated to be $24 \%$. The aim of this study was to determine the prevalence of DM among construction workers and to identify its association with job factors among construction workers in Saudi Arabia. Methods: This is a cross sectional study involving 224 male construction workers aged 20-60 years old which were randomly selected using simple random sampling technique. Sociodemographic, medical history, family history, lifestyle factors and job factors were collected using questionnaire. Random blood sugar (RBS) level was used as a screening method to identify workers with possible DM and workers with high RBS level were subsequently referred to medical practitioner for further investigation. The data were analysed using SPSS. Results: Prevalence of DM among construction workers were $8.9 \%$ (20 workers). Known cases of diabetic was 5.8\% (13 workers), while newly diagnosed cases of DM were $3.12 \%$ (7 workers). Positive family history was found to have positive association with $\mathrm{DM}$ (AOR=8.6; 95\% Cl: 2.4-30.4), while physical activities were found to be protective against development of DM (AOR=0.2; 95\% Cl: 0.1-0.7). Job factors such as work style, working overtime, shift work and shift hours were found to be not statistically significant. Conclusion: The prevalence of DM among construction workers were $8.9 \%$. The factor that contributed to development of DM was positive family history, while the factor that reduced the risk was physical activity. There were no association between job factors and development of DM in this study. 


\title{
ASSOCIATION OF BLOOD GLUCOSE AND HEAVY METALS AMONG ADULTS IN TANJUNG KARANG, SELANGOR.
}

\author{
SHARUL RIZAN ILIAS, MOHD HASNI JA'AFAR, \\ Department of Community Health, Faculty of Medicine, Universiti Kebangsaan \\ Malaysia Medical Centre, Jalan Yaacob Latif, Bandar Tun Razak, 56000 Cheras, \\ Kuala Lumpur, Malaysia.
}

Introduction: The prevalence of diabetes mellitus (DM) is rising worldwide, especially among adults in Malaysia. This study was aimed to determine the association between blood glucose with heavy metals such as cadmium, arsenic, lead, nickel and manganese. Method: This was a cross sectional study that used purposive sampling amongst adults in Tanjung Karang, Selangor. It was conducted within six months involving all healthy adults. Enrolled respondents answered a standardized questionnaire and about $10 \mathrm{mls}$ of their venous blood was extracted and kept in a metal-free EDTA container for heavy metal analysis using Inductively Coupled Plasma Mass Spectrometry (ICP-MS). The finger prick technique was used for their blood glucose measurement. The statistically significant level was $p$ value of less than 0.05. Results: A total of 271 respondents was recruited in the study. The prevalence of hyperglycemia was $29.5 \%$. In bivariate analysis, factors that significantly associated with high blood glucose was the older age group $(p=0.005)$, and high blood cadmium ( $p=0.005)$. In Multiple Logistic Regression, factors remain significant were age group and cadmium; and fit the final model which was assessed by interaction, multicollinearity, Hosmer-Lemeshow $(p=1.0)$ and overall classification percentage (70.8\%). Conclusion: Advanced age and blood cadmium are significant factors for high blood glucose. Other metals such as arsenic, lead, nickel and manganese were not related to high blood glucose. 
Biomedical Sciences

Poster

\title{
BLOOD PRESSURE-RAISING EFFECT FOLLOWING INTAKE OF REPEATEDLY HEATED PALM AND SOY OILS
}

\author{
XIN-FANG LEONG ${ }^{1}$, MOHD RAIS MUSTAFA², KAMSIAH \\ JAARIN ${ }^{3}$ \\ ${ }^{1}$ Department of Clinical Oral Biology, Faculty of Dentistry, Universiti Kebangsaan \\ Malaysia. \\ ${ }^{2}$ Department of Pharmacology, Faculty of Medicine, University of Malaya. \\ ${ }^{3}$ Pharmacology Cluster, Faculty of Medicine and Defence Health, Universiti \\ Pertahanan Nasional Malaysia.
}

Introduction: Repeatedly heating of vegetable oil may promote oxidation and lead to hypertension. This study was undertaken to investigate the effects of repeatedly heated vegetable oils on blood pressure, lipid peroxidation, nitric oxide and activity of blood pressure-regulating enzymes. Methods: One hundred and ten adult male Sprague-Dawley rats were divided into eleven groups; the control group was fed with normal diet, and the other groups were fed with diet fortified with $15 \%$ weight/weight of palm oil or soy oil in fresh form or heated once, twice, five or ten times, respectively. Blood pressures were measured at the baseline and throughout the 24-week study. Plasma lipid peroxidation, nitric oxide and blood pressure-regulating enzyme levels were assessed prior to treatment and at the end of the study. Results: There was a significant increase $(p<0.05)$ in blood pressure and lipid peroxidation following consumption of repeatedly heated palm or soy oil, with the group administered heated ten times soy oil showing the highest values. Repeatedly heated oil groups had lower nitric oxide and heme oxygenase levels but higher angiotensin-converting enzyme levels compared to other dietary groups. Conclusion: The blood pressure-raising effect of the heated vegetable cooking oils is associated with a reduction in nitric oxide levels. Repeatedly heated vegetable oils may negatively affect the activity of blood pressure-regulating enzymes and increase lipid peroxidation. 


\title{
EFFECTS OF CHLORELLA VULGARIS ON THE DIFFERENTIATION OF HUMAN SKELETAL MUSCLE MYOBLASTS FOR THE PROMOTION OF MUSCLE REGENERATION
}

\author{
NURHAZIRAH ZAINUL AZLAN', YASMIN ANUM \\ MOHDYUSOF', EKRAM ALIAS', SUZANA MAKPOL ${ }^{1}$ \\ ${ }^{1}$ Department of Biochemistry, Faculty of Medicine, Universiti Kebangsaan \\ Malaysia Medical Centre, Jalan Yaacob Latif, Bandar Tun Razak, 56000 Cheras, \\ Kuala Lumpur, Malaysia.
}

Introduction/Aim: Chlorella vulgaris is microscopic unicellular freshwater green algae with high contents of antioxidants. The aim of this study was to determine the effects of $C$. vulgaris on the differentiation of human skeletal muscle myoblast cells (HSMM). Methods: HSMM cell was cultured in Skeletal Muscle Basal Medium (SkBM) until population doubling (PD) 14 (young) and PD 21 (senescent). Immunological staining was performed at day 1, 3, 5 and 7 of myoblasts differentiation using anti-Desmin antibody, Alexa Fluor 488 and Hoescht 33342. Purity of myoblasts was measured and cell differentiation was determined by fusion index, maturation indexand size of myotubes. Myotube surface area was measured by Image J software v1.38. Cell cycle profile was analyzed using BD FACSVerse flow cytometer. Results/Discussion: The myogenicity of myoblast cells was maintained as indicated by $92 \%$ of desmin-positive cells. Young myoblasts differentiation occcured at day 3 of differentiation. Treatment with C. vulgaris increased the rate of differentiation as shown by increased maturation index, size of myotubes, and myotube surface area $(p<0.05)$. Rate of differentiation however was slower in senescent cells which was increased with $C$. vulgaris treatment $(p<0.05)$. Cell cycle profile showed increased senescent cells at G0/G1 phase at day 0 of differentiation while increased G2/M phase in treated myoblasts. At day 1 of differentiation, increased G0/G1 phase and decreased S phase were observed in young cells treated with $10 \mu \mathrm{g} / \mathrm{ml} \mathrm{C}$. vulgaris and senescent myoblasts with or without $C$. vulgaris treatment $(\mathrm{p}<0.05)$. This findings indicate promotion of cell differentiation while cell proliferation was halted. Conclusion: $C$. vulgaris promote myoblasts differentiation as evidenced by higher fusion of myoblasts to form myotubes. 


\title{
BLOOD-BASED PROTEIN INTERACTION AS PROBABLE RECOGNITION OF SPEED AND MEMORY COMPETENCY WITH AGE TRANSITION ACROSS HEALTHY MALAY ADULTS IN MALAYSIA
}

\author{
ZULZIKRY HAFIZ ABU BAKAR, NUR FATHIAH ABDUL \\ SANI, AHMAD IMRAN ZAYDI AMIR HAMZAH, WAN \\ ZURINAH WAN NGAH AND MOHD HANAFI AHMAD \\ DAMANHURI
}

Department of Biochemistry, Faculty of Medicine, Universiti Kebangsaan Malaysia Medical Centre, Jalan Yaacob Latif, Bandar Tun Razak, 56000 Cheras, Kuala Lumpur, Malaysia.

Introduction: Development of ageing population is apparent nowadays. In tandem, transition of age demonstrates increase susceptibility of experiencing cognitive deterioration. Hence, understanding protein interaction might provide better reflection on subjected cognitive competency. Method: 160 recruited subjects divided into Group 30, Group 40, Group 50 and Group 60 consisting of 40 individuals respectively. Subjects were subjected to Digit Symbol test. Obtained plasma was depleted and undergone in-gel digestion. Reconstituted samples were analyzed using Dionex Ultimate 300 RSCL Nano system coupled Q Exactive HF. In-silico analysis was performed using Maxquant and Perseus for bioinformatics purposes. GO analysis was conducted using PANTHER and pathway analysis was done by REACTOME. STRING was used to determine protein-protein interaction. SPSS was applied for statistical analysis. Result: Group 40 and Group 50 scored significantly lower compared to Group 30 while Group 60 demonstrated significant lower performance compared to the other groups. 226 proteins were detected and 133 proteins were selected prior to data filtration. 24 proteins were differentially expressed across group. These proteins were highly expressed in Group 30 and Group 40 while conversely shown in Group 50 and Group 60. Several GO components were involved. 49 pathways were implicated and two of them were associated with cognitive pathology. Formation of protein network was demonstrated which concurrently correlated with subjected cognitive capability. Conclusion: There was deterioration of speed and memory capacity among healthy Malay adults in Malaysia with age. Protein-protein interaction displayed could be a substantial platform in highlighting potential biomarker affecting subjected cognitive competency. 
Biomedical Sciences

Poster

\title{
DOES AGEING AFFECT CIRCULATING FEEDING HORMONES AND BRAINSTEM GLUCOREGULATORY PROTEINS IN FEEDING PATHWAY?
}

\author{
HAJIRA RAMLAN, NOR AZURA MUDA AND HANAFI \\ AHMAD DAMANHURI
}

Department of Biochemistry, Faculty of Medicine, Universiti Kebangsaan Malaysia Medical Centre, Jalan Yaacob Latif, Bandar Tun Razak, 56000 Cheras, Kuala Lumpur, Malaysia.

Introduction/Aim: Ageing is defined as the time-related decline in physiological body functions, affecting the survival and reproduction rate. This study is conducted to determine the effect of age on plasma feeding hormones as well as genes and proteins expression in caudal ventrolateral medulla (CVLM) in the brainstem that act together in the regulation of the feeding response. Methods: Male Sprague dawley rats at 3-months $(n=11)$ and 24-months $(n=11)$ old were used in this study. $5 \mathrm{ml}$ of trunk blood was collected and further processed to obtain the plasma samples. Circulating feeding hormones such as cholecystokinin (CCK), ghrelin and leptin were analysed using enzyme-linked immunosorbent assay (ELISA). Rat brain was carefully dissected to obtain the brainstem CVLM region. Further analysis was carried out to determine the level of proteins and genes in CVLM that were associated with feeding pathway. Protein expression of tyrosine hydroxylase $(\mathrm{TH})$, phosphorylated TH at Serine40 (pSer40TH), AMP-activated protein kinase (AMPK), phosphorylated AMPK (phospho AMPK) and Neuropeptide Y (NPY) were determined by western blot. Expression of TH, AMPK and NPY gene were determined by real time PCR. Results/ Discussion: This study demonstrated that plasma CCK-8 and leptin concentration were significantly higher in old rats as compared to the young rats. No changes were evidence on the level of plasma ghrelin. Further analysis in the CVLM showed low basal level of pSer40TH and high basal TH protein expression. Interestingly, AMPK protein was lowly expressed in old rats. Phosphorylated AMPK and NPY protein does not showing any significant difference. No age-related differences were found in basal gene expression of $\mathrm{TH}$, AMPK and NPY in CVLM. As a conclusion, anorexigenic effects of circulating CCK-8 and leptin, together with low level of TH activity and AMPK protein may contribute to the impairment of feeding response in the elderly. 
Biomedical Sciences

Poster

\section{EFFECTS OF ANNATTO TOCOTRIENOL ON METABOLIC SYNDROME IN MALE RATS}

\section{SOK KUAN WONG, KOK-YONG CHIN, SOELAIMAN IMA- NIRWANA}

Department of Pharmacology, Faculty of Medicine, Universiti Kebangsaan Malaysia, Jalan Yaakob Latif, Bandar Tun Razak, 56000 Cheras, Kuala Lumpur, Malaysia.

Introduction: This study aimed to investigate the effects of annatto tocotrienol on metabolic syndrome (MetS) parameters in male rats. Methods: Male Wistar rats were randomised into five groups: baseline $(\mathrm{BL})$, normal $(\mathrm{N})$, metabolic syndrome (MetS), and MetS treated with $60 \mathrm{mg} / \mathrm{kg}$ annatto tocotrienol (MetS+60 aT3) or 100 $\mathrm{mg} / \mathrm{kg}$ annatto tocotrienol (MetS+100 aT3) groups. The baseline group was sacrificed at the onset of study. The normal group was given standard rat chow. The MetS groups were given high-carbohydrate high-fat (HCHF) diet, comprises of fructose, sweetened condensed milk, ghee, Hubble Mendel and Wakeman salt mixture, and powdered rat food. Diet regimen was assigned for a period of 20 weeks. Annatto tocotrienol (60 or $100 \mathrm{mg} / \mathrm{kg}$ ) was given via once-daily oral gavage starting from week 8 . At the end of the end of study, all rats were subjected for the analysis of MetS parameters (including the measurement of abdominal circumference, blood pressure, blood glucose, and lipid profile). Results: Our results indicated that annatto tocotrienol (60 or $100 \mathrm{mg} / \mathrm{kg}$ ) improved both systolic and diastolic blood pressure in MetS rats compared to non-treated MetS rats $(\mathrm{P}<0.05)$. Fasting blood glucose was normalised in rats fed with HCHF diet supplemented with 60 or $100 \mathrm{mg} / \mathrm{kg}$ annatto tocotrienol $(\mathrm{P}<0.05)$. In addition, administration of annatto tocotrienol $(60$ or $100 \mathrm{mg} / \mathrm{kg}$ ) resulted in the reduction of triglyceride and total cholesterol levels in rats with MetS $(\mathrm{P}<0.05)$. Conclusion: Annatto tocotrienol exerts potential effects in ameliorating the medical conditions associated to MetS. 


\title{
EFFECTS OF CHLORELLA VULGARIS ON THE DIFFERENTIATION OF HUMAN SKELETAL MUSCLE MYOBLAST CELL
}

\author{
NURHAZIRAH ZAINUL AZLAN, YASMIN ANUM MOHD \\ YUSOF, EKRAM ALIAS, SUZANA MAKPOL
}

Department of Biochemistry, Faculty of Medicine, Universiti Kebangsaan Malaysia Medical Centre, Jalan Yaacob Latif, Bandar Tun Razak, 56000 Cheras, Kuala Lumpur, Malaysia.

Introduction/Aim: Chlorella vulgaris is microscopic unicellular fresh water green algae with highly contents of antioxidants and had been reported for its pharmacological effects. The aim of this study was to determine the effects of C. vulgaris on the differentiation of human skeletal muscle myoblasts (HSMM) cell for the promotion of muscle regeneration. Methods: HSMM cell from 20 years old female Caucasian was cultured in Skeletal Muscle Basal Medium (SkBM) (Lonza, Walkersville, MD, USA). Myoblast cell at PD 14 and PD 21 were considered young and senescent, respectively. Immunological staining was performed at Day $1,3,5$ and 7 of myoblast differentiation using anti-Desmin antibody as primary antibody, Alexa Fluor 488 as secondary antibody and Hoescht 33342 for nucleus staining. Cells were then observed under EVOS FL Digital Inverted Fluorescence Microscope (Life Technologies, Carlsbad, USA). Purity of myoblast cell, fusion index $(\mathrm{FI})$, maturation index (MI) and size of myotube was determined. Myotube surface area was measured by Image J software v1.38. Cell cycle assay was determined by BD Cycletest TM Plus DNA Reagent Kit and analyzed using BD FACSVerse flow cytometer. Results/Discussion: The percentage of desmin-positive cells was more than $92 \%$ indicate no loss of myogenicity. In Day 5, C. vulgaris treated group showed significantly difference in FI compared to untreated groups in PD 14. As for PD 21, control group showed slower rate in $\mathrm{Fl}$, however, $C$. vulgaris treated group showed significant increase in $\mathrm{Fl}$ as early in Day 3. Observation also showed in PD14, $100 \mu \mathrm{g} / \mathrm{ml} \mathrm{C}$. vulgaris treated group showed significant increase in $\mathrm{Ml}$ since Day 3 as compared to other groups which only showed at Day 5. In PD 21, C. vulgaris treated group showed significant increase in $\mathrm{MI}$ since Day 5 as compared to control group which only seen at Day 7. The size of myotube for PD 14 showed significant increase at Day 5 for $C$. vulgaris treated group as compared to control group at Day 7. As for PD 21, the size of myotube showed significant increase at Day 7, with 4.0, 4.5 and 5.0 nuclei per myotube for control, 10 and $100 \mu \mathrm{g} / \mathrm{ml} \mathrm{C}$. vulgaris treated group, respectively. Myotube surface area in PD 14 showed significant increase in Day 3 for $C$. vulgaris treated group as compared to control group which showed increase at Day 5. While in PD21, myotube surface area showed significantly 
increase in Day 3 for control group, but for $C$. vulgaris treated group only showed significant increase at Day 5. Senescent group showed significant difference in cell cycle analysis for G0/G1 phase at Day 0 compared young group. Despite that, no significant difference in cell cycle analysis for $C$. vulgaris treated group in both PD 14 and 21. This showed that $C$. vulgaris promote proliferation of the cell as also evidenced by the increase of cell population in S phase. Cell cycle analysis at Day 1 showed that significant increase of cell population for all groups in G0/G1 phase as compared to young control group. This is because cell was halt to proliferation as to promote the expression of MYOD for the differentiation of HSMM cell. Based on the results obtained, it can be concluded that $C$. vulgaris promote the differentiation of HSMM cell as evidenced by higher fusion of myoblasts to form myotubes. 


\title{
TREATMENT OF NERVE DEFECTS IN AN ATHYMIC RAT MODEL USING HUMAN MUSCLE STUFFED VEIN AND COMMERCIAL NEUROTUBE
}

\author{
AMINATH IFASHA GASIM', MOHD ZAIM MOHD \\ RASHID ${ }^{1}$, AMIR ADHAM B AHMAD ${ }^{1}$, NOR HAZLA \\ MOHAMED HAFLAH', RASHIDAH ISMAIL @ OHNMAR \\ HTWE', AMARAMALAR NAICKER NAYSADURAY', AZMI \\ BAHARUDIN ${ }^{\prime}$, SHALIMAR ABDULLAH' ${ }^{1}$, RUSZYMAH \\ IDRUS ${ }^{1}$, ANGELA NG MIN HWEI ${ }^{2}$, KHAIRUNNISA RAMLI', \\ LAW ZHE KANG ${ }^{3}$, MD SHARIFUL HASAN SUMON ${ }^{4}$
}

${ }^{1}$ Department of Orthopaedic, ${ }^{2}$ Tissue Engineering Center, ${ }^{3}$ Neurology Unit, Faculty of Medicine, Universiti Kebangsaan Malaysia Medical Centre, Jalan

Yaacob Latif, Bandar Tun Razak, 56000 Cheras, Kuala Lumpur, Malaysia. ${ }^{4}$ Faculty of Medicine, Department of Orthopedics and Health Sciences, Universiti Putra Malaysia, 43400 Serdang, Malaysia

Introduction: Autologous nerve graft is gold standard in peripheral nerve defect We compare the clinical outcome between tissue engineered biological nerve tube construct made of a vein filled with skeletal muscle with the absorbable polyglycolic acid woven mesh tube. Methodology: This is a single centre prospective study consists of 4 groups each consisting of 3 adult athymic rats: nerve defect (ND), reverse autograft (RA), absorbable polyglycolic acid mesh tube (NT), and muscle stuffed vein (MSV). A $15 \mathrm{~mm}$ defect was surgically created in the right sciatic nerve. Gait analysis, pinch test and nerve conduction study (NCS) were performed at 2 weekly intervals until 12 weeks. Results: Gait was analyzed with sciatic function index (SFI). The MSV group suffered from autotomy of the toes of the operated limb at 5 weeks. Mean amplitude and latency values were assessed from NCS. By 12 weeks RA group regained the normal values, where as MSV group achieved $75 \%$ and NT group $70 \%$ of the baseline reading. At 12 weeks, the rats were euthanized and sciatic nerve harvested; The MSV graft has similar diameter as the sciatic nerve and the NT was in continuity and was of similar appearance to muscle. Discussion: The conduits available are all comparable to the gold standard autologous nerve graft. This study specifically focuses on the effectiveness of NT and MSV using athymic rats in a consistent nerve gap. No difference in sensory recovery was seen. Conclusion: NT and MSV are comparable to autologous nerve grafts. 


\title{
THE EFFECT OF STICOPUS CHLORONOTOUS AQUEOUS EXTRACT ON CATABOLIC ACTIVITY AND OXIDATIVE DAMAGE IN HUMAN OSTEOARTHITIS ARTICULAR CHONDROCYTES IN VITRO
}

\author{
MOHD HEIKAL MOHD YUNUS ${ }^{1,2}$, MOHD FAUZI BUSRA ${ }^{2}$, \\ CHUA KEIN HUI ${ }^{1}$, NORZANA ABD GHAFAR ${ }^{3}$, MOHD \\ RIZAL RANI ${ }^{4}$, AHMAD NAZRUN SHUID ${ }^{5}$
}

${ }^{1}$ Department of Physiology, ${ }^{2}$ Tissue Engineering Centre, ${ }^{3}$ Department of Anatomy, ${ }^{4}$ Department of Orthopaedic, ${ }^{5}$ Department of Pharmacology, Faculty of Medicine, Universiti Kebangsaan Malaysia Medical Centre, Jalan Yaacob Latif, Bandar Tun Razak, 56000 Cheras, Kuala Lumpur, Malaysia.

Introduction: The inflammatory mediators namely, proinflammatory cytokines metalloproteinases family (MMPs), inflammatory $\mathrm{PGE}_{2}, \mathrm{COX}-2, \mathrm{NO}$, and free radicals are the most important group of compounds participating in the pathogenesis of Osteoarthritis (OA). They are responsible for the loss of metabolic homeostasis of articular cartilage by promoting catabolic and destructive processes. Sticopus Chloronotous extract contains important compounds that may exert a favorable influence on the course of the disease. The objective of this present study was to investigate the anti-inflammatory and anti-oxidative potential of Sticopus Chloronotous aqueous extract (SCAE) in human OA articular chondrocytes. Methodology: Primary OA chondrocytes isolated from knee joint cartilage removed during surgery were cultured with SCAE. The optimum concentration of SCAE for human articular OA chondrocytes cultures was determined using MTT assay. The effect of SCAE on catabolic genes expression was verified by real-time PCR. Estimation of NO and PGE2 production release in culture supernatant was determined by using commercially available kits and ELISA. Results: Supplementation of 0.05\%-0.5\% SCAE promoted human articular OA chondrocytes proliferation in culture. SAE supplementation tested in these studies was found to be effective anti-inflammatory and anti-oxidative agent, as evidenced by inhibition of IL-1, IL-6, IL-8, MMP-1, MMP-3, MMP-13, COX-2, iNOS and PAR-2 expression. Moreover, in the presence of SCAE in the culture, was able to reduce $\mathrm{NO}$ and PGE2 production significantly. Conclusions: These results suggest that SCAE demonstrated chondroprotective ability by suppressing catabolic activities and oxidative damage. This approach may be potentially useful as a promising therapeutic agent for the treatment OA. 


\title{
DEVELOPMENT OF NERVE CONDUIT USING NEURODIFFERENTIATED HUMAN MSCS AND DECELLULARIZED HUMAN ARTERY FOR PERIPHERAL NERVE INJURY.
}

\author{
HANITA M HUSSIN 1 , MAHAZURA M LAWI ${ }^{3}$, MOHAMED- \\ HAFLAH NH ${ }^{3}$, KASSIM AYM ${ }^{3}$, RUSZYMAH IDRUS ${ }^{2,1}$, \\ YOGESWARAN LOKANATHAN'
}

\author{
${ }^{1}$ Tissue Engineering Centre, ${ }^{2}$ Department of Physiology, ${ }^{3}$ Department of \\ Orthopaedis and Traumatology, Universiti Kebangsaan Malaysia Medical Centre, \\ 56000 Cheras, Kuala Lumpur, Malaysia,
}

Introduction: The treatment of peripheral nerve injury (PNI) remains challenging especially in critical nerve gap (greater than $3 \mathrm{~cm}$ ). Autograft, the current gold standard, has several drawbacks including limited availability of donor graft, donor-site morbidity and mismatch in size in clinical practices. The aim of this study was to analyze the development of nerve conduit using neurodifferentiated human MSCs (ndMSCs) and decellularized human artery, and its implantation into rat's sciatic nerve injury. Methodology: Mesenchymal stem cells (MSCs) were differentiated into neural lineage using $400 \mathrm{~g} / \mathrm{ml}$ of Centella asiatica (pegaga). 1.5 $\mathrm{x} 10^{6}$ of MSCs and ndMSCs were then seeded into decellularized human umbilical cord artery conduit. Then it was subjected to hematoxylin \& eosin (H\&E) and immunohistochemistry (IHC) analysis. Sciatic nerve gap of $1.5 \mathrm{~cm}$ was created in Sprague-Dawley rat and MSCs or ndMSCs seeded conduit was implanted into the injury. Reversed autograft served as the positive control. Results: H\&E staining revealed that the seeded cells attached to the lumen of the conduit. IHC analysis with S100B, P75 NGFR, MBP and GFAP antibodies revealed that MSCs have differentiated into neural lineage, however, with a low expression of neural markers. Implantation of human cells (MSCs and ndMSCs)(n=3) seeded artery conduit into the rat's sciatic nerve gap demonstrated no evidence of rejection as the rats were immunosuppressed with Cyclosporine and Dexamethasone. Conclusion: We successfully developed human MSCs or ndMSCs seeded decellularized artery conduit and implanted it into rats' $1.5 \mathrm{~cm}$ sciatic nerve gap without any sign of rejection. Currently, functional studies on regenerated nerve are ongoing. 
Biomedical Sciences

Poster

\title{
WOUND IRRITATION MODEL UTILIZING SODIUM LAURYL SULPHATE ONTO A LIVING BILAYER CORNEAL EQUIVALENT
}

\author{
NORZANA ABD GHAFAR ${ }^{1}$, NG SOOK LUAN², E. \\ SHARMILA E. LATIF ${ }^{1}$, JEMAIMA CHE HAMZAH ${ }^{3}$, CHUA \\ KIEN HUI ${ }^{2}$ \\ ${ }^{1}$ Department of Anatomy, ${ }^{2}$ Department of Physiology, ${ }^{3}$ Department of \\ Ophthalmology, Universiti Kebangsaan Malaysia Medical Centre, Jalan Yaacob \\ Latif, Bandar Tun Razak, 56000 Kuala Lumpur, Malaysia.
}

Introduction: The development of the in vitro corneal equivalent to replace the use of whole animal for drug irritation test (Draize's test) has gained much interest in the past two decades. The key point in this development is the corneal equivalent must be able to functionally mimic the response as the in vivo cornea. The aim of this study is to develop a wound irritation model using various sodium lauryl sulphate (SLS) concentrations onto the in vitro bilayer corneal equivalent. Methodology: Corneal epithelial cells (CEC) and corneal fibroblasts were isolated from New Zealand White rabbit corneas and culture expanded until passage 1. Corneal stroma was reconstructed by seeding $5 \times 10^{5}$ fibroblasts into a plasma: collagen I (1:1) gel-like scaffold. CEC $\left(1 \times 10^{6}\right)$ were then seeded onto the corneal stroma gellike scaffold and epithelial stratification was achieved via air-liquid interface for seven days to form the bilayer corneal equivalent. Irritation test was performed by applying SLS $0.1 \%$ and $1 \%$ onto the bilayer corneal equivalent. Histological analysis of the corneal equivalent was performed at day 1, day 5 and day 10 post irritation. Results: CEC and corneal fibroblasts of the bilayer corneal equivalent remained viable throughout the experiment. The topical application of the SLS $(0.1 \%$ and $1 \%)$ onto the corneal equivalent causing area of ulceration in the epithelial layer. In SLS $0.1 \%$ group, re-epithelialization was observed at day 5 and almost complete at day 10 compared to control. Epithelial vacuolization and thinning of the epithelium was observed in the SLS 1\% group. The thickness of the stroma remained unchanged and comparable in all groups. Conclusion: SLS $0.1 \%$ is the preferred concentration to demonstrate the response of the in vitro corneal wound irritation test. The reconstructed bilayer corneal equivalent has shown to be functionally stable and able to mimic the response as in the in vivo cornea. 


\title{
QUANTITATIVE POINT OF CARE G6PD ENZYME ACTIVITY LEVELS IN NORMAL SUBJECTS
}

\author{
NAJIAH AJLAA AYUB, DARNINA ABDUL JALIL, RAJA \\ ZAHRATUL AZMA RAJA SABUDIN, AZLIN ITHNIN, CHEAH \\ FOOK CHOE, LIM LEE SIM, HAFIZA ALAUDDIN, MALISA \\ MOHD YUSOFF, SAIDATUL AKMAL AMIR, WAN AHMAD \\ SHUKRI WAN ABDUL AZIZ, AINOON OTHMAN
}

Departments of Pathology, Paediatric, and Laboratory Diagnostic Services, UKM Medical Centre, Kuala Lumpur.

School of Distance Education, University Science Malaysia, Pulau Pinang,

Malaysia.

Department of Medical Sciences II, Faculty of Medicine, Universiti Sains Islam

Malaysia, Kuala Lumpur.

Introduction: Glucose-6-phosphate dehydrogenase (G6PD) deficiency is a common hereditary abnormalities in Malaysia. Screening by semi quantitative fluorescent spot test (FST) could miss moderate G6PD deficiency cases. In this study, we evaluated the performance of point of care test (POCT) kit, Carestart Biosensor 1 as a quantitative screening method compared to the conventional OSMMR2000D G6PD assay method. Materials and method: Cord blood samples of 91 neonates and; peripheral blood samples of 63 paediatrics and 62 adults with normal G6PD activity measured by OSMMR2000D G6PD assay method in Haematology Unit, UKMMC were used to evaluate POCT G6PD assay kit; Carestart Biosensor 1 (Combo kit, by accessbio). Additional finger-prick samples from the same adults were also taken. $5 \mu \mathrm{L}$ of blood sample was applied onto the G6PD test strip and $7 \mu \mathrm{L}$ onto the $\mathrm{Hb}$ strip and measurements were done simultaneously on Carestart Biosensor. Results: The normal means for G6PD activity for neonates, paediatrics and adults by Carestarttm Biosensor 1 were 9.3+1.9 U/g Hb, 6.8+2.0 U/g Hb and $6.3+1.0 \mathrm{U} / \mathrm{g} \mathrm{Hb}$ (both venepuncture and finger-prick), respectively. The cut-off points for severe and moderate G6PD deficiency $(10 \%$ and $60 \%$ of normal mean respectively) were calculated from these means. The correlation studies of POCT assay kit with standard routine assay in paediatric samples showed a strong Pearson correlation coefficient; $r=0.789, p \leq 0.005$, and a similar finding was seen with finger prick and venepuncture samples of adults; $r=0.728, p \leq 0.005$. Conclusion: This study showed that G6PD enzyme activities measured by Carestarttm Biosensor 1 kit were comparable to the established method, OSMMR2000D G6PD assay. 


\title{
APPLICATION OF CUSUM IN MALAYSIA'S HEALTHCARE SETTING
}

\author{
MAZLAN HUSAIN, HAFIZ SULAIMAN, CHEW CHENG \\ HOON, FAIZ DAUD, HANIZAH MOHD YUSOFF
}

Department of Community Health, Faculty of Medicine, Universiti Kebangsaan Malaysia Medical Centre, Jalan Yaacob Latif, Bandar Tun Razak, 56000 Cheras, Kuala Lumpur, Malaysia.

Introduction: The data driven Six Sigma approach optimizes the average $(\mu)$ and reduces the variance $(\sigma)$ of a desired process through improvement of projects/ methods. One of these methods is cumulative sums (CUSUM) charts. CUSUM in healthcare is an objective, quantitative methods to monitor the quality of a doctor's performance based on treatment outcome data which distinguish deviations from an acceptable failure rate. The objective is to review applications of CUSUM in Malaysia's healthcare setting. Methodology: A search conducted in April 2017 in MEDLINE, Embase, CENTRAL, gray literature and other sources using keywordss "CUSUM" OR "cumulative sum" AND "health care" AND "Malaysia" to identify the application of CUSUM in Malaysia's healthcare. Results: Nine out of 913 research articles on CUSUM application in Malaysia's healthcare setting including a CUSUM manual published by $\mathrm{MOH}$ were reviewed. eCUSUM, is an online service initiated by DG of Health, Datuk Dr. Noor Hisham, to support quality improvement strategy by individual clinical services. It aims to improve the current quality measurement and reporting by targeted clinical service that is supported by an established patient registry. CUSUM applications are monitoring of operator/ surgeon's performance in cataract surgery, Tenckhoff insertion, renal biopsy, ERCP and thyroid surgery. CUSUM charts are able to monitor trainees' performance, institutional performance in terms of morbidity in a treatment protocol, monitoring patients' performance in clinical tests for the purpose of diagnosing or detecting progression of diseases and operators' or surgeons' self-monitoring. Conclusion: CUSUM analysis is a statistical and graphical tool that can be used to track the success and failure of a technical skill and examines trends over time. It can be used to demonstrate proficiency in a newly learned technical skill or as a measure of quality assurance once a technical skill has been mastered. Supervisors may utilize CUSUM in determining a trainee's competency in a particular skill. 


\title{
COST EFFECTIVENESS MODEL OF SELF-MONITORING BLOOD GLUCOSE (SMBG) AMONG TYPE 2 DIABETES MELLITUS (T2DM) OUTPATIENTS IN A TEACHING HOSPITAL
}

\author{
ANIZA ISMAIL' ${ }^{1}$, LENY SUZANA SUDDIN², SAPERI \\ SULONG $^{3}$, ZAFAR AHMED ${ }^{4}$, NOR AZMI KAMARUDDIN ${ }^{5}$, \\ NORLELA SUKOR ${ }^{5}$ \\ ${ }^{1}$ Department of Community Health, ${ }^{3}$ Department of Health Information, \\ ${ }^{5}$ Department of Medicine, Faculty of Medicine, Universiti Kebangsaan Malaysia \\ Medical Centre, Jalan Yaacob Latif, Bandar Tun Razak, 56000 Cheras, Kuala \\ Lumpur, Malaysia. \\ ${ }^{2}$ Faculty of Medicine, Universiti Teknologi MARA, Sungai Buloh Campus, \\ Jalan Hospital, 47000 Sungai Buloh, Selangor, Malaysia. \\ ${ }^{4}$ Department of Community Medicine and Public Health, Universiti Malaysia \\ Sarawak, Malaysia.
}

Introduction: Type 2 Diabetes Mellitus (T2DM) is a chronic disease that consumes large amount of healthcare resources globally. As part of DMT2 management, self-monitoring of blood glucose (SMBG) is a direct method by which a person with diabetes can be aware of their level of control of blood glucose. Although it is practically impossible to fully separate it from other components of diabetes management, the effective use of SMBG has several potential benefits in both diabetes education and treatment. This study aims to analyze the cost effectiveness of SMBG practice. Methodology: A prospective cross-sectional costing study was conducted in a teaching hospital. Data from a purposive sample of 100 outpatients with T2DM in year 2014 was gathered using costing checklist was analyzed to populate a decision analytical cost model in order to assess SMBG cost effectiveness from patients' perspective. The model was constructed as a decision tree using Bayesian statistics probability principle. Results: In the baseline cost model, total annual costs for patients who did not practice and practicing SMBG were RM 76.80 and RM 609.80 respectively. Incremental cost effectiveness ratio was RM 10,165.20 per QALY for strategy with SMBG practice. The model was most sensitive to changes in the probability value of improved glucose control with SMBG practice. Conclusion: Decision analysis cost model suggests that SMBG practice in outpatients with T2DM was cost-effective and should be advocated in future. 


\title{
COST EFFECTIVENESS OF PSORIASIS TREATMENT MODALITIES IN MALAYSIAN PUBLIC HOSPITALS
}

\author{
ANIZA ISMAIL ${ }^{1}$, NOR AZMANIZA AZIZAM ${ }^{1,2,}$, NORAZIRAH \\ MD NOR ${ }^{3}$, ZAFAR AHMED ${ }^{4}$, SAPERI SULONG ${ }^{5}$
}

${ }^{1}$ Department of Community Health, ${ }^{3}$ Department of Medicine, ${ }^{5}$ Department of Health Information, Faculty of Medicine, Universiti Kebangsaan Malaysia Medical Centre, Jalan Yaacob Latif, Bandar Tun Razak, 56000 Cheras, Kuala Lumpur, Malaysia.

${ }^{2}$ Centre for Management and Administrative Studies, Universiti Teknologi MARA Puncak Alam, Selangor, Malaysia.

${ }^{4}$ Department of Community Health and Public Health, Faculty of Medicine, Universiti Malaysia Sarawak, Sarawak, Malaysia.

Introduction: Introduction of newer and expensive treatments for psoriasis impose economic burden in many perspectives. Little is known about the most cost effective treatment for moderate to severe psoriasis in this region. The aim of this study was to assess cost effectiveness of four different psoriasis treatments. Methodology: A prospective cohort study was conducted in five hospitals involving moderate to severe psoriasis patients. Costs were calculated from societal perspective using the principle of Step Down and Activity Based Costing (ABC). Costs were calculated for 6 months follow-up duration. Effectiveness was measured by $75 \%$ reduction in psoriasis area severity index (PASI-75) and/or body surface area (BSA) $<5$ and/ or dermatology life quality index (DLQI) 5 within 6 months after treatment is initiated. Results: Costs of treating moderate to severe psoriasis was estimated to be RM645,434.73. Medication accounted for almost 90\% (RM457,014.00) of the total provider cost. Meanwhile, loss of productivity represents 84\% (RM167,439.00) of the total patient's cost. Cost per patient per day for inpatient was RM1,005.24 and RM298.02 per patient per visit for outpatient. Biologic plus topical exhibited greatest effectiveness [ 6 out of $10(60 \%)$ ], followed by systemic plus topical (21 out of $40,51.5 \%$ ), phototherapy plus topical (3 out of 9, 33.3\%) and topical (9 out of $32,28 \%$ ). Total cost required to achieved outcome was RM8,481.00 (topical), RM13,771.33 (phototherapy plus topical), RM6,983.95 (systemic plus topical), RM59,096.00 ( biologic plus topical). Conclusion: Although biologic treatment represents highest efficacy but systemic plus topical treatment was the most cost effective for moderate to severe psoriasis in Malaysia settings. 


\section{IMPACT OF KAIZEN IMPLEMENTATION IN UKM MEDICAL CENTRE}

\section{ONG AIK LIANG ${ }^{1,2}$, LAILA ABUSHAAR ${ }^{1}$, HANIZAH MOHD YUSOFF ${ }^{1}$, FAIZ DAUD ${ }^{1}$}

${ }^{1}$ Department of Community Health, ${ }^{2}$ Department of Pharmacy, Faculty of Medicine, Universiti Kebangsaan Malaysia Medical Centre, Jalan Yaacob Latif, Bandar Tun Razak, 56000 Cheras, Kuala Lumpur, Malaysia.

Background: Kaizen is a practice of continuous improvement that improves quality, productivity, safety at the workplace. It engages everybody in identifying problems and emphasis on low cost implementation. This study describes the experience of implementation of Kaizen to reduce wastages and improve efficiency in a pharmacy of a tertiary hospital. Methods: The occurrence of medication error during prescription filling was due to drug names that is look-alike or sound-alike. Drug storage labeling was identified to cause potential medication error. Secondly, to reduce drug wastage, patients were encouraged to return any unused drugs. Promotional initiatives using pamphlets and buntings were designed for public awareness on the importance of returning any unused medicine. Special collection boxes were placed at pharmacy counters to allow patient to return unused medicines. Continuous monitoring was carried out to ensure sustainability of the improvement. Results: All storage labels for drugs were standardized using visual management with font style of "Tall Man" letter and bright-colour to highlight and differentiate drug name. Proper workflow was implemented through creation of standard work procedure and proper documentation. Cases of wrong filling due to look-alike or sound-alike medicines were minimized. Public awareness on returning unused drugs by patients saw a tremendous increase. Total annual drug returned from patients was worth RM421,549.69 in year 2014 and RM534,442.57 in year 2015. The drugs returned were recycled and reused and this directly translates to cost savings. Conclusion: Kaizen tools and concept were successfully implemented as it improves in work efficiency, eliminate wastage and increase values within the Department of Pharmacy in UKM Medical Centre. 


\title{
RELATIONSHIP BETWEEN PERCEPTION ON LEADERSHIP STYLES IN WORKPLACE AND OOCUPATIONAL STRESS AMONG EMPLOYEE
}

\author{
MOHD FADHLI MOHD FAUZI1,3, FADZRUL HAFIZ \\ JOHANI ${ }^{1,3}$, ONG AIK LIANG ${ }^{2,3}$, FAIZ DAUD ${ }^{3}$, HANIZAH \\ MOHD YUSOFF ${ }^{3}$
}

\begin{abstract}
${ }^{1}$ Ministry of Health Malaysia
${ }^{2}$ Department of Pharmacy, ${ }^{3}$ Department of Community Health, Faculty of Medicine, Universiti Kebangsaan Malaysia Medical Centre, Jalan Yaacob Latif, Bandar Tun Razak, 56000 Cheras, Kuala Lumpur, Malaysia.
\end{abstract}

Background: Occupational stress occurs when leadership styles do not meet the capabilities and needs of a worker. It has great impact affecting both employee and organization. Study objective was to determine the prevalence between leadership styles and occupational stress among employee and its relationship. Methodology: Cross-sectional study was carried out through online social media, targeting working adults. A snowball sampling was employed in which the research participants recruited other participants from among their acquaintances. This online survey adopted validated survey questionnaires; 1) Multifactor Leadership Questionnaire (Othman 1994), and 2) Job Stress Level Inventory (Rasudin et al. 2016). Results: There were 447 respondents with mean age of $32.22 \pm 6.28$ years. Majority were female $(57.27 \%)$, Malay $(91.28 \%)$, married $(66.44 \%)$ and with high education qualification (86.80\%). Majority worked in Selangor and Wilayah Persekutuan (53.47\%) and attached to government agencies (59.06\%). Data indicates that perceived transformational and transactional leadership styles practiced by leaders at their workplace are at moderate level with both account for $51.2 \%$ and $81.7 \%$ respectively. Respondents revealed their stress level were at average level of $44.3 \%$. There was a significant relationship with weak negative correlation between transformational leadership style and occupational stress $\left(r^{2}=\right.$ $-0.182, p<0.05)$. As for transactional leadership style, the relationship was significant with a moderate negatively correlated occupational stress $\left(r^{2}=-0.554, p<0.05\right)$. Conclusion: Transactional leadership style showed moderate relationship with occupational stress while transformational leadership style had weak relationship with occupational stress. Employees have less occupational stress in organization whereby leaders' practices prominent transactional leadership style. 
FINANCIAL TSUNAMI AMONG YOUNG ADULTS IN MALAYSIA

\author{
NUR ASHIQIN ABDUL RAHMAN, NUR ADIBAH MAT \\ SARUAN, FAIZ DAUD, HANIZAH MOHD YUSOFF
}

Department of Community Health, Faculty of Medicine, Universiti Kebangsaan Malaysia Medical Centre, Jalan Yaacob Latif, Bandar Tun Razak, 56000 Cheras, Kuala Lumpur, Malaysia.

Financial literacy is the knowledge and understanding of financial concepts and motivation to apply such knowledge to make effective financial decisions. Young adults are the main contributors to the country's economy development. According to Malaysia Insolvency Department, cases of bankruptcy showed an increasing trend from year 2008 (13,855 cases) and 2012 (19,575 cases). Out of these $56.8 \%$ (11,134 cases) were among young adults. Studies have shown that poor financial management among young adults are influenced by easy access to online shopping, instant emotional relieve, peer influence, the need to be in trend, high financial dependency on parents and the desire to own expensive cars and unaffordable homes. Researchers concluded that poor financial management among young adults are mainly due to poor financial literacy. Three components of financial literacy were identified; 1) knowledge, 2) attitude and 3) behavior of financial management. Financial literacy among young adults in Malaysia was still low and this is a major cause of bankruptcy. Preventive measures which can be applied are; parental guidance on money management, awareness on savings for emergency use and retirement age, financial management, education in secondary schools, seeking professional financial advice and self-discipline. Good financial management can be instilled in young adults by using Theory of Planned Behaviour. Poor financial management on the other hand will affect them during the old age when money is needed for medical expenses, post-retirement daily expenses and maintaining all the assets owned. As young adults are the main contributors to the country's economy, preventive measures must be taken to ensure the newer generation of young adults are not entangled with similar financial issues which will further contribute to the rise of bankruptcy in Malaysia. 
Infection Immunity

Poster

TUBO-OVARIAN ABSCESS CAUSED BY STREPTOCOCCUS PNEUMONIAE: A USUAL PATHOGEN AT AN UNUSUAL SITE

\author{
NG BENG KWANG, NAJAH SAHIRAN, MOHD HASHIM \\ OMAR, LIM PEI SHAN \\ Department of Obstetrics and Gynaecology, Faculty of Medicine, Universiti \\ Kebangsaan Malaysia Medical Centre, Jalan Yaacob Latif, Bandar Tun Razak, \\ 56000 Cheras, Kuala Lumpur, Malaysia.
}

Introduction: Female genital tract infection is not uncommon. However, tuboovarian abscess secondary to Streptococcus pneumoniae is extremely rare. Methodology: We report a case of tubo-ovarian abscess caused by Streptococcus pneumoniae. Results: A 46-year-old Para 3 presented with two weeks history of lower abdominal pain and constipation. Assessment showed presence of right adnexal mass and free fluid at Pouch of douglas. Thus, decision was made for diagnostic laparoscopy with working diagnosis of ovarian cyst accident. Intraoperatively, right tubo-ovarian abscess was found. It was drained. Pus was sent for culture and sensitivity, which revealed infection with Streptococcus pneumoniae. Conclusion: This case demonstrated the diagnostic dilemma. Management of such rare infection was revisited. 
Infection Immunity

Poster

CMV ENDOTHELIITIS: THE SUSPICIOUS CULPRIT BEHIND FAILED CORNEAL TRANSPLANTS

\section{NURUL AIN SHAHRUDIN, AIDA ZAIRANI ZAHIDIN, UMI KALTHUM MOHD NOH, WAN HASLINA WAN ABDUL HALIM, NORSHAMSIAH MD DIN}

Faculty of Medicine, Universiti Kebangsaan Malaysia Medical Centre, Jalan Yaacob Latif, Bandar Tun Razak, 56000 Cheras, Kuala Lumpur, Malaysia.

Introduction/Aim: Cytomegalovirus (CMV)-related corneal endotheliitis is an inflammation of the corneal endothelium caused by CMV. It typically presents as coin-shaped keratic precipitates (KPs), with or without corneal edema. These case series highlight the clinical presentation of CMV endotheliiatis and the challenge in diagnosing this condition in recurrent failed penetrating keratoplasty (PK). Methods: Case series Results/discussion: We presented 3 cases of recurrence failure in PK secondary to CMV endotheliitis. Case 1 and 2 were pseudophakic patients, while case 3, patient has previous history of recurrent anterior uveitis. Case 1 underwent PK four times, and case 3 had repeat PK once. Meanwhile, case 2 had endothelial keratoplasty twice before diagnosis of CMV endotheliitis was made, following positive culture of aqueous humour. The visual acuity ranged from $1 / 60$ to hand movement. All patients had pigmented keratic precipitates (KP), and two of them had typical coin-shaped KP. Oral valganciclovir was instituted for all patients consisting of $900 \mathrm{mg}$ bidaily for 2 weeks, followed by $900 \mathrm{mg}$ once daily for 6 months. Additionally, topical ganciclovir eyedrop $0.5 \%$ was given every 4 hourly with dexaminim four times a day. Repeated AC tap after 6 months of treatment was negative for CMV while cases 1 and 2 are still on treatment. Conclusion $\mathrm{CMV}$ endotheliitis is an increasingly important cause of failed PK. We recommend anterior chamber tap in suspicious cases of repeatedly failed corneal transplant, regardless of the presence of coin-shaped KP or not. Minimum treatment with oral valganciclovir is important to eradicate the problem, before proceeding with another corneal transplant. 


\title{
CUTANEOUS MYCOSES CAUSED BY NON-DERMATOPHYTIC FUNGI: DATA FROM UKM MEDICAL CENTRE
}

\author{
CHUAN HUN DING, ASRUL ABDUL WAHAB AND \\ NAJIHAN ABDUL SAMAT MUTTAQILLAH \\ Department of Medical Microbiology \& Immunology, Faculty of Medicine, \\ Universiti Kebangsaan Malaysia Medical Centre, Jalan Yaacob Latif, Bandar Tun \\ Razak, 56000 Cheras, Kuala Lumpur, Malaysia.
}

Introduction: Cutaneous mycoses are infections of the skin and its appendages (i.e. hair and nails) by fungi. Although dermatophytes are often considered the main aetiological agents of cutaneous mycoses, fungi isolated from dermatological specimens can vary both geographically and temporally. Methodology: This retrospective study involved the analysis of culture results from patients diagnosed with cutaneous mycosis from January 2013 to July 2014. For each specimen, direct microscopic examination was performed with $10 \%$ potassium hydroxide. Each specimen was also cultured on Sabouraud dextrose agar, Sabouraud dextrose + chloramphenicol agar and on Mycobiotic agar. All fungi were identified at least to the genus level based on colonial and microscopic morphology. Results: A total of 289 culture results were analysed. Most of the specimens were nail clippings $(50.5 \%)$, followed by skin $(46 \%)$ and hair $(3.5 \%)$. A total of 350 different fungi were cultured from the 289 specimens. From hair, half of the fungi cultured were dermatophytes, followed by yeasts $(30 \%)$ and non-dermatophytic fungi (NDM) (20\%). Skin specimens yielded a much lower proportion of dermatophytes, at only $14.3 \%$. More than half of the fungi cultured from skin were NDMs (55.1\%), followed by yeasts (30.6\%). Lastly, the proportion of dermatophytes from nail clippings was only $4.5 \%$, with NDMs accounting for $59.8 \%$ and yeasts $35.7 \%$. Conclusion: The role of dermatophytes as agents of cutaneous mycoses is declining, especially when onychomycoses are concerned. When designing treatment regimes for cutaneous mycoses, the antifungal agents should have activity against yeasts and NDMs. 


\section{SENSITISATION TO AERO AND FOOD ALLERGENS AND THEIR ASSOCIATION (INCLUDING RISK FACTORS) FOR ALLERGIC DISEASES IN BRUNEI DARUSSALAM IN 2015 AND 2016}

\section{MOHAMAD HAZIQ EMRAN', CHIENG SIEW ENG CHRISTINA ${ }^{2}$, SURITA MOHAMAD TAIB ${ }^{2}$, ANNE CATHERINE CUNNINGHAM ${ }^{1}$}

${ }^{1}$ PAPRSB Institute of Health Sciences, Universiti Brunei Darussalam, Brunei Darussalam.

${ }^{2}$ Raja Isteri Pengiran Anak Saleha Hospital (RIPAS) Hospital, Jalan Putera AlMuhtadee Billah, Bandar Seri Begawan BA1712, Brunei Darussalam.

Introduction: Rising levels of allergy have led to increasing concern of this health issue. Patterns of sensitisation vary depending on location, environment, biological, physical and genetic components. In Southeast Asia, the trend suggests that there is an increase in sensitisation to aeroallergens specifically house dust mite. This research has focused on the recent IgE data specific to aero and food allergensthroughout the population of Brunei Darussalam as well as their association with each other and other influencing factors. Methods: This retrospective cohort study includes all patients who were subjected to blood specific IgE testing from January 2015 to December 2016 in the Department of Laboratory Services, RIPAS hospital, Ministry of Health, Brunei Darussalam. Data collected includes the specific IgE titre, total IgE titre, demographics and patients' histories. Results/Discussion: A total of 223 patients were investigated with 170 patients sensitised to one or more allergens. House dust mite sensitisation was prevalent in this population $(n=113)$. There was a significant correlation between atopic dermatitis and the 5 commonest allergens (d1 D. Pteronyssinus $(P<0.001)$, d2 $D$. farinae $(P<0.001)$, d201 Blomia tropicalis $(P=0.001)$, f13 Peanut $(P<0.001)$ and $\mathrm{f} 24$ Shrimp $(P=0.001))$. Sensitisation towards house dust mite dominated the allergy profile of the country. Total IgE has a very strong significant correlation with specific $\lg \mathrm{E}(P<0.001)$. 


\title{
ANTIBACTERIAL ACTIVITY OF D-ALLOSE RARE SUGAR
}

\section{NURUL MAHFUZAH HASSAN, SITI HANNA MUHARRAM, SUWARNI MD DIAH}

\author{
PAP Rashidah Sa'adatul Bolkiah Institute of Health Sciences, Universiti Brunei \\ Darussalam, Jalan Tungku Link, Brunei Darussalam.
}

Introduction: Natural products are considered as important source of new antibacterial agents. Rare sugars particularly D-allose has been proven to acquire potential medical advantages which include cryoprotective, anti-oxidative, antihypertensive, immunosuppressant, anti-inflammatory, anti-tumour, and anticancer. Recently, D-allose has captured the attention of numerous researchers due to its physiological effects and commercial interest. However, the antibacterial activity of D-allose is still unknown. This novel study aims to investigate the antibacterial activity of D-allose against a clinical isolate of Methicillin-resistant Staphylococcus aureus (MRSA), a control strain of Pseudomonas aeruginosa (ATCC), and both control strain (ATCC 6305) and a clinical isolate (RSP2) of Streptococcus pneumoniae. Methods: Disk diffusion and well diffusion tests were used to investigate the presence of antibacterial activity of D-allose different states (unboiled, boiled, non-fresh, and fresh) against four clinical bacterial strains as stated above. In this study, minimum inhibitory concentration (MIC) was also used to find the lowest concentration $(\mu \mathrm{g} / \mathrm{ml})$ of $\mathrm{D}$-allose that will inhibit the growth of Streptococcus pneumoniae. Determination of the type of D-allose antibacterial activity (bactericidal or bacteriostatic) against the above four clinical bacterial strains were tested using kinetic growth assays. Statistical significance was determined with Mann-Whitney test and Wilcoxon matched-pairs signed rank test by Prism 7 GraphPad Software, Inc. Results: Among the four clinical bacterial strains, there is a significant difference in the zone of inhibition against both ATCC and clinical strains of Streptococcus pneumoniae when compare to penicillin G. Fresh with boiled D-allose has shown a significant difference in antibacterial activity against both ATCC and clinical strains of Streptococcus pneumoniae. Conclusion: D-allose could only act as an antibacterial agent against both control and clinical strains of Streptococcus pneumoniae unlike Methicillin-resistant Staphylococcus aureus (MRSA) and Pseudomonas aeruginosa. 


\title{
NON-TUBERCULOUS MYCOBACTERIA IN EXTRAPULMPNARY TUBERCULOSIS IN AN IMMUNOCOMPETENT PATIENT: A RARE CLINICAL ENTITY
}

\author{
NG BENG KWANG, KEMBANG AZIAH YAKOB, RAHANA \\ ABD RAHMAN, ABDUL KADIR ABDUL KARIM, ANI \\ AMELIA ZAINUDDIN, ZALEHA ABDULLAH MAHDY \\ Department of Obstetrics and Gynaecology, Faculty of Medicine, Universiti \\ Kebangsaan Malaysia Medical Centre, Jalan Yaacob Latif, Bandar Tun Razak, \\ 56000 Cheras, Kuala Lumpur, Malaysia.
}

Introduction: Extrapulmonary tuberculosis is uncommon. Infection with nontuberculous Mycobacterium is even rarer in an immunocompetent patient. Methodology: We report a case of non-tuberculous Mycobacterium in extrapulmonary tuberculosis. Results: A 37-year-old foreign worker Para 3 presented with one-week history of suprapubic pain associated with fever. Assessment showed presence of right adnexal mass. She was treated with intravenous antibiotics with the working diagnosis of tuboovarian abscess. However, as she did not respond to treatment, exploratory laparotomy was performed. Intra-operatively, it was noted that there was a right mature cystic teratoma with slough and cheesy material all over the abdominal cavity as well as ascites. The diagnosis of Nontuberculous Mycobacterium was confirmed with PCR testing on the peritoneal fluid. Conclusion: This case demonstrated the diagnostic dilemma. Management of such rare infection was revisited. 
Infection Immunity

Poster

\title{
TROPICAL PYOMYOSITIS: A CASE REPORT AND LITERATURE REVIEW
}

\author{
ILYAAS ALI-NOOR, ASHRAFF MOHD-ARIFF \\ Department of Orthopedic \& Traumatology, Faculty of Medicine, Universiti \\ Kebangsaan Malaysia Medical Centre, Jalan Yaacob Latif, Bandar Tun Razak, \\ 56000 Cheras, Kuala Lumpur, Malaysia.
}

Tropical pyomyositis is a primary bacterial infection of the skeletal muscles. It is usually misdiagnosed or diagnosed late due to the lack of specific signs, a wide range of differential diagnosis, unfamiliarity with the disease and atypical manifestations. This condition should be considered in healthy or immunocompromised patients with fever, muscle pain, leucocytosis and elevated inflammatory markers. An early CT/MRI is warranted to aid in the diagnosis of this disease. A case of tropical pyomyositis is presented highlighting the challenge in diagnosis. 


\title{
FACTORS AFFECTING MOTHERS' PERCEPTION TOWARDS CHILDREN WITH CLEFT DEFORMITY
}

\author{
MOHD ROHAIZAT HASSAN', MOHD HAFIZ YAHYA ${ }^{2}$, \\ NORMALA BASIRON ${ }^{3}$, ZAIRIZAM ZAKARIA ${ }^{3}$, MOHD \\ RIZAM ABDUL RAHMAN', HAZLINA MOHD MISKAM', \\ SAZMAN WAHAB ${ }^{1}$, NORFAZILAH AHMAD ${ }^{1}$, AZMAWATI \\ MOHAMMED NAWI', NAZARUDIN SAFIAN ${ }^{1}$
}

'Department of Community Health, Faculty of Medicine, Universiti Kebangsaan Malaysia Medical Centre, Jalan Yaacob Latif, Bandar Tun Razak, 56000 Cheras, Kuala Lumpur, Malaysia.

${ }^{2}$ Department of Medical Social Work, ${ }^{3}$ Department of Plastic \& Reconstructive Surgery, Hospital Kuala Lumpur.

Introduction: A study was conducted to determine the level of mothers' perception on children with cleft deformity and its associated factors. Methods: A total of 110 mothers with children attending a Plastic and Reconstructive Surgery Clinic participated in this study. Data was gathered from a guided interview using a questionnaire that assesses the level of perception and its associated factors. The level of perception was evaluated from a scoring and further divided into four domains namely psychosocial, care management, treatment and education. Results: The level of perception is high in all four domains ranged from $62 \%$ for treatment and $80 \%$ for education. Factors that were significantly associated with the level of perception were ethnicity, religion, type of cleft deformity and level of information. Conclusion: Information regarding cleft deformity must be tailored toward personal characteristics and type of cleft deformity to improve mothers' perception on this problem. 


\title{
CONSERVATIVE MANAGEMENT FOR POST-CAESAREAN SECTION BLADDER FLAP HAEMATOMA: A FEASIBLE AND SAFE APPROACH
}

\author{
NG BENG KWANG, RAIMI ZAMRIAH, LIM PEI SHAN, \\ MOHD HASHIM OMAR \\ Department of Obstetrics and Gynaecology, Faculty of Medicine, Universiti \\ Kebangsaan Malaysia Medical Centre, Jalan Yaacob Latif, Bandar Tun Razak, \\ 56000 Cheras, Kuala Lumpur, Malaysia.
}

Introduction: Bladder flap haematoma is a potential complication after closure of visceral peritoneal during caesarean section. Up to date, there was no clear guideline or standardised protocol with regard to the management of such cases. Methodology: We report a case of huge bladder flap haematoma developed after caesarean section and was managed conservatively. Results: A 22-year-old para 1 underwent emergency lower segment caesarean section for fetal distress. The intra-operative course was uneventful and she was discharged well. She presented again two weeks later with fever and lower abdominal pain. Assessment revealed a collection of $8.5 \times 7.7 \times 7.5 \mathrm{~cm}$ anterior to the uterus, between the bladder and lower uterine segment. She was given 2 weeks of antibiotics and the collection gradually decreased in size and resolved at 6 weeks of follow up. Conclusion: This case demonstrated a feasible and safe approach for conservative management of bladder flap haematoma. Management of such cases was reviewed and discussed. 


\title{
ASSOCIATION OF MENTAL HEALTH STATUS AND MARITAL SATISFACTION AMONG THE INFERTILITY WOMEN WITH IN- VITRO FERTILIZATION
}

\author{
ROSNAH SUTAN', SORAYA MOHD TAUFIK', ZAINUL \\ RASHID MOHD. RAZI ${ }^{2}$
}

${ }^{1}$ Department of Community Health, 2'Department of Obstetrics and Gynaecology, Faculty of Medicine, Universiti Kebangsaan Malaysia Medical Centre, Jalan Yaacob Latif, Bandar Tun Razak, 56000 Cheras, Kuala Lumpur, Malaysia.

Psychological reactions to infertility creates troublesome especially to a woman and has been reported related to stress. Varies method of health technologies have been introduced to help women conceived but the success rate is depend on multifactor. The mental health status and the marital satisfaction also deal with the effect of the treatment. In-vitro fertilization is one of the treatments for women who have infertility problem been practiced in UKMMC. A cross-sectional study was conducted to determine the association between the marriage satisfaction and the mental health status among women who undergone in-vitro fertilization's treatment in UKMMC. Randomly recruitment of the 250 respondents from Maternal Assisted Clinic UKMMC was carried out using validated self-administered questionnaire. Marital Satisfaction and General Health Questionnaire-12 were used. Result showed that $81.2 \%$ of the women had moderately poor level of marriage satisfaction and the mental health status was shown poorly in $25.6 \%$ of respondents. Surprisingly, there was no association between marriage satisfaction and mental health status among the women undergoing in vitro fertilization. However, shorter duration of infertility of less than 10 years was significantly associated with poor mental health status $(p=0.038)$. Associating the infertile women who faced poor mental health status with poor marital satisfaction should not be the focus in treatment of fertility assistance. However, effort to help the women with shorter duration of infertility should be the focussed. 


\title{
CASE SERIES INVOLVING OBSTETRICS EXPERIENCES AND OUTCOMES IN CONNECTIVE TISSUE DISEASE PATIENT IN UKMMC
}

\author{
MOHD SHAHRIR MOHAMED SAID, CHEW KAH TEIK, \\ SYAHRUL SAZLIYANA SHAHARIR, EEU JIAN BIN, AHMAD \\ SYAHIR MOHAMED YAZID, NURHASIFAH ABD AZIZ, \\ ANUSIYA A/P CHANDRA, FATIN NADIAH AHMAD YAZID
}

Introduction: The aim of the study was to observe the obstetrics experiences and the outcomes in pregnant autoimmune disease patients. Materials and methods: A retrospective study was done and a total of 58 cases of pregnancy were taken from year 2010-2015 in Universiti Kebangsaan Malaysia Medical Centre (UKMMC). Patients were selected from a list of pregnant women admitted to Patient Admission Centre (PAC) UKMMC diagnosed with CTD and the data was collected from their medical records. Results: Fifty eight pregnancies were observed in 44 women where there were fifty pregnancies $(86.2 \%)$ with SLE, $4(6.9 \%)$ pregnancies with RA and $4(6.9 \%)$ pregnancies with APS. There were $6(10.3 \%)$ pregnancies in active group and $52(89.7 \%)$ pregnancies in remission group. Among the 58 pregnancies, there were $29(50.9 \%)$ birth with no complication, $9(15.5 \%)$ miscarriages, $8(13.8 \%)$ premature babies, $2(3.4 \%)$ stillbirth, $1(1.7 \%)$ intrauterine growth restriction, 1 $(1.7 \%)$ neonatal death and $7(12.1 \%)$ others (pre eclampsia, impending eclampsia, oligohydramnios, chorioamnionitis, persistent urinary tract infection, fetal distress and placenta previa). Rate of live birth is affected by type of CTD $(x 2=6.520, p=0.038)$ and anti double stranded DNA $(x 2=6.157, p=0.021)$. Pregnancy has a significant association with Complement 3 (C3) value $(t=2.003, p=0.05)$. Conclusion: This study showed there is a significant relationship between antidsDNA and type of CTD with pregnancy. C3 value also showed significant changes in pre pregnancy and during pregnancy. 


\title{
PERIPHERALLY INSERTED CENTRAL CATHETER INSERTION USING VEIN-VIEWING DEVICE IN NEONATES: A FIRST TIME SUCCESS
}

\author{
ZAFRI ISMADI MOHD ANIS', SHAREENA ISHAK', ADLI ALI', \\ FAIZ DAUD ${ }^{2}$ \\ ${ }^{1}$ Department of Paediatrics, ${ }^{2}$ Department of Community Health, Faculty of \\ Medicine, Universiti Kebangsaan Malaysia Medical Centre, Jalan Yaacob Latif, \\ Bandar Tun Razak, 56000 Cheras, Kuala Lumpur, Malaysia.
}

Introduction: Peripherally inserted central catheter (PICC) is a standard of care for critically ill neonates. However, its cannulation is technically more challenging in neonates. The aim of this study is to assess whether Accuvein, a near infrared vein-viewing device, is effective in improving first attempt success rate and length of time needed for PICC insertion. Methodology: This is a randomized controlled trial conducted on neonates requiring PICC insertion at a level $3 \mathrm{NICU}$. Prior to randomization, difficult intravenous access (DIVA) score, a clinical prediction rule for first-attempt success, was estimated. A DIVA score of 4 has more than $50 \%$ likely chance of failing the first cannulation attempt. The first-attempt success rates and procedural times between the Accuvein and control group were compared. Results: Sixty patients were enrolled, 30 in each group. The first-attempt success rate was $57.7 \%(n=17)$ in the Accuvein group and $37.7 \%(n=11)$ in the control group. Accuvein group was associated with successful first-attempt success (OR 2.26, 95\%Cl: $0.80-6.36, \mathrm{P}=0.1231$ ). Subgroup analysis of 35 neonates with DIVA score 4 showed a higher first attempt success rate in the Accuvein group (11/17) as compared to control group $(5 / 18)(p=0.028)$. There was no significant difference in procedural time between the two groups (580s vs $414 \mathrm{~s}, \mathrm{p}=0.458$ ). Conclusion: There was no significant difference in procedural time for PICC insertion between the two groups. However, better first attempt success was seen using Accuvein in neonates with difficult veins with a two-fold success. 


\section{PRELIMINARY ASSESSMENT OF PARENTS AWARENESS ON NUTRITION INTAKE AMONG CHILDREN WITH AUTISM IN MALAYSIA}

\section{INDERJIT KAUR, NURUL IZZATY HASSAN, NOOR AKMAL SHAREELA ISMAIL}

School of Chemical Sciences and Food Technology, Faculty of Science and Technology, Universiti Kebangsaan Malaysia.

Department of Biochemistry, Faculty of Medicine, Universiti Kebangsaan Malaysia Medical Centre, Jalan Yaacob Latif, Bandar Tun Razak, 56000 Cheras, Kuala Lumpur, Malaysia.

Background: Appropriate diet and nutrition are vital for children with autism. Many parents with autistic children are not aware of their children's appropriate diet and nutrition. Objective: The aim of this study is to investigate the awareness of nutrition intake among parents with autistic children. Methods: 75 questionnaires has been distributed to children aged 2 to 14 years with Autism Spectrum Disorder (ASD) were included in this nutrition survey. Nutrition intake and the type of dietary supplement given to the children was investigated. Results: Most of the parents agree $(52.7 \%)$ agree that a special diet is needed for autism and $70 \%$ of the parents give their children supplements. The parents had low awareness regarding intake of complex sugar. Awareness regarding casein free food was also found low because most of the parents are unsure about both the casein-free food and whether dairy products should be avoided by their children. The awareness to whether Austim children should be given gluten free food was also found to be low. While almost half of the respondents believed that their children diet have enough nutrients and that junk food should be avoided by their children, a high number of them admitted that they allowed junk food consumption for their children at least once week. This highlights need of a proper and suitable food guidance for parents with autistic children in Malaysia. Conclusion: This study demonstrates ASD parents' awareness on nutrition intake of their children. 


\title{
REPRODUCTIVE HEALTH AND RELIGIOSITY PRACTICE AMONG THE MUSLIM INDONESIAN WOMEN FACTORY WORKERS IN MALAYSIA
}

\author{
PINTA PUDIYANTI SIREGAR ${ }^{1}$, ROSNAH SUTAN' ${ }^{1}$, USMAN \\ JAKFAR ${ }^{2}$, KAMILAH MOHAMMAD AMIR'
}

'Department of Community Health, Faculty of Medicine, Universiti Kebangsaan Malaysia Medical Centre, Jalan Yaacob Latif, Bandar Tun Razak, 56000 Cheras, Kuala Lumpur, Malaysia.

${ }^{2}$ Islamic Sciences, Al Madinah International University, Jalan Tengku Ampuan Zabedah E 9/E, Sekyen 9, 40100 Shah Alam, Malaysia

A cross sectional study was done in a Pre Wedding Seminar held in Cyberjaya, Putrajaya, Malaysia. The study aimed was to examine the relationship between Islamic and reproductive knowledge with reproductive health practice among Indonesian women in Malaysia. The respondents were the migrant workers who work in factories around Kuala Lumpur, Selangor, Negeri Sembilan and Malacca. A validated questionnaire was developed and used to cover the religiosity and reproductive health knowledge and practice. Islamic knowledge was derived from 20 statements that grouped into 3 parts: aqidah, syariah and akhlak. The reproductive health knowledge was gained from 20 statements related to menstrual cycles, reproduction organs, sexually transmitted diseases, and vaginal discharge. The reproductive health practice was assessed using 20 statements related to personal health care and social interaction with opposite sex. There were 182 out of 270 respondents participated in the study. Result showed that $76.9 \%$ were aged between $20-25$ years old, $84.6 \%$ have completed high school, $92.9 \%$ were unmarried and almost all were originally from Central Java. There were $12.6 \%$ had low Islamic knowledge score and low prevalence of healthy reproductive health practice. The mean was $17.3 \pm \mathrm{sd} 2.0$, for Islamic knowledge, means of $11.6 \pm \mathrm{sd}$ 2.0 for reproductive health knowledge and $42.9 \%$ had good reproductive health practice. A significant association was noted between high Islamic knowledge and good reproductive health practice $(p<0.05)$. Islamic and reproductive knowledge is extremely valuable in helping the workers to gain insight to protect themselves and practicing good reproductive health. 


\title{
PATIENT EDUCATION IN A CHILD DEVELOPMENT CENTRE
}

\author{
SAFIAH ATIQAH ADANAN, FAIZ DAUD \\ Department of Community Health, Faculty of Medicine, Universiti Kebangsaan \\ Malaysia Medical Centre, Jalan Yaacob Latif, Bandar Tun Razak, 56000 Cheras, \\ Kuala Lumpur, Malaysia.
}

Introduction: The early years of a child's life are very important for their development. Every child has their own unique developmental progress depending on their own traits, ability and environment. The objective of this study was to identify the patient education practices in a child development centre. Methods: Observation was done during counseling and treatment sessions at the Child Development Centre in UKM Medical Centre. Two sessions were observed involving a behaviour counselor, a pediatrician and parents of patients. Results: Both consultation sessions involved children aged 5-years-old and constituted history taking in an informal manner. The child was assessed based on activities such as drawing shapes, identifying animals, climbing chairs, walking in a straight line and passing softballs. The patient education throughout the session revolve around advice for parents to be more involved in pre-schools activities, playing more with the child and reading books to the child. While both parents complaint lack of time due to work obligation, parental commitment is vital for the development of each child. Suggestions and options were discussed during the sessions. Language was also emphasized during the session as to prepare the child for primary school. The patient and parents benefited from the health education once they provide full participation and become interactive with the healthcare provider. Conclusion: Patient education depends largely on the case of the patient. Overall the education is focused on effective parenting practices as this would have an impact towards the developmental milestone of the child. 


\title{
SOCIAL RESPONSIBILITY: A METHOD TO INJECT HUMANITY BACK INTO MEDICAL SCHOOL TEACHING. A DESCRIPTIVE ANALYSIS
}

\author{
HALIM ISMAIL \\ Department of Community Health, Faculty of Medicine, Universiti Kebangsaan \\ Malaysia Medical Centre, Jalan Yaacob Latif, Bandar Tun Razak, 56000 Cheras, \\ Kuala Lumpur, Malaysia.
}

Introduction: In corporate world, social responsibility activities are gaining recognition as a way to boost a company profile. It is a method of implying that their company is doing well and as such could start contribute back to the community. In medicine, the daily duty of a medical doctor is in the business of healing people therefore medical lecturers would think that there is no reason to teach students about social responsibity despite such activity has already embeded in their teaching activites without them realising it. The aim of this study in to determine whether an activity conducted by a group of students during their medicine and society 3 (MS3) posting had achieved the learning outcome of installing social responsibility among them. Method: A group consist of nine students were instructed to identify a case subject during their community survey to do an indepth interview and home visit and present their finding to their supervisor. The supervisor role is to guide the students on the important elements that they should concentrate upon and suggest intervention activities. At the end of the posting, the students were required to present their case study and be assessed by their supervisor. Results: The students were able to comple their task as instructed and rather than just suggesting the intervention activities as required, they actually end up performing these activities. Conclusion: The activitiy perfomed during the students MS3 posting was able to install social responsibility among the students and help injecting humanity element back into medical school teaching program. 


\title{
DECONSTRUCTIVE MEDIA: WHEN UNETHICAL INFORMATION IS MOST COMMUNICATED
}

\author{
DIYANA MOHD MOKHTAR, WAN ROSMAWATI WAN \\ ISMAIL, FAIZ DAUD
}

\begin{abstract}
Department of Community Health, Faculty of Medicine, Universiti Kebangsaan Malaysia Medical Centre, Jalan Yaacob Latif, Bandar Tun Razak, 56000 Cheras, Kuala Lumpur, Malaysia.
\end{abstract}

Background: Media is a platform that can be used to exchange information. It has tremendously evolved throughout the centuries, in line with the advances of the communication technologies. The usage of media deconstruction is undeniably common as a primary tool in promoting bussinesses worldwide. Unethical deconstructive media occurs when the information conveyed are not true, false claimed purposely to maximize profit disregarding the negative implications that might arise afterwards. Issues: We explore the usage and complications of unethical deconstructive media practices in food products such as Soursop and Cellmax supplement which were made believe to treat cancer; complementary health services such as doula and ozone therapy; cosmetic products such as QuPuteh and Tati Skincare; and bottled water products such as Air Anugerah. Actions by respective authorities were also discussed. These issues were obtained from various social media such as blogs, Facebook, Instagram, WhatsApp and Twitter; and the mass media such as newspapers, television and radio. Strategies: Recommendations to control the unethical practices includes strict enforcement of the Malaysian Code of Advertising Practice 2008 on social media by the Advertising Standards Authority Malaysia (ASA); proper social media monitoring by the Malaysian Communications and Multimedia Commission (MCMC); and aggressive health promotion applying deconstructive media technique by the Ministry of Health. Consumers should take full responsibility to verify the safety of products or devices used, and make necessary reports to assist the authorities. 


\title{
AUTOGRAFT ALLOGRAFT METHOD IN SKELETAL RECONSTRUCTION
}

\author{
RASHID MZ, MOHAMED-HAFLAH NH, KASSIM AYM \\ Department of Orthopaedics \& Traumatology, Faculty of Medicine, Universiti \\ Kebangsaan Malaysia Medical Centre, Jalan Yaacob Latif, Bandar Tun Razak, \\ 56000 Cheras, Kuala Lumpur, Malaysia.
}

Introduction: Large skeletal defect remains a complex entity for orthopedic surgeons. Many advocate usage of distraction ostegenesis via ilizarov method and this requires good surrounding soft tissue. However in a case of oncology-tumor, much of the local soft tissues are removed to provide adequate excision. Ziran et al described the iliotibial-encasing technique as soft tissue support while bone healing takes place. We explore the autograft-allograft method in a case of well diffrentiated chondrosarcoma. Methods: A 30-year-old Malay lady, presented with swelling over dorsal aspect of fourth metacarpal region. Radiograph showed 'popcorn' apperance over distal fourth metacarpal bone. Biopsy was taken revealed as enchondroma and was advised for excision. Intraoperatively, the tumour was removed from cartilage uptil base of metacarpal. The iliotibial band harvested and was put as 'graft bed' over the lumbricals muscle. Tricalcium phosphate was used as scaffold. Two Kirschner wires were inserted in crossed manner. The graft was sutured in tubular manner (Figure 1). Result: During follow up, there were no signs of infection. Her radiograph showed gradual reduction in metacarpal height. At one-year post-operative, bone substitute resorbed entirely, however hand cascade remained favorable. Patient was able to grip despite lesser strength. We attribute this to soft tissue fibrosis of the autograft. In hindsight, usage of tricortical iliac bone graft may stimulate osteogenesis as well as structural support. Conclusion: Autograft-allograft method of ilitibial band swathe technique provides soft tissue envelope for bone graft incorporation. 


\title{
FORENSIC RECONSTRUCTION FROM UNIDENTIFIED SKELETAL REMAINS
}

\author{
FARIDAH MOHD NOR, SRIJIT DAS \\ Faculty of Medicine, Universiti Kebangsaan Malaysia Medical Centre, Jalan \\ Yaacob Latif, Bandar Tun Razak, 56000 Cheras, Kuala Lumpur, Malaysia.
}

Introduction: Skeletal remains were found by a passer-by in a thick bush by a water dam, and a wrist watch was found at the site of recovery. Methodology: Anthropologic analysis and dental charting revealed a female Mongoloid adult person consistent with an estimated dental age between 20 to 40 years. DNA profiling was performed from bone dust, though no comparison could be made as there were no relatives available. Results: The manner and cause of death were unascertained. Conclusion: The case is reported for its rarity, and its unique difficulty in determining the cause of death in skeletal remains. 


\title{
MEDIAN MONONEUROPATHY AMONG HEALTHCARE WORKER - IS IT YOU?
}

\author{
NABILAH OTHMAN ${ }^{1,2}$, RADHIKA SRIDHARAN ${ }^{3}$, \\ AZMAWATI NAWI ${ }^{4}$, FAIZ DAUD ${ }^{4}$, RABANI REMLI ${ }^{2}$, \\ NURSYAZWANA $Z^{2}$, HAMIDAH $\mathrm{H}^{2}$, SITI ZALEHA $\mathrm{S}^{2}$ \\ 'Department of Medicine, Hospital Tuanku Jaafar Seremban, Negeri Sembilan, \\ Malaysia. \\ ${ }^{2}$ Department of Medicine, ${ }^{3}$ Departmentof Radiology, ${ }^{4}$ Department of Community \\ Health, Faculty of Medicine, Universiti Kebangsaan Malaysia Medical Centre, \\ Jalan Yaacob Latif, Bandar Tun Razak, 56000 Cheras, Kuala Lumpur, Malaysia.
}

Introduction: Median mononeuropathy at the wrist is defined as patient with abnormal Nerve Conduction Study (NCS) but asymptomatic of Carpal Tunnel Syndrome (CTS). A quarter of asymptomatic workers with an abnormal median NCS across the wrist will develop symptoms of CTS. The objective was to assess the median mononeuropathy at the wrist among healthcare worker in UKM Medical Centre. Method: Twenty-six healthcare workers in UKM Medical Centre were recruited. All were asymptomatic of CTS in both hands. Thus, a total of 52 hands were assessed. Nerve conduction study was performed on bilateral hands by trained neurology laboratory technician. Data collected were analysed using SPSS. Results: Subjects occupations were hospital attendants (46.2\%), office clerks $(19.2 \%)$, laboratory technicians $(15.4 \%)$, staff nurses $(15.4 \%)$ and doctor $(3.8 \%)$. The mean ages were $41.2 \pm 7.63$ years. Majority were obese with mean BMI of $29.1 \pm 4.66$. A total of 16 hands (30.8\%) were detected to be positive NCS while 36 hands $(69.2 \%)$ were negative NCS. Among the positive NCS $(n=16)$, majority had similar NCS findings as mild CTS $(n=9,56.3 \%)$, moderate CTS $(n=6,37.5 \%)$, and severe CTS $(n=1,6.2 \%)$. Subjects with positive NCS were hospital attendants $(n=11,68.7 \%)$, office clerks $(n=3,18.8 \%)$ and staff nurses $(n=2,12.5 \%)$. Hospital attendant were associated with positive NCS (OR 3.9, 95\%Cl: 1.10-13.68, P=0.0341). Conclusions: Median mononeuropathy at the wrist is prevalent among healthcare staffs especially hospital attendants, in whom the risk of developing CTS is threefold. 


\title{
REPAIR OF THE ANNULAR LIGAMENT IN THE ELBOW USING A SYNTHETIC GRAFT
}

\author{
LEVIN KESU BELANI, MOHD HEZERY HARUN, JAMARI \\ SAPUAN, SHALIMAR ABDULLAH \\ Department of Orthopaedics, Faculty of Medicine, Universiti Kebangsaan \\ Malaysia Medical Centre, Jalan Yaacob Latif, Bandar Tun Razak, 56000 Cheras, \\ Kuala Lumpur, Malaysia.
}

Introduction: Monteggia fracture is commonly treated with an open anatomical reduction and stable fixation of the ulna fracture. The radial head will automatically reduce once anatomical fixation of the ulna is achieved. Methodology: We report a case of a 45-year-old male who was thrown off his motorcycle and landed on his right upper limb, which caused pain and deformity of his right forearm. Radiographs revealed a Monteggia fracture (Bado class II). Reduction and fixation of ulna fracture with DCP was achieved during surgery, but unfortunately the radial head could not be reduced. Post-operative radiographs showed a radio-capitellar dislocation with an anterior displacement of the radial head. Ultrasound confirmed an annular ligament tear. We proceeded with a second surgery. The radio-capitellar joint and radial head was exposed through the Kocher approach. The annular ligament was torn and severely ruptured. We proceeded to reconstruct the annular ligament. In order to prevent donor site morbidity, we decided to use a synthetic graft "Orthotape" together with a bone anchor. Results: The patient was well at 2 months post-surgery with good range of motion of elbow joint as well as forearm pronation and supination. His elbow range of motion was $0^{\circ}$ to $110^{\circ}$ and he was also able to pronate up to $45^{\circ}$ and supinate up to $60^{\circ}$. Conclusion: Reconstruction of annular ligament with combination of synthetic graft (Ortho- tape) and anchor bone suture provide stable fixation with good clinical outcome. 


\title{
THORNS FROM THE PALM-OIL TREE RESULTING IN A MASS IN THE FINGER
}

\author{
KHAIRUL ANWAR, LEVIN KESU BELANI, SHALIMAR \\ ABDULLAH, JAMARI SAPUAN \\ Department of Orthopaedic and Traumatology, Faculty of Medicine, Universiti \\ Kebangsaan Malaysia Medical Centre, Jalan Yaacob Latif, Bandar Tun Razak, \\ 56000 Cheras, Kuala Lumpur, Malaysia.
}

Introduction: Palm oil thorn injury is common in regions where the plant is cultivated. It has a latent period with a pain free and asymptomatic phase until the inflammation phase which could well be months after the initial injury. Methodology: A 41-year-old male presented with a one month swelling over the PIPJ of his right index finger which was increasing in size but did not limit his motion. He had no numbness, fever or constitutional symptoms. Five months prior to presentation, he had a palm-oil thorn pricked into his right index finger. He claimed to have removed the thorn completely. He had no subsequent problems. There was a uniform swelling overlying the proximal interphalangeal joint of the index finger that was soft and not inflammed. Range of motion was full and the patient is able to perform a full grip. Results: Radiographs showed no abnormality. Ultrasound reported tiny $2 \mathrm{~mm}$ echogenic lines with a possibility of a foreign body with inflammatory changes. We excised the swelling under local anaesthesia. The synovial tissue surrounding the joint was hypertrophic with no evidence of infection. Synovectomy was performed and a fine thorn particle was found embedded inside the synovial tissue. Conclusion: A prick by a palm oil thorn is a forgotten injury in the urban setting of countries with palm-oil industries. We need to have a high index of suspicion and the importance of a detailed history to link any possibilities as patients may present late to the hospital months after the initial incident. 


\title{
POST-OPERATIVE PAIN RELIEF MODALITIES IN PATIENTS UNDERGOING TOTAL KNEE ARTHROPLASTY IN HOSPITAL KUALA LUMPUR: AN OBSERVATIONAL STUDY
}

\author{
TAN TSE TSIANG ${ }^{1}$, AZRIN MOHD AZIDIN², ELEANOR \\ FE FEY CHEW ${ }^{2}$, JOANNA OOI SU MIN', MOHD SHAHIR \\ ANUAR ${ }^{1}$, MUHAMMAD MAAYA ${ }^{1}$ \\ 'Faculty of Medicine, Universiti Kebangsaan Malaysia Medical Centre, Jalan \\ Yaacob Latif, Bandar Tun Razak, 56000 Cheras, Kuala Lumpur, Malaysia. \\ ${ }^{2}$ Hospital Kuala Lumpur
}

One hundred and nine patients undergoing unilateral total knee arthroplasty in Hospital Kuala Lumpur were included in this prospective observational study conducted to observe the various post-operative pain relief modalities. The majority of patients (88 subjects, or $80.7 \%$ ) received local anesthetic infusion via a femoral catheter. Eleven subjects $(10.1 \%)$ received intravenous patient-controlled analgesia, whereas 10 subjects (9.2\%) received continuous spinal-epidural analgesia. Pain scores at rest and at movement were taken every 4 hourly for the first 24 hours, and 12-hourly up to 48 hours. In terms of severe pain (score 6) during the study period, there was a single incidence for patients using PCA, three incidences for those on epidural catheter and a total of 22 incidences for the patients who had the femoral nerve catheter block. Even though continuous infusion of local anesthetic via a femoral catheter was the preferred post-operative pain relief modality of choice, there was a high failure rate due to catheter dislodgement $(26.1 \%)$, resulting in severe pain and requiring conversion to other pain relief modalities. The pain scores at 24 and 48 hours post surgery for PCA, epidural infusion and femoral nerve catheter infusion were comparable, and these modalities were found to have provided adequate pain relief after total knee arthroplasty. 


\section{4-WEEKS INTERVENTION OF MOBILE PHONE TEXT MESSAGING (LET'S QUIT!) ON SMOKING CESSATION AMONG UNIVERSITY STUDENTS: A NON RANDOMIZED CONTROLLED TRIAL}

\section{AZMAWATI MN, NURASHIDAH M, CHEN MJ, ALVIN S, NOOR FS}

\section{Department of Community Health, Faculty of Medicine, Universiti Kebangsaan Malaysia Medical Centre, Kuala Lumpur, Malaysia.}

Introduction: There is an increasing prevalence of cigarette smoking among university students. The aim of study was to determine effectiveness between mobile phone text messaging intervention and motivational intervention in increasing quit rate which was biochemically verified at 4 weeks. Methods: A non-randomized control trial $(n=60)$ was conducted among smokers aged between 18-24 years old. Intervention group received mobile phone text message comprising motivational message and tips to quit smoking whereas the control group received informational pamphlet. An evaluation was done by using an assisted administered questionnaire to measure the pre and post outcome of quit rate, timeline follow-back (TLFB) method, Fagerstrom test for nicotine dependence (FTND), and carbon monoxide (CO) level. Results: There were significant decrease in the mean of average cigarette smoked for the past one week (TLFB) in the intervention group compared to the control group $(p=0.027)$ from pre to post intervention assessment. However, there was no significant differences were observed between the 2 groups in terms of quit rate $(p=0.204), F T N D(p=0.880)$ and CO level $(p=0.981)$ outcomes. Conclusion: For shortterm mobile phone text messaging smoking cessation intervention, only reduced TLFB result was significant. Even though this study does not achieve its aim in helping smoker to quit, this intervention still gives a positive outcome. For future research, consistent and longer time period of intervention will able to achieve smoking cessation among university students. 


\section{A CASE OF SYSTEMIC LUPUS ERYTHEMATOSUS (SLE) WITH VISUAL FIELD DEFECT SECONDARY TO HYPERTENSIVE RETINOPATHY}

\section{HOR SHI MEI ${ }^{1}$ NORSHAMSIAH MD DIN ${ }^{1}$ MUSHAWIAHTI MUSTAPHA ${ }^{2}$ HAZLITA MOHD ISA ${ }^{1}$}

${ }^{1}$ Department of Ophthalmology, Faculty of Medicine, Universiti Kebangsaan Malaysia Medical Centre, Jalan Yaacob Latif, Bandar Tun Razak, 56000 Cheras, Kuala Lumpur, Malaysia.

${ }^{2}$ Ophthalmology Clinic, Gleneagles Kuala Lumpur, Block A \& Clock B, 286 \& 288, Jalan Ampang, 50450 Kuala Lumpur, Malaysia.

Introduction: We report a case of SLE with persistent visual field defect secondary to previous hypertensive retinopathy insult which was found during hydroxychloroquine retinopathy screening. Method: A case report Results: A 23-year-old lady presented with both eye progressive painless blurring of vision for two weeks in 2011. Prior to that she had malar rash, hair loss, photosensitivity and bilateral leg swelling. Ocular examination revealed right vision 6/60 and left vision 6/24. Both optic disc were swollen with extensive peripapillary cotton wool spot (CWS), flame shape haemorrhages, dilated and tortuous vessels with macular oedema. Systemic examination revealed blood pressure of $176 / 111 \mathrm{mmHg}$, malar rash and alopecia. Diagnosis of grade 4 hypertensive retinopathy secondary to SLE was made. The diagnosis was confirmed by positive ANA/ dsDNA, low C3/ C4 and renal biopsy showed lupus nephritis. She was treated with oral prednisolone, hydroxychloroquine, cyclosporin A. Throughout the monitoring for hydroxychloroquine toxicity, both eye vision were $6 / 9$, but serial visual field showed non-progressive left superior and inferior scotoma while right eye showed inferior scotoma. The intraocular pressure was normal with pink optic disc and cup disc ratio of 0.3. Optical coherence tomography (OCT) showed temporal and nasal retinal nerve fiber layer thinning bilaterally. However, OCT macular, fundus fluorescein angiography and autofluorescence were normal. The visual field defect was concluded secondary to CWS indicating microinfarction of the retinal nerve fiber secondary to previous hypertensive retinopathy. Conclusion: Non-progressive visual field defects may occur after the appearance of CWS in hypertensive retinopathy and it should not be overlook when diagnosing glaucoma or hydroxychloroquine toxicity. 


\section{AN ADVANCED OLFACTORY NEUROBLASTOMA WITH COMPRESSIVE OPTIC NEUROPATHY}

\section{WAN NI GOH ${ }^{1}$, NORSHAMSIAH MD DIN ${ }^{1}$, MAE-LYNN CATHERINE BASTION' ${ }^{1}$ AND SALINA HUSSAIN ${ }^{2}$}

${ }^{1}$ Department of Ophthalmology, ${ }^{2}$ Department of Otorhinolaryngology, Faculty of Medicine, Universiti Kebangsaan Malaysia Medical Centre, Jalan Yaacob Latif, Bandar Tun Razak, 56000 Cheras, Kuala Lumpur, Malaysia.

Introduction: A case of rapid progressive compressive optic neuropathy in olfactory neuroblastoma $(\mathrm{ONB})$, a rare tumour originating in the olfactory epithelium with wide variety of clinical behaviours. Method: case report Result: A 48-year-old lady was referred from ENT clinic for co-management of orbital involvement in ONB. She presented with 1 week progressive left eye proptosis and diplopia. Her vision 6/6 bilaterally, no significant findings in anterior and posterior segments. Computed tomography (CT) showed tumour extending from nasal cavity to anterior cranial fossa, paranasal sinuses and left medial orbital wall but notwithout involve involving optic nerve. She was diagnosed with ONB Kadish C stage. She underwent transcribiform-transplanum endoscopic excision of the tumour and left orbital decompression. Tumour at the orbital apex was unremoveable. Postoperatively, vision remained good, proptosis and diplopia improved. After 4 weeks, she had epistaxis and worsened left eye proptosis, blurred vision (6/24) and restricted eye movement. Left RAPD was positive with hyperemic optic disc. CT revealed involvement of left optic nerve and optic canal. Emergency bifrontal craniotomy tumour debulking was done, followed by 3 cycles of chemotherapy (Cisplatinum and Etoposide). She defaulted the radiotherapy. Tumor extended to orbital extraconal space bilaterally. She developed left eye severe proptosis with exposure keratopathy and irreversible compressive optic neuropathy (no light perception). Patient deceased 9 months after diagnosis due to advanced ONB. Conclusion: We should aim for complete removal of ONB. Incomplete excision could cause more aggressive clinical course and higher mortality rate. 


\title{
ATYPICAL HLA-B27 ASSOCIATED PANUVEITIS (A CASE REPORT)
}

\author{
WAN NI GOH, MAE-LYNN CATHERINE BASTION, AMIN \\ AHEM, HAZLITA MOHD ISA
}

Department of Ophthalmology, Faculty of Medicine, Universiti Kebangsaan Malaysia Medical Centre, Jalan Yaacob Latif, Bandar Tun Razak, 56000 Cheras, Kuala Lumpur, Malaysia.

Introduction: Human Leukocyte antigen (HLA)-B27 associated uveitis is typically presents as anterior uveitis and up to half already have a diagnosis of ankylosing spondylitis. Treatment of HLA B-27 anterior uveitis is usually topical therapy. We describe a case of HLA-B-27 patient who presented with panuveitis and treated with systemic immunosuppressive. Methodology: Case report Result: A 43 yearold lady who was diagnosed with idiopathic bilateral panuveitis since 2007 under private clinic presented with both eyes redness for 2 weeks and blurring right vision for a month. Clinical features were suggested of relapse of idiopathic panuveitis. There were no systemic complaints. Patient recovered within a month after being treated with oral prednisolone, mycophenolate mofetil and increased dose of topical prednisolone acetate. Unfortunately she had frequent recurrences, progressively worsening inflammation over the year, particularly right eye. She developed complication of right eye vitritis, vasculitis and high intraocular pressure. Further investigation confirmed that she was HLA-B27 posititve and excluded the infective and other causes. Oral methotrexate $10 \mathrm{mg}$ weekly and folinic acid $15 \mathrm{mg}$ daily were added. She was referred to rheumatologist for co-management. Her symptoms improved and vision remained good. Conclusion: HLA B27 immunotyping is useful in cases of idiopathic panuveitis that have frequent recurrences and relapse and patients may have no systemic symptoms at presentation to the ophthalmologist. In cases of relapsing HLA B27 panuveitis a lower threshold in initiating systemic and combined immunosuppressant therapy is needed. Treatment with this combination is effective in maintaining good vision. 


\title{
ATYPICAL PRESENTATION OF PIGMENTED PARAVENOUS RETINOCHOROIDAL ATROPHY
}

\author{
FATIN HANISAH FIRMAN', HAZLITA DATO' MOHD ISA², \\ JEMAIMA CHE HAMZAH ${ }^{3}$ \\ 'Ophthalmology Discipline, Faculty of Medicine UiTM \\ ${ }^{2}$ Gleneagles Kuala Lumpur \\ ${ }^{3}$ Department of Ophthalmology, Faculty of Medicine, Universiti Kebangsaan \\ Malaysia Medical Centre, Jalan Yaacob Latif, Bandar Tun Razak, 56000 Cheras, \\ Kuala Lumpur, Malaysia.
}

Introduction: To describe a unique case of pigmented paravenous retinochoroidal atrophy with vasculitis and exudative retinal detachment Methods: A Case Report Discussion: A healthy 28-year-old Malay male, with no family history of ocular disorders, was found to have hyperpigmentation over terminal retinal vascular arcades bilaterally and provisionally diagnosed with atypical retinitis pigmentosa, corresponded by electroretinogram. He presented a year later with left eye blurring of vision, mild anterior segment inflammation and exudative retinal detachment involving the inferior temporal arcade. Fundus fluorescein angiography showed hypofluorescence at terminal vessels with vasculitic changes. He was started on oral Prednisolone but had worsening inflammation and retinal detachment. Upon literature review, we found a rare case in Bangalore, India of pigmented paravenous retinochoroidal atrophy (PPRCA) with vasculitis in which the patient responded favourably to anti-TB. Commencement of antitubercular medication caused initial improvement but he then worsened and was on oral Azathioprine. Subsequently, he developed cystoid macula oedema, treated with intravitreal Ranibizumab. Infective parameters and vasculitic study came back negative. Upon further discussion, anti-TB was stopped and oral Valganciclovir and ointment Aciclovir started as his exudative retinal detachment is thought to be secondary to viral cause, which showed slow improvement. However, we faced issues with treatment compliance and increased intraocular pressure secondary to topical steroids. This case is unique as there are no cases of PPRCA with vasculitis and exudative retinal detachment yet to be reported in literature and many facets of management of this case has been challenging. 
Non Communicable Disease

Poster

\title{
DEEP IN THE CORNEA - UNDERSTANDING THE PHYSICS BEHIND DEEP CORNEAL INJURIES
}

\author{
ANDREA BARR K, MUSHAWIATI MUSTAPHA, UMI \\ KALTHUM \\ Department of Ophthalmology, Faculty of Medicine, Universiti Kebangsaan \\ Malaysia Medical Centre, Jalan Yaacob Latif, Bandar Tun Razak, 56000 Cheras, \\ Kuala Lumpur, Malaysia.
}

\begin{abstract}
Aim: To highlight various ways of intrastromal corneal foreign bodies (FB) presentation and to discuss the physics of corneal FB injury. Method: Case report Results: CASE 1: A 27 year old gentleman, presented with left eye (LE) pain and photophobia for one month, which gradually worsened. He gave history of a metal nail piece entering his LE one month ago, while hammering. Visual acuity in LE was 6/12, 6/9 and right eye (RE) was perfect. The LE was white on examination and showed a metal piece measuring $1.8 \mathrm{~mm}$, embedded in the posterior layer of the cornea, away from the pupil. Anterior segment optical coherence tomography showed near full thickness penetration of the FB. The FB was removed in the operation theatre. CASE 2: A 37 year old man had a metal brush wire enter his RE while at work. His friend pulled out the metal wire, but patient still had persistent RE pain and redness. He presented 1 day later. Visual acuity was 6/9, 6/6 bilaterally. RE was injected with an intrastromal metal FB situated at the superior margin of the pupil, measuring $1 \mathrm{~mm}$. There was no full thickness penetration of the cornea. Anterior chamber showed mild inflammatory reaction. The FB was removed intraoperatively and corneal wound was sutured. We will be discussing on the physics of corneal FB penetration. Conclusion: Corneal foreign bodies present in various ways. The mechanism and impact of injury is important in determining management and prognosis of the injury to the eye.
\end{abstract}




\section{FALSE LOCALISING SIGN}

\section{LING TEIK JUNE, HANISAH ABDUL HAMID, AMIN AHEM}

Department of Ophthalmology, Faculty of Medicine, Universiti Kebangsaan Malaysia Medical Centre, Jalan Yaacob Latif, Bandar Tun Razak, 56000 Cheras, Kuala Lumpur, Malaysia.

Introduction: Idiopathic intracranial hypertension is a disorder of raised intracranial pressure without any evidence of infection, vascular abnormality, space-occupying lesion, hydrocephalus or alteration of consciousness. Objective: To report a case of idiopathic intracranial hypertension presented with bilateral sixth cranial nerve palsies. Methodology: Case report. Results: A 17 years old Malay girl, who has underlying eczema, allergic rhinitis and obesity presented with headache for the past 2 weeks and associated with binocular horizontal diplopia for 1 week prior to presentation. She denied history of trauma, nausea, vomiting, blurring of vision, oral contraceptive pill usage or steroid intake. Upon initial assessment, he visual acuity was 6/18 in the right eye (OD) and 6/9 in the left eye (OS). Relative afferent pupillary defect was absent. Anterior segment examination was unremarkable bilaterally. Fundus revealed bilateral optic discs swelling with tortuous and dilated vessels. There was evidence of bilateral sixth cranial nerves involvement as evidenced by presence of diplopia at all gazes and limitation in abduction of bilateral eyes. Other cranial nerves and neurological assessment were normal. Perimetry showed bilateral enlargement of blind spots. A computed tomography (CT) scan of the brain was ordered immediately and showed normal findings. Lumbar puncture was performed and the opening pressure was 52cmCSF. Cerebrospinal fluid was sent for analysis and all the results were normal. She was treated as idiopathic intracranial hypertension and started on oral acetazolamide 250mg twice daily and advised on lifestyle modification. Conclusion: Bilateral sixth cranial nerve palsies may be the early manifestation of idiopathic intracranial hypertension. 
Non Communicable Disease

\title{
OPTIC NEURITIS IN MULTIPLE SCLEROSIS - HOW ATYPICAL IT CAN BE
}

\author{
SYAMIL SALMI, RONA A NASARUDDIN, JEMAIMA CHE \\ HAMZAH \\ Department of Ophthalmology, Faculty of Medicine, Universiti Kebangsaan \\ Malaysia Medical Centre, Jalan Yaacob Latif, Bandar Tun Razak, 56000 Cheras, \\ Kuala Lumpur, Malaysia.
}

Introduction: To report a newly diagnosed case of multiple sclerosis (MS) in a patient presenting with atypical optic neuritis. Method: Case report Results: A 54-year-old man with underlying diabetes mellitus and hypertension presented with a subacute, painless and progressive visual loss in the left eye. Examination revealed a visual acuity of 6/6 and no light perception in the right \& left eye, respectively. Relative afferent pupillary defect was present in the left eye and funduscopy did not reveal any papillitis. Visual evoked potential demonstrated increased latency and reduced amplitude of P100 in the left eye. Systemically, he was asymptomatic. Magnetic resonance imaging of the brain and orbit revealed multiple white matter lesions involving the corpus callosum, pericallosal, periventricular and juxtacortical regions with left optic nerve enhancement. Presence of cerebrospinal fluid oligoclonal bands further supported the diagnosis of MS. He was commenced on intravenous methylprednisolone, followed by oral prednisolone as recommended by the Optic Neuritis Treatment Trial. He was also initiated on interferon beta-1. Currently, his vision is count fingers at 1 foot. Conclusion: This case highlights that MS should be entertained as one of the differential diagnoses for atypical optic neuritis, even though our patient did not fit neatly into the characteristic MS demographics. Prompt systemic treatment is beneficial in terms of limiting physical disability and preserving the quality of life, in an otherwise poor prognosis clinical condition. 
Non Communicable Disease

\title{
VARDENAFIL-INDUCED NON-ARTERITIC ISCHAEMIC OPTIC NEUROPATHY
}

\author{
ALIYYA BADARUDDIN, MIMIWATI ZAHARI, MAY MAY \\ $\mathrm{CHOO}$ \\ Department of Ophthalmology, University of Malaya Medical Centre, Kuala \\ Lumpur.
}

Objective: To describe a case of vardenafil-induced non-arteritic anterior ischemic optic neuropathy (NAION). Introduction: Vardenafil (Levitra) is a selective inhibitor of phosphodiasterase- 5 used in the treatment of erectile dysfunction. Vardenafil has been linked to NAION, the most common cause of acute optic nerve injury in individuals over the age of 50. Method: A case report. Results: A 58-year-old gentleman with no known co-morbidities presented to us complaining of left eye (LE) inferior hemifield defect for 1 week. It was painless, sudden in onset, and non-progressive. It was preceded by the patient taking vardenafil. LE examination demonstrated that vision was 6/12, 6/9. Relative afferent pupillary defect was positive. Red desaturation and light brightness were $60 \%$. The anterior segment was unremarkable. The left eye fundus showed hyperemic superior half of the optic disc with pale temporal margin and tortuous vein superotemporally. Cup-disc-ratio was 0.1. CT brain did not show evidence of acute stroke. His total cholesterol and low density lipoprotein levels were raised. The patient was started on aspirin and a statin. MRI/MRA and Color vision D-15 test were normal. He was advised to stop taking vardenafil. Five months later, his visual acuity and visual field test remain the same. Red desaturation and light brightness have improved to $80 \%$. The optic disc margin remains blurred superiorly. Conclusion: Vardenafil is a possible causative factor for NAION. However, the dosage and duration of treatment with vardenafil linked to the development of NAION remain unknown. 


\title{
CONCEPTUAL FRAMEWORK IN EMPOWERING ADOLESCENT KNOWLEDGE ON ONE HEALTH USING 'TEEN'S HEALTH IN A HEALTHY WAY"PACKAGE.
}

\author{
ROSNAH SUTAN', GUNASEELAN GURUSETHAN', \\ HAMENUDIN HAMZAH', IDA DALINA NOORDIN', \\ MASSITAH MIHAT ${ }^{1}$, NORAZILAH JAMIL', SULIANA SHUIB ${ }^{1}$ \\ ${ }^{1}$ Department of Community Health, Faculty of Medicine, Universiti Kebangsaan \\ Malaysia Medical Centre, Jalan Yaacob Latif, Bandar Tun Razak, 56000 Cheras, \\ Kuala Lumpur, Malaysia.
}

Worldwide, humans are implicated by health problems attributed by unhealthy environments and diseases spread from animals. The concept of One Health emphasizes on human behaviour and interaction with animals and the surrounding environment as the triad of infectious disease development. Adolescent group is well known as active and eager to adventure in new knowledge. The adolescent is the best targeted as potential messenger to enhance population on One Health disease prevention. The 'Teen's Health in a Healthy Way' is an intervention package which has been developed after a thorough synthesizing evidence-based related to One health diseases and approaches in public prevention. The process of developingthe intervention package covered 3 stages: plotting consequences, gaps and causes in a problem tree analysis, constructing and developingthe initial packageand consultations with experts for consensus. The package was tested among the 12-13 years old teenager of Form 1 secondary schools in Mukim Beranang, Selangor. Awareness and knowledge related to One Health diseases focusing on disease presentations, causative agents, routes of transmission, treatment and disease prevention practiceswere tested using self-administered pre- and post-questionnaires. Three components were identified for the package intervention developmentnamely interactive talks, skill-enhancing activities like handwashing demonstration and gamese.g.dart, word search, jigsaw puzzle. A total of 84 teenagers were recruited in the program that lasted for 1 hour with direct observation by their teachers.The mean pre-test knowledge's score was $13.58 \pm 2.48$ and it improved to $17.88 \pm 1.96$ which showed significantly increasing adolescent's knowledge on One Health. In conclusion, adolescent group can be used as an agent to disseminate information to their school colleagues using interactive gaming method like 'Teen's Health in a Healthy Way' package. 


\title{
AMBASSADOR OF DARKNESS: DEPRESSION IN YOUNG ADULTS
}

\author{
MOHD SHAFIK ABDUL MAJID, MUHAMMAD HANEEF \\ AZME, FAIZ DAUD, HANIZAH MOHD YUSOFF \\ Department of Community Health, Faculty of Medicine, Universiti Kebangsaan \\ Malaysia Medical Centre, Jalan Yaacob Latif, Bandar Tun Razak, 56000 Cheras, \\ Kuala Lumpur, Malaysia.
}

Background: The lifetime prevalence of having depression among adults in most countries is between $8 \%$ and $12 \%$ (Kessler,2003). Studies involving primary care patients exhibited a lifetime prevalence of depression in Malaysia ranges between $6.7 \%$ to $14.4 \%$. The World Health Organization has ranked depression as the 4 th leading cause for disability worldwide and it is projected that depression will rise to 2 nd ranking by 2020 . The lifetime risk of suicide among patients with untreated depression ranges from $2.2 \%$ to $15 \%$ (Friedman, 2007). Method: A review which includes journals regarding depression among young, news articles discussing depression which were written by experts (psychiatrists and psychologists), websites of support groups or self-help groups which convey assistance for depression or effective parenting skills, newspapers clips and Facebook/social media postings by young Malaysians right before they commit suicide. This review was done with the intention to identify the causes and risk factors of depression among young Malaysians, its impact to our society and ways to strategies in dealing with the problem. Result: Depression is increasingly more prevalent in Malaysia among the young adults due to stressors such as stressful working conditions, the increase in cost-of-living, the "sandwiched-generation" phenomenon and the negative influence of social media. Having poor coping mechanism and communication skills are significant risk factors for having depression. Depression is highly linked to suicide. The loss of the young life to suicide, coupled with the loss of effective workdays among the young adult workers due to depression lead to economic consequences. It is estimated in the United States (US) that employers loose a total of between 17 to 44 billion US dollars annually due to depression. There is a lack of study regarding the economic impact of depression locally. In Malaysia, the symptoms of people with depression often go unnoticed and untreated, due to lack of awareness or denial among the public. Less than half of diagnosed patient received sufficient treatment, even though effective treatments were available. Conclusion: Depression is becoming more common and prominent among young adults. Efforts to increase the awareness of depression among the general public will hopefully lead to earlier intervention, better prognosis, increased productivity and reduce the risk of suicide among young Malaysians. Good communication skills and good coping mechanism must also be trained and promoted among Malaysians to reduce the likelihood of depression. 
Social Medicine

Poster

\title{
LIVING IN GLUTTONY: PANDEMIC OF BEAUTIFICATION
}

\author{
AZNIDA ZAKI, SAFIAH ATIQAH ADANAN, ZURAIDAH \\ ZAIDUN, FAIZ DAUD
}

Department of Community Health, Faculty of Medicine, Universiti Kebangsaan Malaysia Medical Centre, Jalan Yaacob Latif, Bandar Tun Razak, 56000 Cheras, Kuala Lumpur, Malaysia.

Beauty in things exists merely in the mind which contemplates them. Definition of beauty depends on individual's perception based on his or her experience, society and time. Nowadays, people are trying to appear as beautiful as per their own definition by using beauty products such as whitening creams, supplements and even invasive procedure such as Botox injection. It takes a lot of efforts to become as gorgeous as the models and celebrities. Individual are willing to invest money to become beautiful however, at the same time, jeopardizing health and life for that sake. Social media, peer pressure, and consumer's ignorance are among the major factors contributing to this phenomenon. Meanwhile social media has led consumer to choose incorrectly. Peer and society also put a lot of pressure on individuals to look good in everyone's eyes. Ignorance regarding side effects of products or procedures is the main problem of individuals making the wrong choice. Several solutions proposed to overcome this gluttony includes; 1) Enforcing the existing law to minimize harm to consumers; 2) Establishing a social media intervention team to monitor social media and also to utilize it to promote healthy behaviour; 3) Encouraging a good personality among community through the promotion of healthy behaviour as well as nurturing a good moral and personality in children. Seeking beauty is the right of every individual, thus consumer need to have a good knowledge on the product they choose. It is also important for us to provide a secure platform for them to seek the beauty they want. 


\title{
INORDINATE AMUSEMENT: THE WORLD OF FANTASIA
}

\author{
ABDUL RAHMAN RAMDZAN, AMMAR AMSYAR, FAIZ \\ DAUD
}

Department of Community Health, Faculty of Medicine, Universiti Kebangsaan Malaysia Medical Centre, Jalan Yaacob Latif, Bandar Tun Razak, 56000 Cheras, Kuala Lumpur, Malaysia.

Introduction: Lesbian, gay, bisexual and transgender or LGBT has now becomea growing trend globally and Malaysia is not exempted. Issues and trends: In Western countries, LGBT is recognized for their rights like other civilians. Efforts to legalize same-sex marriage by law and constitution are in full swing. In England, married gay couples continuously advocate recognition of their marriage by law. Locally, COMANGO or Non-Governmental Organizations Coalition Malaysia had submitted a number of demands urging Malaysia to recognize the rights of sexual orientations and gender identity. Sexuality Merdeka is an annual event held in Kuala Lumpur promoting sexuality rights. Unlawful gay clubs and spas have been operating secretly in Malaysia due to erroneous demand. Factors: A person's tendency toward LGBT can be influenced by psychosocial and environmental factors. Having a dysfunctional family, history of sexual abuse and early exposure to homosexual activity were associated with LGBT tendency. Increasing trend of LGBT nowadays is contributed by normalization of LGBT culture and increase accessibility to internet among youngsters, whom drive by their adventurous nature and lack of guidance from parents. Impacts: LGBT practices can affect self, society and nation. Homosexuals have an average 25-years shorter life expectancy than heterosexual. Infectious disease such as HIV and Hepatitis B transmission may pose a threat to public health. Nation will loss productivity and population dynamic will be affected due to decreasing heterosexual marriage and future offspring. Strategies: LGBT groups should be approached and its trend should be addressed effectively so that its negative consequences can be curbed. Settings like l'laj Home and Pink Triangle are good efforts to reach out to these people. Religious and educational institutions need to create awareness and provide the correct understanding of this uprising culture. Government should reinforce the law restricting events that promote this trend such as Sexuality Merdeka, LGBT social networking sites and books related to LGBT. Strong family institution is most crucial to save our future generation from being influenced by these sexual disorientations. Conclusion: LGBT movementare fast encroaching into the Malaysian society. Thus various parties should pull efforts together in dealing with this predicament and hindering its normalization within our beloved country. 


\title{
SLANDEROUS PHENOMENA: THE MODERN CANNIBALISM
}

\author{
NUR EZDIANI MOHAMED, SITI DIYANA IBRAHIM, FAIZ \\ DAUD
}

\begin{abstract}
Department of Community Health, Faculty of Medicine, Universiti Kebangsaan Malaysia Medical Centre, Jalan Yaacob Latif, Bandar Tun Razak, 56000 Cheras, Kuala Lumpur, Malaysia.
\end{abstract}

Issue/Problem: Defamation is any statement made either verbally or in written form that can harm another person's reputation or character. In Malaysia, the first lawsuit of defamation was won by the CEO of Berjaya Group, where else, in the Ministry of Health Malaysia $(\mathrm{MOH})$, the most famous case happened in 2016 involving a doctor who filed a lawsuit against a husband and wife. The slander does not only affect doctor, but also the other medical fraternity such as assistant medical officer and nurses. Slanders involved a wide range of aspects, from services or treatment given to matters within $\mathrm{MOH}$ jurisdiction such as spreading lie and news on fake medication. Analysis of circular produced by the Director General of Health in his official blog from October 2016 until February 2017 revealed around10\% of circular each month werereleased in response to viral-related issues or libel. For example the circulation of story on fake rice which indirectly will affect reputation of $\mathrm{MOH}$ as the regulator on food safety. Strategies: This study looks into strategies done or could be exercised from individual to the country level in order to overcome defamationregarding $\mathrm{MOH}$. At the individual level, one can exercise 'SO POS'. This involved referring back to the listed source and critically judge the value and content $(\mathrm{S})$, going back to official source for confirmation $(\mathrm{O})$, referring to the prime media instead of following on social media $(\mathrm{P})$, wait for official statement from the authorised person/body (O) and stop from spreading libel (S). At the ministrial level, official and unofficial route were provided to stop libel. For example, every health institution or state health department are encouraged to have their own web page as well as Facebook page. These will include a route called (customer feedback) which will allow any report to be channeled directly to the relevant authority. Unofficial Facebook page/group, tweeter and blog were developed to help in clarifying any libel/slander in a systematic and evidence-based manner. At the country level, there are acts that govern defamation issues such as Akta Fitnah 1957, Akta Hasutan 1948 (pindaan 1971), Kanun Keseksaan (Akta 574) and Akta Komunikasi dan Multimedia 1998. Recently, a new website sebenarnya.my was launched at the country level to counter and provide the true story of any libel. The impact of defamation could be positive as it may strengthen the bond within the medical fraternity. However, there are many more negative affects causing individual psychological disturbances and diminishing credibility of an organization. 
Social Medicine

Poster

\title{
NUTRITIONAL STATUS OF UNDER FIVE YEARS OLD INDIGENOUS CHILDREN LIVING IN LAKE CHINI AND ITS ASSOCIATION WITH SOCIAL DETERMINANT FACTORS
}

\author{
ZALEHA MD ISA, NORHASYIMAH JUMA'A \\ Department of Community Health, Faculty of Medicine, Universiti Kebangsaan \\ Malaysia Medical Centre, Jalan Yaacob Latif, Bandar Tun Razak, 56000 Cheras, \\ Kuala Lumpur, Malaysia.
}

Introduction: Nutritional status is an important aspect of one's life. Someone with adequate nutrient will have a good status of health. Undernutrition leads to long-term effect and may increase child mortality rate worldwide. This situation is associated with risk factors including social determinant factors such as demography, economy, knowledge on food intake, behavior, attitude, and food taboos. The aim of this study was to identify social determinant factors influencing nutritional status of under five years old indigenous children in Lake Chini, Pahang. Methodology: A cross-sectional study was conducted among 90 children in three Orang Asli villages in Lake Chini, Pahang. Questionnaire, Seca height instrument and Tanita body composition analyzer were used to collect data. Results: A total of $48.9 \%$ children under five in Lake Chini were underweight and the prevalence was higher among boys. In the analysis of association between social determinant factors and nutritional status, mother's attitude domain showed a significant association with children's nutritional status, in which children's underweight status was associated with negative attitude of mothers on child food intake $\left(X^{2}=7.464, p\right.$ $=0.024)$. Conclusion: The prevalence of underweight was high among Lake Chini indigenous children and it was influenced by their mother's attitude. Therefore, mothers in Lake Chini should be given specific education to improve their attitude towards their child's nutrition. 
Social Medicine

Poster

\title{
UNHEALTHY CULTURE: EXTREME SOCIALIZATION, SCAPING IN SELFIE SYNDROME
}

\author{
RAUDAH ABD RAHMAN, RENUGA DEVI KANABALAN, \\ FAIZ DAUD
}

\begin{abstract}
Department of Community Health, Faculty of Medicine, Universiti Kebangsaan Malaysia Medical Centre, Jalan Yaacob Latif, Bandar Tun Razak, 56000 Cheras, Kuala Lumpur, Malaysia.
\end{abstract}

This century, the global population are witnessing dramatic change in culture and socialization. Culture is defined as all the behaviours, ways of life, arts, beliefs and institution of a population that are passed down from generation to generation. Socialization is a term used by sociologists and anthropologists, to refer to the process of inheriting and disseminating norms, customs, and ideologies. A breech from the norm of culture and socialization produces an outcome known as extreme socialization. The current trend is the selfie addiction or Selfie Syndrome. Oxford dictionary defined selfie as "A photograph that one has taken of oneself, typically one taken with a Smartphone or webcam and shared via social media". Before the rise of this concept, the thought of taking self-portraits existed among people using self-timers on the cameras. The Selfie syndrome is reported to be related with narcissism, a body dysmorphic disorder and obsessive compulsive disorder. Extreme narcissistic personality disorder due to addiction to Selfie leads to involvement in preoccupation with self and how one is perceived by others. Narcissists pursue gratification from vanity and the admiration of their own physical and intellectual attributes. Hence extreme selfie phenomenon derives from the desire in exploring and compete with trendy selfies which many of them endanger and track out the culture. To tackle this mushrooming culture, it is important to set solution such as providing proper introduce a healthy way using social media, moral education by parents and teachers on appearance, behavioural counselling on self-motivation and self-control of unnecessary use of social media. Spending quality time with family and friends, regular recreational activities and cognitive behavioural therapy are several methods to curb the Selfie Syndrome. 
Social Medicine

Poster

\title{
SOCIAL, EMOTIONAL AND FAMILY LONELINESS AMONG THE ELDERLY IN PONTIAN DISTRICT, JOHOR
}

\author{
SHAMSUDIN K' ${ }^{1}$ HUSSEIN SZ ${ }^{2}$ \\ ${ }^{1}$ Community Health Department, ${ }^{2}$ Nursing Department, Faculty of Medicine, \\ Universiti Kebangsaan Malaysia Medical Centre, Jalan Yaacob Latif, Bandar Tun \\ Razak, 56000 Cheras, Kuala Lumpur, Malaysia.
}

Introduction: Loneliness is a widespread problem that is often not diagnosed and frequently under-treated especially in elderly even though numerous studies have been documented loneliness has significant impact on the quality of life. Aims: The aim of this study was to identify the prevalence of social, emotional and family loneliness among the elderly as well as to examine the relationship of any kind of the loneliness with socio-demographic characteristics. Method: This study is a cross-sectional community survey and the study sample consists of 414 elderly in Pontian District Johore Malaysia. Loneliness was measured using the short-form Social and Emotional Loneliness Scale for Adults (SELSA-S). Results/Discussion: The results revealed $39.9 \%$ of respondents experienced emotional loneliness, $34.7 \%$ experienced social loneliness and $9 \%$ experienced family loneliness. This outcomes of this study had contributed the existing knowledge regarding loneliness that can be used in prevention strategies of loneliness that help the elderly aging to adapt to life at the end of the age. 


\title{
DILEMMA IN OPTIC NERVE GLIOMA: TO TREAT OR NOT TO TREAT?
}

\author{
BIN HOO TEO', SAFINAZ MOHD KHIALDIN', MALISA \\ AMI', LOH C-KHAI ${ }^{2}$ \\ ${ }^{1}$ Department of Ophthalmology, ${ }^{2}$ Department of Paediatrics, Faculty of Medicine, \\ Universiti Kebangsaan Malaysia Medical Centre, Jalan Yaacob Latif, Bandar Tun \\ Razak, 56000 Cheras, Kuala Lumpur, Malaysia.
}

Introduction: Optic pathway glioma (ONG) may arise in any part of the visual pathway, including the optic nerve. It comprises approximately 3-5\% of childhood tumours and commonly involve patients in their first decade of life. Method: Case report Case report: A 13 years old girl with underlying myopia, presented with painless unilateral blurring of vision for the past 1 month. Her best corrected visual acuity was right eye (RE) 6/7.5 and left eye (LE) 6/60. On examination, there was proptosis of the LE associated with left abnormal optic nerve function. The left optic disc was swollen with optociliary shunt. The diagnosis of left optic nerve glioma was made with the aid of radiological imaging. The choices of management include conservative observation, chemotherapy, radiotherapy or surgical debulking. Each of the treatment option was weighed between the benefits and consequences. The timing of initiation of treatment was also an important consideration in view of the benign, slow growing and self-limiting manner of this condition, close monitoring with regular imaging was opted for this patient. Conclusion: The timing and treatment modalities for optic nerve glioma are highly controversial. The management should be individualised with case-to-case basis. We reported a case of Optic Nerve Glioma and discussed the treatment dilemma in this case based on the current evidences available. 


\title{
EFFECTS OF PLATINUM NANOPARTICLES IN HYDROGEN PEROXIDE TREATED HUMAN LUNG CANCER CELL LINE IN EPITHELIAL SODIUM CHANNEL AND PKC PATHWAY
}

\author{
FATIMAH YUSOF, NOOR AKMAL SHAREELA ISMAIL
}

Department of Biochemistry, Faculty of Medicine, Universiti Kebangsaan Malaysia Medical Centre, Jalan Yaacob Latif, Bandar Tun Razak, 56000 Cheras, Kuala Lumpur, Malaysia.

Platinum nanoparticles (PtNPs) are potent antioxidant in reversing oxidative stress related diseases such as lung cancer. Epithelial sodium channel (ENaC) consist of three subunits which are $\alpha-, \beta-$, and $\gamma$-ENaC which assist lung liquid clearance and subsequently increase the efficiency of gas exchange. Therefore, PtNPs are suggested to show antioxidant properties and regulate $\mathrm{ENaC}$ expression via PKC pathway in lung cancer. Our objective is to determine the effect of PtNPs in human adenocarcinoma lung cancer cell line, A549 cells through ENaC expression and PKC pathway. Cells were cultured until 95\% confluency prior to determine cell viability, antioxidant capacity, nanoparticle uptake, DNA damage, ROS production, antioxidant enzymes (superoxide dismutase (SOD), glutathione peroxidase (GPx), catalase, (CAT)), both gene expression and protein expression of ENaC and PKC. Acute treatment (3 hours) was chosen to avoid nanoparticles toxicity. PtNPs exhibit antioxidant properties to counteract DNA damage and quench superoxide caused by $\mathrm{H} 2 \mathrm{O} 2$. There was no significant differences between the groups for SOD, GPx and CAT activity. $\mathrm{H} 2 \mathrm{O} 2 / \mathrm{PtNPs}$ exhibits lower $\alpha$-ENaC, phospho T308 and MAPK6 protein expression as compared to control group. PtNPs increased three subunits $\mathrm{ENaC}(\alpha-, \beta-, \gamma-)$ protein and decreased PKC $\alpha$ expression in relation to $\mathrm{H} 2 \mathrm{O} 2$. In conclusion, cells treated with PtNPs were shown to reverse oxidative damage through less DNA damage which subsequently quench ROS production. Oxidative stress downregulate $\alpha-, \beta$, and $\gamma$-ENaC protein expression and increase PKC protein expression. Thus, PtNPs treatment shows antioxidant effects and regulates ENaC expression via PKC pathway in A549 cells. 


\title{
IMMUNE RECOVERY UVEITIS IN LEUKEMIA
}

\author{
LING TEIK JUNE, MUNIRAH ABD RASHID, RONA ASNIDA \\ NASARUDDIN, JEMAIMA CHE HAMZAH
}

Department of Ophthalmology, Faculty of Medicine, Universiti Kebangsaan Malaysia Medical Centre, Jalan Yaacob Latif, Bandar Tun Razak, 56000 Cheras, Kuala Lumpur, Malaysia.

Introduction: Immune recovery uveitis is commonly reported among HIV patients with cytomegalovirus retinitis following the commencement of highly active antriretroviral therapy. Objective: To report a case of immune recovery uveitis in leukemia following the resolution of leucopenia. Methodology: Case report Result: A 14 years old Malay girl with underlying relapsed acute myeloid leukemia and neutropenia with fungal septicemia was referred for routine ophthalmology assessment. Initial assessment showed visual acuity of $6 / 6$ bilaterally and normal anterior segment. Fundus showed multiple pinpoint choroiditis scattered throughout the fundus bilaterally. However, there was no haemorrhage, vitritis, retinitis or vasculitis seen. She was treated as bilateral fungal-related choroidits and was already started on potent intravenous antifungal and antibiotic prior to the assessment. However, about 3 weeks after the initial assessment, she presented with sudden onset of left eye blurring of vision, pain and redness for the past 3 days. Visual acuity was $6 / 9$ in the right eye and 6/18 in the left eye. There was presence of anterior chamber cells grade 4+ and pseudohypopyon in left eye. However, right eye anterior segment was normal. Fundus showed similar findings but lesions were more well defined, contracted and improved as compared to initial assessment. She was treated as immune reactive uveitis as her leucopenia was completely resolved at that point of time after 1 week course of granulocyte colony-stimulating factor. Conclusion: Sudden onset of dropped vision in any patient with resolution of immunity may be contributed by immune recovery uveitis. 
Tumor Oncology

Poster

UNDIFFERENTIATED PLEOMORPHIC SARCOMA OF THE PSOAS: A RARE CASE PRESENTING WITH HYDRO-NEPHROSIS AND DEEP VENOUS THROMBOSIS

\author{
NOR HAZLA MOHAMED HAFLAH, ABDUL YAZID MOHD \\ KASSIM, MUHAMMAD SHUKRI MUHAMMAD SAFIAN \\ Department of Orthopaedics and Traumatology, Faculty of Medicine, Universiti \\ Kebangsaan Malaysia Medical Centre, Jalan Yaacob Latif, Bandar Tun Razak, \\ 56000 Cheras, Kuala Lumpur, Malaysia.
}

Introduction: Retroperitoneal soft tissue sarcoma is a rare entity accounting for about $6.6 \%$ of all cases of sarcoma while a primary iliopsoas sarcoma is rarer with the incidence being about 1\% of all sarcomas. Methodology: Our patient was a 65 years old gentleman who presented with a 1-month history of left loin pain radiating to the groin. The pain was aggravated by flexion of the hip and associated with constipation and difficulty in ambulation. Palpation of the abdomen revealed mild tenderness and a vague mass at the left lower quadrant. The left lower limb was swollen and oedematous but was non-tender. Computed tomography and magnetic resonance imaging revealed a left psoas soft tissue mass with presence of left hydroureter and hydronephrosis (blood investigations showed increasing urea and creatinine levels) and a Doppler ultrasound revealed extensive deep venous thrombosis (DVT) of the left lower limb. Results: Biopsy result of the left psoas mass came back as undifferentiated pleomorphic sarcoma and patient subsequently underwent excision of the tumour via the anterior retroperitoneal approach. A left ureteric stent and an inferior vena cava filter was also placed with the aid of our urology and interventional radiologist colleagues. Post-operatively, patient made a satisfactory recovery with gradual recovery of the renal function and resolution of the left lower limb DVT. Conclusion: A multidisciplinary approach in management of a retroperitoneal soft tissue sarcoma is vital in ensuring a good outcome. 


\title{
MALIGNANT BONE TUMOUR: A SINGLE INSTITUTION EXPERIENCE
}

\author{
BOON PING BEH, HO WAI KOO, C KHAI, SIE CHONG \\ LAU, HAMIDAH ALIAS
}

Paediatric Haematology/Oncology Unit, Department of Paediatrics, Faculty of Medicine, Universiti Kebangsaan Malaysia Medical Centre, Jalan Yaacob Latif, Bandar Tun Razak, 56000 Cheras, Kuala Lumpur, Malaysia.

Introduction: In Malaysia, solid bone tumours rank $4^{\text {th }}$ highest among cancers in children $<14$ years old and rank third between the age of $15-24$ years old. Malignant bone tumours constitute $6 \%$ of child malignancy. Osteosarcoma and Ewing are the most encountered. Method: Retrospective review of malignant bone tumours patients presented to paediatric oncology unit, UKMMC from year 2010 to 2016. Results: There were total of 17 patients, 13 (76\%) osteosarcoma and 4 (24\%) Ewing sarcoma. Male to female ratio of 1.8. Racial distribution were Malay $8(47 \%)$, Chinese $3(18 \%)$, India $2(12 \%)$ and $4(23 \%)$ foreigners. Mean age at presentation was 12 years old. Majority, 14 (82\%) had $<6$ months of symptoms. Common complaints were pain, swelling and decrease range of movement. One osteosarcoma and one Ewing sarcoma patient had loss of appetite and weight, others had no constitutional symptoms. The commonest site was lower long bone which comprised of $11(65 \%)$, followed by 3 (17\%) each for upper long bone and pelvic region. 11 (65\%) of them had metastatic disease at presentation, majority had lungs metastasis except one had lungs and liver involvement and one with multifocal bone disease. For those with metastatic lesions, 5 (45\%) defaulted prior or during chemotherapy died, 2 $(18 \%)$ completed treatment but died from lung recurrence, $2(18 \%)$ loss from follow up, one died from sepsis during treatment, one Ewing sarcoma patient was alived 3 years from diagnosis and one osteosarcoma 5 months with stable disease. 6 $(35 \%)$ had localised disease at presentation, 2 foreigners were loss from follow up and others all had limb salvage surgery survived. Conclusion: Our patients with metastatic lesions at presentation were 3 fold higher compare to data from developed countries. Effort should be done to increase awareness to detect early disease. 